Portland State University

PDXScholar

7-6-1995

\title{
O-Phthalaldehyde Modification of Sarcoplasmic Reticulum Calcium Release
}

Steffen Koehler

Portland State University

Follow this and additional works at: https://pdxscholar.library.pdx.edu/open_access_etds

Part of the Physics Commons

Let us know how access to this document benefits you.

\section{Recommended Citation}

Koehler, Steffen, "O-Phthalaldehyde Modification of Sarcoplasmic Reticulum Calcium Release" (1995). Dissertations and Theses. Paper 5022.

https://doi.org/10.15760/etd.6898

This Thesis is brought to you for free and open access. It has been accepted for inclusion in Dissertations and Theses by an authorized administrator of PDXScholar. Please contact us if we can make this document more accessible: pdxscholar@pdx.edu. 


\section{THESIS APPROVAL}

The abstract and thesis of Steffen Koehler for the Master of Science in

Physics were presented July 6, 1995 and accepted by the thesis committee and the department.

COMMITTEE APPROVALS:
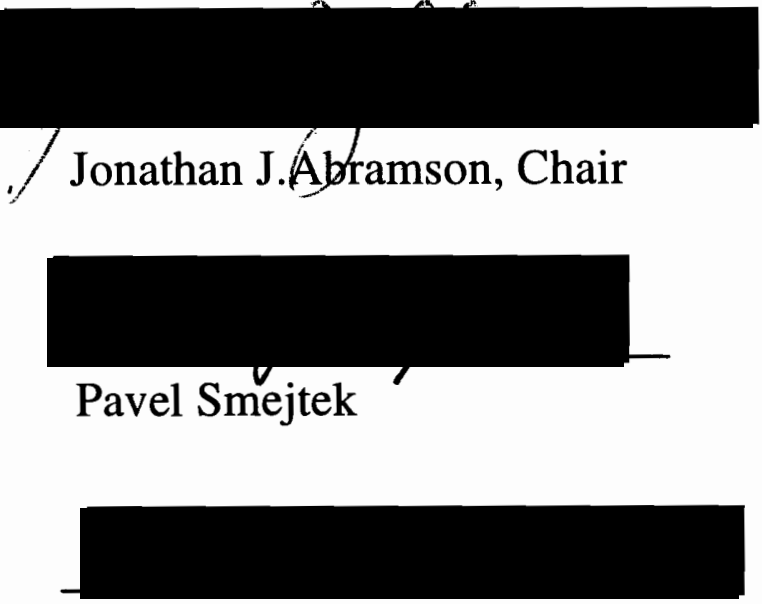

Carl C.Wamser

Representative of the Office of Graduate Studies

DEPARTMENT APPROVAL:

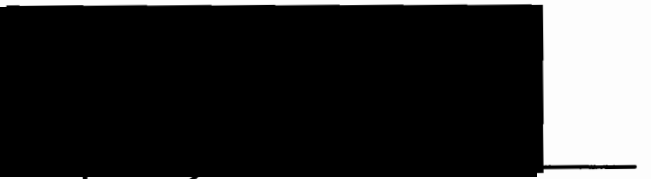

Erik Bodegom, Chair

Department of Physics

$* * * * * * * * * * * * * * * * * * * * * * * * * * * * * * * * * * * * * * * * * * * * * * * * * * * * * * * * * * * * *$

ACCEPTED FOR PORTLAND STATE UNIVERSITY BY THE LIBRARY

by
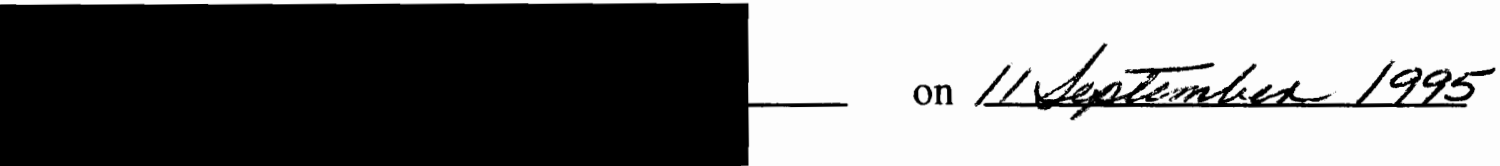


\begin{abstract}
An abstract of the thesis of Steffen Koehler for the Master of Science in Physics presented July 6, 1995.
\end{abstract}

\title{
Title: O-Phthalaldehyde Modification of Sarcoplasmic Reticulum Calcium Release
}

Muscle contraction is a phenomena which fascinated already the ancient Greeks. People have long sought to understand the mechanism of muscle contraction. Today we know that in order for muscle to contract, an action potential propagates from the nerve cell to the muscle cell. Upon arriving at the muscle cell, via a mechanism called ExcitationContraction (E-C) coupling, $\mathrm{Ca}^{2+}$ is released from an intracellular membrane system, the sarcoplasmic reticulum (SR), into the intracellular fluid. The increase of intracellular $\mathrm{Ca}^{2+}$ initiates the interaction between the contractile units which results in force development and tension. The least well understood step in the contractile process is mechanism of E-C coupling. During the last 15-20 years various theories have been proposed to describe this process. Our laboratory came up with a theory several years ago, that critical sulfhydryl groups on a protein, the ryanodine receptor(RyR)/Ca ${ }^{2+}$ release channel, are oxidized and subsequently reduced during the process of contraction and relaxation. In this thesis a reagent, o-Phthalaldehyde (OPA), was used to better understand the gating mechanism of the $\mathrm{RyR} / \mathrm{Ca}^{2+}$ release channel. This reagent has the ability to form an isoindole derivative with the amino acids cysteine and lysine, if they are separated by not more than $3 \AA$.In this study, it was shown that OPA interacts directly with the $\mathrm{Ca}^{2+}$ release channel by forming a 
covalent derivative with a critical thiol and a nearby lysine. High affinity $\left[{ }^{3} \mathrm{H}\right] \mathrm{Ryanodine}$ binding to the $\mathrm{RyRlCa}{ }^{2+}$ release channel is activated by $<130 \mu \mathrm{M}$ OPA, but is inhibited by OPA at concentrations ranging from $200-300 \mu \mathrm{M}$ OPA. This biphasic behavior indicates that at least two sets of cysteine-lysine pairs regulate $\mathrm{Ca}^{2+}$ channel activity. Moreover, the binding of OPA results in increasing the affinity of the receptor for the binding of ryanodine, in $\mathrm{Ca}^{2+}$ independent manner, which may indicate that there are two different sets of RyRlCa ${ }^{2+}$ release channels present in the SR. 


\section{o-PHTHALALDEHYDE MODIFICATION OF SARCOPLASMIC RETICULUM CALCIUM RELEASE}

by

STEFFEN KOEHLER

A thesis submitted in partial fulfillment of the requirements for the degree of

\section{MASTER OF SCIENCE in PHYSICS}

Portland State University

1995 
dedicated to

My Parents 


\section{ACKNOWLEDGEMENTS}

I want to thank all the people who made a contribution to this thesis. Special thanks deserves my adviser Dr. Jonathan J. Abramson. He provided me with a very interesting and fascinating project. I really enjoyed all the discussions with him and I'm very thankful that he was always so patient and spent so much time answering all my questions. It was really not easy for me, not to accept his offer to stay at PSU for a Ph.D. I think I had just a really great time together with him. Additional, I want to thank all the other members of our lab, especially Terry G. Favero for reading my thesis, his helpful advises, and his wonderful way of improving everyone's mood, Tony Zable, Alexander Braun, Sarah Beth Gopman, and Michael Hein for their contributions to discussions. Mentioning also deserve the committee members, Drs. Pavel Smejtek and Carl Wamser for their time, they spent on reading my thesis and for their helpful comments. I am glad that I met so many nice people during my stay in Portland. I want to thank my buddies Rado, Volker, Alex, Mike, Christoph, Allison, and Mary Beth having spent such a wonderful time together. Last but not least special thanks to my parents who always supported me in everything I was doing and gave me the possibility to spent one year in the USA. 
ACKNOWLEDGEMENTS $\ldots \ldots \ldots \ldots \ldots \ldots \ldots \ldots \ldots \ldots \ldots$ IV

LIST OF TABLES $\ldots \ldots \ldots \ldots \ldots \ldots \ldots \ldots \ldots \ldots \ldots \ldots \ldots \ldots$ VIII

LIST OF FIGURES $\ldots \ldots \ldots \ldots \ldots \ldots \ldots \ldots \ldots \ldots \ldots \ldots \ldots \ldots$ IX

\section{CHAPTER I}

1 THE CALCIUM RELEASE CHANNEL. $\ldots \ldots \ldots \ldots \ldots \ldots \ldots \ldots \ldots$

1.1 Introduction $\ldots \ldots \ldots \ldots \ldots \ldots \ldots \ldots \ldots \ldots \ldots \ldots$

1.2 Morphology of the muscle $\ldots \ldots \ldots \ldots \ldots \ldots \ldots \ldots \ldots 2$

1.2.1 Muscle in general

1.2.2 Physiological anatomy of skeletal muscle

1.3 Excitation-Contraction Coupling:

Systems and Proteins involved $\ldots \ldots \ldots \ldots \ldots \ldots \ldots . \ldots$

1.3.1 General Model

1.3.2 Sarcoplasmic Reticulum

1.3.3 Ryanodine Receptor/ $\mathrm{Ca}^{2+}$ Release Channel

1.3.4 Transverse Tubule

1.3.5 Dihydropyridine Receptor

1.3.6 Calcium Channel (general)

1.4 Models of Excitation-Contraction Coupling .......... 21

1.4.1 Introduction

1.4.2 Electrical Coupling

1.4.3 Mechanical Coupling

1.4.4 Chemical Coupling

1.4.4.1 Phosphorylation by

Inositol 1,4,5-triphosphate

1.4.4.2 Sulfhydryl Oxidation

1.4.5 Other Proteins interacting with the

Ryanodine Receptor 
1.5 Pharmacology of SR $\mathrm{Ca}^{2+}$ Release ............ 29

1.5.1 Inhibitors of $\mathrm{Ca}^{2+}$ release

1.5.2 Stimulators of $\mathrm{Ca}^{2+}$ release

1.6 Ryanodine Binding $\ldots \ldots \ldots \ldots \ldots \ldots \ldots \ldots \ldots \ldots, 32$

1.7 Theory and experimental techniques

of ligand-binding studies $\ldots \ldots \ldots \ldots \ldots \ldots \ldots \ldots . \ldots \ldots$

1.7.1 Introduction

1.7.2 Experimental strategies

1.7.3 Saturation experiments

1.7.4 Kinetic experiments

1.7.4.1 Association rate

1.7.4.2 Dissociation rate

1.8 o-Phthalaldehyde $\ldots \ldots \ldots \ldots \ldots \ldots \ldots \ldots \ldots \ldots \ldots 43$

\section{CHAPTER II}

2 METHODS AND MATERIALS $\ldots \ldots \ldots \ldots \ldots \ldots \ldots \ldots \ldots \ldots \ldots \ldots$

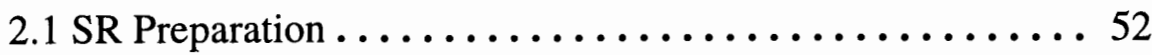

2.2 Chemicals $. . \ldots \ldots \ldots \ldots \ldots \ldots \ldots \ldots \ldots \ldots \ldots . \ldots 5$

2.3 Determination of the Protein Concentration .......... 54

$2.4\left[{ }^{3} \mathrm{H}\right]$ Ryanodine Binding Studies $\ldots \ldots \ldots \ldots \ldots \ldots \ldots \ldots$

2.4.1 Measurements of Association Kinetics

2.4.2 Measurements of Dissociation Kinetics

2.5 Measurements of $\mathrm{Ca}^{2+}$ efflux $\ldots \ldots \ldots \ldots \ldots \ldots \ldots . \ldots 57$

\section{CHAPTER III}

3 SPECTROPHOTOMETRIC ASSAY OF CALCIUM EFFLUX . . . . . . 60

3.1 OPA stimulated $\mathrm{Ca}^{2+}$ Release $\ldots \ldots \ldots \ldots \ldots \ldots \ldots 60$

3.2 Inhibition of $\mathrm{Ca}^{2+}$ Release by Ruthenium Red $\ldots \ldots \ldots \ldots 62$ 


\section{CHAPTER IV}

4 RYANODINE BINDING ASSAYS $\ldots \ldots \ldots \ldots \ldots \ldots \ldots \ldots \ldots \ldots$

4.1 OPA stimulated Ryanodine Binding ............ 65

4.2 Association Experiment ................. 67

4.3 Dissociation Experiment $\ldots \ldots \ldots \ldots \ldots \ldots \ldots \ldots \ldots$

4.4 Scatchard Analysis ................... 73

$4.5 \mathrm{Ca}^{2+}$-dependent Ryanodine Binding $\ldots \ldots \ldots \ldots \ldots \ldots . \ldots 79$

4.5.1 OPA dependence

4.5.2 Time dependence

4.6 DTT-dependent ryanodine binding $\ldots \ldots \ldots \ldots \ldots \ldots . . .61$

4.7 Lysine-dependent ryanodine binding . . . . . . . . . 84

4.8 Competition between OPA and CPM ........... 85

\section{CHAPTER V}

5 SPECTROPHOTOMETRIC ASSAY OF THE REACTIVITY OF OPA . . . 89

\section{CHAPTER VI}

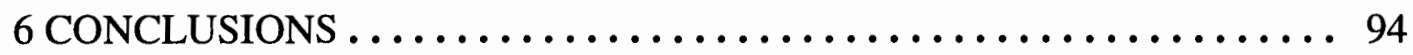

REFERENCES $\ldots \ldots \ldots \ldots \ldots \ldots \ldots \ldots \ldots \ldots \ldots \ldots \ldots \ldots$ 


\section{LIST OF TABLES}

TABLE

PAGE

1. Observed binding rate, $\mathrm{k}$, as a function of OPA concentrations $\ldots \ldots \ldots 70$

2. Dissociation rate, $\mathrm{k}_{-1}$, as a function of OPA concentrations $\ldots \ldots \ldots \ldots 73$

3. Association rate, $\mathrm{k}_{+1}$, and $\mathrm{K}_{\mathrm{d}}$ as a function of OPA concentrations $\ldots \ldots 74$

4. Dissociation constant $K_{d}$ and number of maximal binding sites $B_{\max }$ as a function of OPA concentrations $\ldots \ldots \ldots \ldots \ldots \ldots \ldots \ldots \ldots \ldots \ldots \ldots$

5. Reactivity of the OPA-lysine complex with 2-mercaptoethanol as a function of incubation time of OPA and lysine $\ldots \ldots \ldots \ldots \ldots \ldots 90$

6. Reactivity of the OPA-lysine complex with 2-mercaptoethanol as a function of incubation of the OPA-lysine complex with 2 -mercaptoethanol $\ldots \ldots \ldots \ldots \ldots \ldots \ldots \ldots \ldots \ldots \ldots \ldots$. 91

7. Reactivity of the OPA-2-mercaptoethanol complex with lysine as a function of incubation time with lysine 


\section{LIST OF FIGURES}

FIGURE

PAGE

1. Organization of skeletal muscle $\ldots \ldots \ldots \ldots \ldots \ldots \ldots \ldots \ldots \ldots \ldots, 4$

2. The transverse tubule-sarcoplasmic reticulum system $\ldots \ldots \ldots \ldots \ldots . \ldots$

3. Mechanism for isoindole formation $\ldots \ldots \ldots \ldots \ldots \ldots \ldots \ldots \ldots, \ldots 4$

4. Absorption spectra of OPA and its derivatives $\ldots \ldots \ldots \ldots \ldots \ldots \ldots 48$

5. The interaction of ME with OPA $\ldots \ldots \ldots \ldots \ldots \ldots \ldots \ldots \ldots \ldots, 48$

6. Schematic representation of the reaction between the $C$ subunit and OPA .. 50

7. $\mathrm{Ca}^{2+}$ release rate from $\mathrm{SR}$ vesicles as a function of OPA concentration .............................. 61

8. $\mathrm{Ca}^{2+}$ release rate as a function of ruthenium red concentration ........ 64

9. $\left[{ }^{3} \mathrm{H}\right]$ ryanodine binding as a function of OPA concentration $\ldots \ldots \ldots \ldots 66$

10. $\left[{ }^{3} \mathrm{H}\right]$ ryanodine binding as a function of time $\ldots \ldots \ldots \ldots \ldots \ldots \ldots, 68$

11. The logarithm of the ratio of $B_{\max } /\left(B_{\max }-B(t)\right)$ as a function of time $\ldots \ldots 69$

12. $\left[{ }^{3} \mathrm{H}\right]$ ryanodine dissociation as a function of time $\ldots \ldots \ldots \ldots \ldots \ldots \ldots 71$

13. Logarithm of $B(t) / B(0)$ as a function of time $\ldots \ldots \ldots \ldots \ldots \ldots \ldots .72$

14. Bound ryanodine as a function of added ryanodine $\ldots \ldots \ldots \ldots \ldots \ldots 75$

15 Scatchard plot from figure $14 \ldots \ldots \ldots \ldots \ldots \ldots \ldots \ldots \ldots \ldots \ldots$

16. $\left[{ }^{3} \mathrm{H}\right]$ ry anodine binding as a function of free $\mathrm{Ca}^{2+}$ concentrations in the presence of different OPA concentrations . . . . . . . . . . 80

17. $\left[{ }^{3} \mathrm{H}\right]$ ryanodine binding as a function of free $\mathrm{Ca}^{2+}$ concentrations

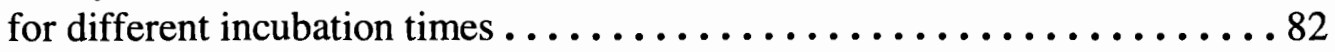

18. $\left[{ }^{3} \mathrm{H}\right]$ ryanodine binding as a function of DTT $\ldots \ldots \ldots \ldots \ldots \ldots \ldots . \ldots 3$ 
19. $\left[^{3} \mathrm{H}\right]$ ryanodine binding in the presence of $90 \mu \mathrm{M}$ OPA and an excess of lysine $\ldots \ldots \ldots \ldots \ldots \ldots \ldots \ldots \ldots \ldots \ldots \ldots \ldots \ldots$

20. $\left[^{3} \mathrm{H}\right]$ ryanodine binding as a function of OPA in the presence of $0.5 \mu \mathrm{M} \mathrm{CPM} \ldots \ldots \ldots \ldots \ldots \ldots \ldots \ldots \ldots . \ldots \ldots 7$

21. Absorption as a function of 2 -mercaptoethanol .............. 93 


\section{CHAPTER I}

\section{THE CALCIUM RELEASE CHANNEL}

\subsection{INTRODUCTION}

Calcium ions are the most important second messenger in biological systems. $\mathrm{Ca}^{2+}$ is involved in the control of enzyme activity, neurotransmitter release, secretion, calcium activated potassium channel opening, and in the control of muscle contraction.

Muscle contraction and force development depends on the intracellular $\mathrm{Ca}^{2+}$ concentration. After the muscle cell becomes stimulated by the attached neuron, the intracellular $\mathrm{Ca}^{2+}$ concentration increases and the contractile proteins, the myofibrils, are caused to contract. To relax the muscle, the intracellular $\mathrm{Ca}^{2+}$ must be decreased. A intracellular membrane system, the sarcoplasmic reticulum, is responsible for regulating the intracellular $\mathrm{Ca}^{2+}$ concentration. The mechanism by which it decreases the $\mathrm{Ca}^{2+}$ concentration is well known, while the mechanism of releasing $\mathrm{Ca}^{2+}$ out of the sarcoplasmic reticulum remains unknown.

The focus of this thesis is the study of the mechanism of $\mathrm{Ca}^{2+}$ release from white rabbit skeletal muscle sarcoplasmic reticulum. 


\subsection{MORPHOLOGY OF THE MUSCLE}

\subsubsection{Muscle in general}

There are three types of muscles: skeletal, smooth and cardiac muscle. Cardiac muscle is only found in the heart. Skeletal muscle is connected to the skeletal system through tendons. Smooth muscle is composed of far smaller fibers, usually $2 \mu \mathrm{m}$ to $5 \mu \mathrm{m}$ in diameter and only $50 \mu \mathrm{m}$ to $200 \mu \mathrm{m}$ in length, in contrast to the skeletal muscle fibers that are as much as 20 times as wide (in diameter) and thousand of times as long. Of the three muscle types, skeletal muscle responds most quickly to electrical stimulation (2-5 $\mathrm{ms})$. Cardiac muscle is slightly slower than skeletal muscle $(20-50 \mathrm{~ms})$, and is more regulated by hormonal effectors. Smooth muscle is slower than both cardiac and skeletal muscle, and contains a poorly defined sarcoplasmic reticulum. The mechanism underlying smooth muscle contraction is similar to that found in skeletal and cardiac muscle. Essentially the same chemical substances cause contraction in smooth muscle as in skeletal muscle, but the physical arrangement of smooth muscle fibers is entirely different. 


\subsubsection{Physiologic anatomy of skeletal muscle}

Skeletal muscle contains numerous fibers ranging in size from $10 \mu \mathrm{m}$ to $80 \mu \mathrm{m}$ in diameter. These muscle fibers are surrounded by a plasma membrane which is called the sarcolemma (SL). The muscle cell has up to 100 nuclei and mitochondria. In most muscles the fibers extend the entire length of the muscle. The end of the muscle fiber is connected to tendons which are inserted into the bones.

Each muscle fiber consists of hundreds to thousands of myofibrils. These myofibrils are responsible for muscle contraction. They are made up largely of actin and myosin filaments. Electron micrographs display a well defined striated pattern of the myofibrils.

The actin filaments are attached on both sides of the Z-disc, which passes from myofibril to myofibril to attach all the myofibrils in one muscle fiber. The regions where only the actin filaments are located, are called the I-bands, because they are isotropic to polarized light. These bands appear light under the electron microscope. The region where the myosin and actin filaments overlap is called the A-band, because it is anisotropic to polarized light. On the surface of the myosin filaments there are a lot of so called crossbridges that can interact with the actin filaments and cause muscle contraction. They are located all over the myosin filament except for the very middle. The region in the middle of two Z-discs which consists only of myosin filaments is called the H-band. The region of 


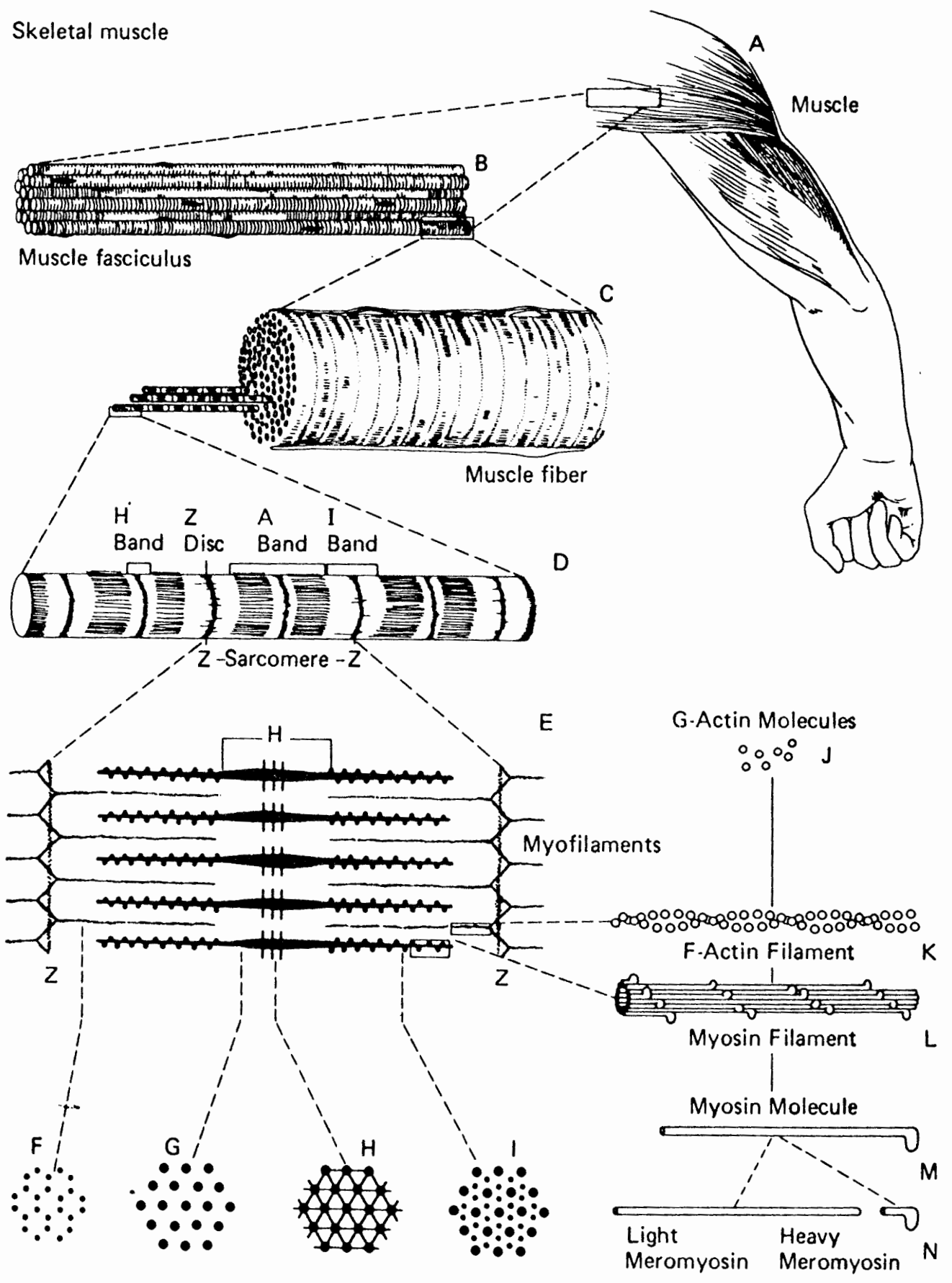

Figure 1 Organization of skeletal muscle, from the gross to the molecular level. F, G, H, and I are cross-sections at the levels indicated. (From Bloom and Fawcett: A Textbook of Histology. Philadelphia, W. B. Saunders Company, 1975.) 


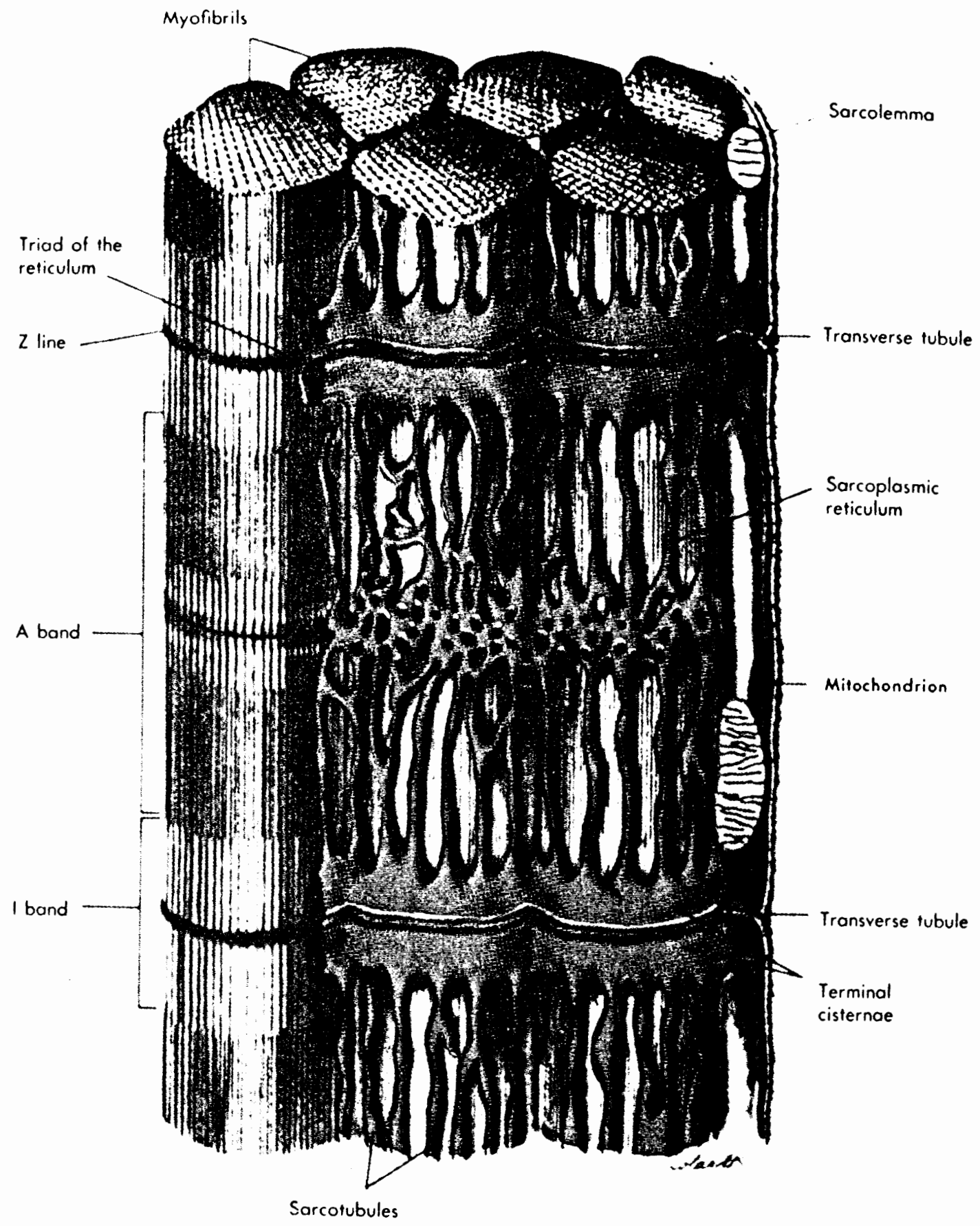

Figure 2 The transverse tubule-sarcoplasmic reticulum system (From Bloom and Fawcett: A Textbook of Histology. Philadelphia, W. B. Saunders Company, 1975. Modified after Peachey: J. Cell Biol. 25:209, 1965.) 
the myofibril which is between two Z-discs is called a sarcomere. It has a length of $2 \mu \mathrm{m}$ if the muscle is in its resting state.

During contraction and relaxation only the $\mathrm{H}$ and I-band change their length, while the I-band always shortens or lengthens symmetrically with respect to the Z-disc. In the resting state the actin filaments totally overlap the myosin filaments and they slightly overlap each other. If the muscle is stretched then the actin filaments don't overlap anymore and at the center of the A-band there is only the myosin filament and the H-band is visible.

To understand the molecular mechanism of contraction, one has to examine in more detail the interaction between myosin and actin. The myosin filament is composed of about 200 myosin molecules, each having a molecular weight of about 480,000 . The myosin molecule consists of 2 heavy $(200,000)$ and four light $(20,000)$ polypeptide chains. The two heavy chains coil around each other to form a double helix. At one end of this double helix chain, each chain is folded into a globular protein mass called the myosin head. The other end of this double helix chain is called the tail. The four light chains are parts of the myosin heads, two to each head. The tails of the myosin are bundled together to form the body of the filament. In addition to the tail, the helix part of the chain provides an extension outward from the body along with the head, which is called the arm. The head and the arm together is called the cross-bridge, and it is believed that it is flexible at two positions (hinges). One position is where the arm leaves the body of the myosin filament and the other where the two heads attach to the arm. The hinged arms allow the heads to move either far away from the body or to come closer. The hinged heads are very 
important for the actual contraction process. The myosin filament is twisted so that successive sets of cross-bridges are axially displaced from the previous set by 120 degrees, and so that the cross-bridges extend in all directions around the filament.

The actin filament is composed of three different components: actin, tropomyosin, and troponin. The backbone of the actin filament is a doublestranded F-actin protein molecule. The two strands are wound in a helix with a complete revolution every $70 \mathrm{~nm}$. Each of the two strands is composed of polymerized G-actin molecules with a molecular weight of 42,000 . For each revolution there are about 13 molecules in each strand. To every G-actin molecule there is one molecule of ADP attached. These ADP molecules are the active sites on the actin filaments with which the cross-bridges interact to cause muscle contraction. Therefore there is one active site every $2.7 \mathrm{~nm}$ on the actin filament.

In addition, the actin filament contains two tropomyosin strands which are loosely attached to one F-actin strand, respectively. This protein strand which consists of a polymer of tropomyosin molecules covers the active sites during the resting state of the muscle, and prevents the interaction between the actin and myosin filaments.

Troponin, which is made up of three globular protein molecules, is also attached to the actin filament. One of the three globular proteins (Troponin I) has a strong affinity for actin, another (Troponin T) for tropomyosin, and the third (Troponin C) strongly binds calcium ions. The task of this complex is to attach the tropomyosin to the actin. The calcium binding complex is responsible for activating the muscle contraction. 
The myofibrils are suspended inside the muscle fiber in a matrix called sarcoplasm, which is composed of intracellular constituents. The fluid of the sarcoplasm contains large quantities of potassium, magnesium, phosphate, and soluble enzymes. In addition there are a lot of mitochondria and an extensive endoplasmic reticulum, which in the muscle fiber is called the sarcoplasmic reticulum. The mitochondria is responsible for creating ATP, and the sarcoplasmic reticulum is extremely important for the muscle contraction because of its ability to store and release calcium ions.

\subsection{EXCITATION-CONTRACTION COUPLING: SYSTEMS AND PROTEINS INVOLVED}

\subsubsection{General model}

Initiation of contraction in skeletal muscle begins with the arrival of the action potential in the muscle fiber. Skeletal muscle fibers are excited by large myelinated nerve fibers. The innervate skeletal muscle fibers at the neuromuscular junction are located near the middle of the muscle fiber so that the action potential can spread out from the middle to both ends of the fiber allowing nearly coincident contraction of all sarcomeres of the muscle.

The sarcolemma invagination at the position of the Z-disc is called the transverse tubule (T-tubule). These T-tubules allow the action potential to travel through the entire 
thickness of the muscle fiber, and therefore every myofibril can be rapidly affected by the penetrating action potential. After the action potential has traveled down the T-tubule, the sarcoplasmic reticulum releases calcium ions. These ions bind to troponin $\mathrm{C}$ which allows actin and myosin to interact in the presence of ATP. The actin and myosin move closer together and this results in a production of tension.

Muscle contraction will continue until the calcium ion concentration in the sarcoplasmic fluid is reduced to resting levels $(0.6-1.0 \mu \mathrm{M})$. Immediately after the calcium is released from the sarcoplasmic reticulum another protein which is called the $\mathrm{Mg}^{2+}-\mathrm{Ca}^{2+}-$ ATPase pumps these calcium ions back into the SR by hydrolyzing ATP to ADP and $\mathrm{P}_{\mathrm{i}}$. For each mole of ATP hydrolyzed, 2 mole of $\mathrm{Ca}^{2+}$ are transported into the SR. The free calcium concentration in the sarcoplasmic fluid decreases and inhibits the interaction between actin and myosin which leads to muscle relaxation. In order to maintain a longer contraction of the muscle, a series of action potentials has to propagate along the sarcolemma.

\subsubsection{Sarcoplasmic Reticulum}

The sarcoplasmic reticulum (SR) is a membrane system surrounding the myofibrils and is responsible for controlling the intracellular $\mathrm{Ca}^{2+}$ concentration in skeletal and cardiac muscle. One of the two main proteins in the SR are the $\mathrm{Ca}^{2+}-\mathrm{Mg}^{2+}$-ATPase and the 
Calcium Release Channel. The ATPase, a $105 \mathrm{kDa}$ protein, pumps $\mathrm{Ca}^{2+}$ ions into the $\mathrm{SR}$ in order to obtain a calcium gradient across the SR membrane.

$\mathrm{Ca}^{2+}$ is released following an action potential which stimulates the $\mathrm{SR} \mathrm{Ca}^{2+}$ release channel. This $\mathrm{Ca}^{2+}$ diffuses into the sarcoplasm because of a high $\mathrm{Ca}^{2+}$ gradient across the membrane. After the channel has opened, the calcium pump immediately starts to transport the calcium ions back into the SR. This entire cycle of $\mathrm{Ca}^{2+}$ release and uptake can be completed in a time range of milliseconds. ${ }^{56}$

The SR is structurally organized in two distinct regions: longitudinal SR and junctional SR (jSR) or terminal cisternae. The longitudinal SR stretches along the length of each sarcomere and connects the terminal cisternae which is located at each end of the sarcomere. The junctional SR is generally sac-like and thicker than the longitudinal region. It is found on both sides of the Z-disc adjacent to the T-tubule. The association of the terminal cisternae and the T-tubule forms a triad.

By means of density-gradient centrifugation it was possible to identify two distinct fractions of the SR: light SR (LSR) and heavy SR (HSR). It has been shown that LSR is isolated from the longitudinal region while HSR contains membranes from the terminal cisternae ${ }^{59 .)}$. LSR contains $90 \%$ of the $\mathrm{Mg}^{2+}-\mathrm{Ca}^{2+}$-ATPase pumps. The principal function of the light $\mathrm{SR}$ is to pump the calcium back into the $\mathrm{SR}$ following $\mathrm{Ca}^{2+}$ release.

The HSR is composed of proteins from the LSR along with the $\mathrm{Ca}^{2+}$ release channel and calsequestrin. Calsequestrin, a protein associated with the junctional face membrane ${ }^{15 .), 31 .), 90 .)}$ has a high capacity and a low affinity for calcium binding ${ }^{29 .)}$. Therefore during the resting phase of the contractile process most of the calcium in the SR diffuses 
to the terminal cisternae region and binds to calsequestrin. Thus, the terminal cisternae is responsible for both storing and releasing of calcium ions.

It is believed that the calcium release protein is mainly localized in the terminal cisternae region of the SR. Experiments with SR vesicles from light and heavy SR fractions showed that the calcium release rates are much higher from heavy SR vesicles than from light SR vesicles. ${ }^{61}$

Electron micrographs reveal several proteins embedded in the terminal cisternae membrane of the SR, and a gap between the SR and the T-tubule of approximately ${ }^{56} 120$ $170 \AA$. The junctional foot protein (JFP) is a homotetramer (i.e., it is composed of 4 equal subunits) and is localized in the terminal cisternae region with a molecular weight ${ }^{106}$ of about 535,000. From analysis of the amino acid sequence, approximately one tenth of each subunit (high molecular weight protein) forms a transmembrane region, while the remainder of the protein lies outside the membrane, and is considered the foot which spans the gap between the SR and the T-tubule.

In addition to being identified as the calcium release channel and the JFP, this protein also binds with high affinity the plant alkaloid ryanodine.

\subsubsection{Ryanodine receptor/Ca ${ }^{2+}$ release channel}

Excitable and nonexcitable cells contain one or both of two intracellular $\mathrm{Ca}^{2+}$ release channels. Release of $\mathrm{Ca}^{2+}$ from intramembrane compartments can be triggered by the 
binding of the second messenger inositol 1,4,5-trisphosphate $\left(\mathrm{IP}_{3}\right)$ to the $\mathrm{IP}_{3}$ receptor/Ca release channel. It also can be mediated by the ryanodine receptor (RyR)/Ca ${ }^{2+}$ release channel in response to a surface membrane action potential and/or a change in the concentration of a second messenger by a mechanism referred to in muscle as excitationcontraction (E-C) coupling.

In muscle at the junctional region of the SR, large protein structures are present that span the gap between the SR and the transverse tubule. These structures have been termed feet and are now commonly known as ryanodine receptor $/ \mathrm{Ca}^{2+}$ release channels because of the presence of an intrinsic $\mathrm{Ca}^{2+}$ channel activity, and the ability to bind the plant alkaloid ryanodine with high affinity and specificity. The RyR ion channel has been purified from muscle and neural tissue as a $30 \mathrm{~S}$ protein complex comprised of 4 polypetides of about 5000 amino acid residues each.

From a variety of tissues including rabbit skeletal muscle ${ }^{36,48,101}$ the RyR has been purified with retention of its $\left[{ }^{3} \mathrm{H}\right]$ ryanodine binding and intrinsic channel activities. In most of these studies, the membrane-bound RyR was solubilized using the zwitterionic detergent CHAPS and high ionic strength $(1.0 \mathrm{M} \mathrm{NaCl})$ and then, as shown by density gradient centrifugation, purified as a $30 \mathrm{~S}$ protein complex.

SDS gel electrophoresis suggests that the purified RyRs of mammalian skeletal and cardiac muscle $^{7,39,40,48}$, brain $^{47,58}$, crustacean skeletal muscle ${ }^{96}$, and C. elegans ${ }^{46}$ contain a single major high molecular weight polypeptide with a calculated $M_{r}$ of about 560,000 , as determined by cloning and sequencing of the complementary DNA of the mammalian skeletal and cardiac muscle RyR isoforms. ${ }^{73,75,107,122}$ 
Electron microscopy studies have revealed that the purified $30 \mathrm{~S}$ RyRs of mammalian skeletal ${ }^{48,92}$ and cardiac $^{7}$ muscle and $\operatorname{brain}^{48}$ have an overall morphology identical to the protein bridges (feet) that span the T-tubule-SR junctional gap in isolated SR fractions of vertebrate skeletal muscle. The four leaf clover-like (quatrefoil) appearance of negative-stained samples, the apparent sedimentation coefficient of $30 \mathrm{~S}^{48}$, and crosslinking ${ }^{49}$ and scanning transmission electron microscopy studies ${ }^{93}$ have demonstrated a tetrameric assembly of the high molecular weight subunits of the CHAPSpurified skeletal RyR. Studies with averaged images of negatively stained ${ }^{118}$ and frozen hydrated ${ }^{84}$ specimens indicate an overall dimension of $27 \times 27 \times 14 \mathrm{~nm}$ for the skeletal RyR (resolution of about $3 \mathrm{~nm}$ ).

The primary structure of three mammalian RyR isoforms has been determined by cDNA cloning and sequencing. The isoforms are encoded by three different genes coding for a skeletal muscle (RyR1) ${ }^{107,122}$ cardiac muscle (RyR2) ${ }^{73,75}$, and brain (RyR3). ${ }^{33}$

Expression studies with the skeletal and cardiac muscle cDNAs in cultured cells and Xenophus oocytes suggest that the $M_{r} 560,000$ polypeptides are sufficient to form ryanodine-, caffeine- and $\mathrm{Ca}^{2+}$-sensitive $\mathrm{Ca}^{2+}$ channels. ${ }^{38,73,107}$ The skeletal muscle cDNA encodes a protein of 5032-5037 amino acids, whereas the cardiac muscle and brain cDNAs were found to encode proteins of $4968-4976$ and 4872 amino acids, respectively. Comparison of the predicted amino acid sequences of the skeletal and cardiac muscle and brain receptors reveals a large number of conserved regions throughout the sequence of the three RyRs with an overall identity of $66-70 \%$ and greater than $90 \%$ in the 250 amino acid carboxy-terminal portion. The only other protein shown so far to display significant 
sequence homology with the $\mathrm{RyR}$ is the $\mathrm{IP}_{3}$ receptor ion channel, which is similarly comprised of four polypeptides of 2701-2749 amino acids each. ${ }^{12}$

Hydropathy plots suggest that the $M_{r} 560,000$ polypeptides consist of two major structural regions: the carboxy-terminal pore region, which is thought to consist of as few as four ${ }^{107}$ and as many as ten or possibly twelve ${ }^{122}$ putative transmembrane segments, presumably the $\mathrm{Ca}^{2+}$ release channel, and a large extramembrane region, which is thought to correspond to the cytoplasmic foot structure.

It was shown ${ }^{48}$ that the complete tetramer is necessary for ryanodine binding and channel activity.

\subsubsection{Transverse Tubule}

The T-tubule is an invagination of the sarcolemma deep into the muscle fiber, but the protein components of these two membrane systems are quite different. It was found that the average density of the $\mathrm{Na}^{+}-\mathrm{K}^{+}$-ATPase in T-tubules is about 6 times less than in the $\mathrm{SL}^{114}$. In addition the density of $\mathrm{Na}^{+}$channels in the T-tubule is 4 times less than it is in the SL. One the other hand, calcium channels are 3 to 4 times more dense in the T-tubule than in the SL.

The major problems in examining the structure and function of the T-tubule are its small size, and the difficulty in isolating adequate amounts of T-tubule vesicles. Also when isolated, contamination with SR and/or SL proteins is likely. Therefore different 
preparations of T-tubule membranes show varying amounts of different protein components. Reports range from 15 to 27 different proteins.

Interaction between the SR and T-tubule occurs at specialized junctions called peripheral couplings, dyads and triads or, collectively E-C units. Peripheral couplings are formed between one SR cisternae and the SL. Dyads and triads are internal junctions comprised of either one or two junctional SR cisternae and a T-tubule segment. Muscle fibers of different species have various combinations of these three types of junctions.

Electron microscopy reveals the location and structure of the junctional foot protein, which spans the gap between the SR and the T-tubule. It has four large subunits symmetrically located around a central less dense area. Ordered disposition and close proximity between adjacent feet are maintained in isolated SR vesicles. ${ }^{68}$ The center to center distance between feet in arrays is $26-32 \mathrm{~nm}$ in muscles of vertebrates and $27-28 \mathrm{~nm}$ in invertebrates. The arrangement, although tetragonal in both cases, differs slightly.

The quatrefoil foot structure is readily visible in the isolated RyR molecule, but the latter has an additional feature: a smaller, stain-excluding or raised central platform that also shows a four subunit structure and is rotated by $45^{\circ}$. The platform presumably corresponds to the intramembrane domain of the molecule. Indeed, in freeze-fracture replicas of the junctional SR membrane, a small intramembrane quatrefoil is revealed at the location of each foot ${ }^{13}$. Feet have unique large cytoplasmic domains that may directly contact components of the T-tubules.

On the basis of immunocytochemistry and the structural similarity between feet and purified RyR, it is reasonable to assume that all arrays of feet found in EMs of skeletal 
muscle are composed of RyRs. The converse is not necessarily true, i.e., the lack of detection of feet by EM does not exclude the presence of RyRs in cases where the molecules do not form an array, since single feet are difficult to detect in EMs.

From these observations one knows that $\mathrm{SR} \mathrm{Ca}^{2+}$ release channels in skeletal muscle are located in the SR membrane immediately adjacent to the T-tubules.

\subsubsection{Dihydropyridine Receptor (DHPR)}

A high percentage of the proteins found in T-tubules are slowly activating $\mathrm{Ca}^{2+}$ channels known as dihydropyridine (DHP) sensitive calcium channels. ${ }^{90}$ The gating characteristics of these channels are sensitive to several DHPs.

These channels probably have two important roles in the process of muscle contraction $^{4,32,108}$. First, they supply calcium to the myoplasm, which is essential for the contraction process. Most of these calcium channels are found in the T-tubule, not in the SL. ${ }^{108}$ Analysis of DHP binding shows that T-tubules bind 50 pmole DHP/mg membrane, versus isolated SL which only binds 1.5 pmole $\mathrm{DHP} / \mathrm{mg}$ membrane. Also, less than 0.005 $\mathrm{U} / \mathrm{mg} \mathrm{Ca}^{2+}$-ATPase activity is detected in the SL, compared to $2.42 \mathrm{U} / \mathrm{mg}$ activity in SR. ${ }^{90}$ However, less than $5 \%$ of the high affinity DHP binding sites in intact skeletal muscle are actually functional $\mathrm{Ca}^{2+}$ channels. These results were obtained by measuring DHP binding to intact skeletal muscle and comparing these results with voltage clamp measurements of $\mathrm{Ca}^{2+}$ channel block. ${ }^{95}$ To block the the current, 100 to 1000 fold the 
expected concentration of DHP was necessary. Yet it has been observed that low concentrations of a DHP inhibit both SR $\mathrm{Ca}^{2+}$ release and charge movement which is recorded just before contraction. ${ }^{86}$

This charge movement is due to a movement of charged protein groups located in the T-tubule membrane. These proteins have been postulated to be the voltage sensors of E-C coupling. ${ }^{9,87,109,111}$ DHPRs are composed of one each of five subunits $\left(\alpha_{1}, \alpha_{2}, \beta, \gamma, \delta\right)^{17,23}$, all of which have been sequenced and expressed..$^{26,67,89,108,110}$ The $\alpha_{1}$ subunit is channel forming and contains the DHP-binding site of the molecule..$^{67,70,74,78,108}$

Dysgenic muscle has been an essential tool in understanding the role of DHPRs. A point mutation in the gene for $\alpha_{1}$ subunit of $\mathrm{DHPR}^{24,109}$ results in undetectable levels of the protein and reduction, but not total absence, of specific DHP binding. ${ }^{81,85}$ The decrease in DHP binding, lack of slow inward calcium currents and charge movement, and interruption of E-C coupling in dysgenic fibers, and the rescue of functions and currents in fibers transfected with the cDNA for the DHPR constitute compelling evidence for identification of DHPRs with the voltage sensors of E-C coupling.

cDNA for cardiac DHPR, expressed in dysgenic cells, results in $\mathrm{Ca}^{2+}$ currents with fast cardiac-type kinetics and in E-C coupling that is dependent on extracellular ${ }^{110} \mathrm{Ca}^{2+}$. In experiments using various skeletal-cardiac cDNA chimeras, the components responsible for the faster kinetics of the cardiac DHPR and for the ability to sustain skeletal muscle type E-C coupling (independent of extracellular $\mathrm{Ca}^{2+}$ ) have been identified.

In the T-tubule a group of four proteins is found with the help of the EM. This group is called tetrads. The images show that the four components of the tetrads are 
located almost exactly above the four subunits of the feet, which strongly indicates that feet and tetrads can interact with each other. There are some indirect lines of evidence that the tetrads are composed of four DHPRs. The strongest is that tetrads are missing in dysgenic myotubes, which lack normal DHPRs ${ }^{24,82}$, but small clusters of them are present in these myotubes after transfecting them with the cDNA for the missing DHPRs. ${ }^{105}$

\subsubsection{Calcium channels (general)}

A number of ion channels exist to help generate an electric field across membranes. Using the Goldman equation, one can calculate the transmembrane potential, given the relative ionic permeability and ionic concentrations on the two sides of the membrane. Channels are usually named according the specific ion that most favorably passes through them. Both cation $\left(\mathrm{Ca}^{2+}, \mathrm{Na}^{+}, \mathrm{K}^{+}\right)$and anion $(\mathrm{Cl})$ channels exist. Within the same cell, two channels can conduct the same ions but they may differ in kinetics, conductance and threshold mechanism. Channel activation may occur due to ligand binding or due to changes in the transmembrane electrical potential. Ligand activation occurs when a chemical reagent binds to an appropriate site on the channel, and as a consequence, channel gating is modified. Voltage gated channels are activated by a change in the transmembrane potential. Calcium channels in the brain and nerve cells or the potassium and sodium channels in the nerve cells, which are responsible for the action potential, are voltage-gated ion channels. 
Calcium channels can be divided into 3 categories according to their kinetics. ${ }^{57} \mathrm{~L}$ type, T-type, and $\mathrm{N}$-type channels. L-type channels are found in the heart and in the Ttubules of skeletal muscle cells. They have long-lasting $(>700 \mathrm{~ms})$, non-inactivating currents. They are also activated by high voltage and have a relatively high $\mathrm{Ba}^{2+}$ conductance of $25 \mathrm{pS}$. The T-type channels have transient currents which inactivate completely after $50 \mathrm{~ms}$. They are activated at low voltage and they have a small $\mathrm{Ba}^{2+}$ conductance of $8 \mathrm{pS}$. Normally they are found in neurons. The $\mathrm{N}$-type channel is an intermediate of the $\mathrm{L}$ - and T-type channel. It inactivates quickly $(50 \mathrm{~ms})$ but needs to be activated by high voltage and is intermediate in $\mathrm{Ba}^{2+}$ conductance $(13 \mathrm{pS})$.

Skeletal muscle contains at least two types of $\mathrm{Ca}^{2+}$ channels, one with fast and one with slow kinetics. ${ }^{10}$ The DHP-sensitive $\mathrm{Ca}^{2+}$ channel in the T-tubule has a slowly inactivating $\mathrm{Ca}^{2+}$ current (L-type channel).

Since the $\mathrm{Ca}^{2+}$ channel of the SR is not located in the outer muscle cell membrane, it can't be examined with the patch clamp technique. Therefore this channel is not categorized as a $\mathrm{L}, \mathrm{T}$, or $\mathrm{N}$ type channel.

The RyR/Ca ${ }^{2+}$ release channel is a cation-selective channel that displays an unusually large ion conductance for monovalent $\left(\approx 600\right.$ and $\approx 750 \mathrm{pS}$ with symmetric $500 \mathrm{mM} \mathrm{Na}^{+}$ and $250 \mathrm{mM} \mathrm{K}^{+}$as the current carrier, respectively) and divalent ( $\approx 100-150 \mathrm{pS}$ with 50 $\mathrm{mM} \mathrm{Ca}^{2+}$ trans) cations.

Reconstitution of the CHAPS-purified skeletal muscle RyR channel into planar lipid bilayers reveals several novel features. They are not readily observed in studies with the native release channel because of the presence of $\mathrm{SR} \mathrm{K}^{+}$and $\mathrm{Cl}^{-}$channels, which are also 
incorporated into the bilayers during SR vesicle fusion. The purified RyR channel displays a high conductance for $\mathrm{Ca}^{2+}$ and monovalent cations and high selectivity for cations over anions. $^{48,51,101}$

The appearance of multiple subconductance states present within the channel tetramer is a frequently observed phenomenon upon reconstitution of the detergentsolubilized purified channel. ${ }^{51,101}$ Three subconductances were apparent that correspond to $1 / 4,1 / 2$, and $3 / 4$ of the native conductance level. Appearance of multiple conductances has been proposed to be due either to the presence of a channel comprised of four subunits, each containing an individually conducting pore, or a single conducting pore present in several discrete conductance states within the tetrameric assembly of the $M_{r}$ 560,000 subunits. In either case cooperative interactions among the subunits must occur to account for the multiple conductance behavior of the release channel.

The observation of an essentially identical conductance behavior of various RyRs suggests that the pore of the RyR ion channel is highly conserved. In agreement with this prediction, the putative pore region in the C-terminal domain shows a high extent of sequence similarity among the mammalian skeletal, cardiac, and brain RyR isoforms. ${ }^{33}$ 


\subsection{MODELS OF EXCITATION-CONTRACTION COUPLING}

\subsubsection{Introduction}

Excitation contraction coupling means the link between the excitation of the motorneuron and the contraction of the muscle cell. The manner in which the T-tubule communicates with the SR to open the calcium release channel remains a mystery.

In cardiac muscle, $\mathrm{E}-\mathrm{C}$ coupling is dependent on extracellular $\mathrm{Ca}^{2+}$. A plasmalemmal dihydropyridine-sensitive $\mathrm{Ca}^{2+}$ current represents a major pathway for the entry of extracellular $\mathrm{Ca}^{2+}$ during an action potential. ${ }^{11}$ The resulting rise in intracellular $\mathrm{Ca}^{2+}$ concentration is thought to trigger the massive release of $\mathrm{Ca}^{2+}$ from the SR by opening RyR ion channels ${ }^{18,71}$ closely apposed to the plasmalemma in structural complexes called couplings. ${ }^{103}$

Morphological $^{103}$ and more recent immunocytochemical ${ }^{42,44}$ and $\left[{ }^{3} \mathrm{H}\right]$ ryanodine binding $^{44}$ studies showing the presence of an appreciable portion of RyRs without any plasmalemmal contact in mammalian (corbular SR) and avian (extended junctional SR) heart suggest that the cardiac RyR may be activated by $\mathrm{Ca}^{2+}$ or some other effector in the absence of a close association with the cardiac dihydropyridine receptor (DHPR)/Ca ${ }^{2+}$ channel. 
However, in skeletal muscle, E-C coupling is independent of extracellular calcium. ${ }^{8,21,23,87}$ Many models have been proposed, but the mechanism is still unresolved. Three models for E-C coupling exist: electrical, mechanical and chemical coupling.

There are different ways to study the E-C coupling. Among the most important are measurements of high affinity $\left[{ }^{3} \mathrm{H}\right]$ ryanodine binding, vesicle $\mathrm{Ca}^{2+}$ flux experiments, planar bilayer membrane reconstitution experiments, and SDS gel electrophoresis.

\subsubsection{Electrical coupling}

The motorneuron sets up an electrical impulse in the muscle cell which propagates along the membrane and the T-tubule deep into the muscle. Therefore, the idea of electrical coupling is reasonable. The coupling would occur by depolarizing the SR membrane, which would cause the opening of the $\mathrm{Ca}^{2+}$ release channel (CRC). Eisenberg ${ }^{27}$ showed by theoretical considerations that capacitative coupling is very unlikely. However, since the JFP lies between the SR and T-tubule, an electrical signal may propagate along this protein from the T-tubule to the SR and cause a depolarization. The theory of the depolarization is unlikely, because there exists only a gradient for calcium across the SR membrane. In addition the CRC, when reconstituted in lipid bilayer, is only slightly voltage dependent. 


\subsubsection{Mechanical coupling}

Mechanical coupling proposes that effects of charge movement in the T-tubule membrane may induce calcium release from the SR by a direct molecular interaction between components of the two membranes. Depolarization could cause a conformational change of the JFP and therefore open the CRC with the foot part of the JFP serving as a plunger.

Conversely, it is known that an alternate disposition of tetrads is found in some muscles (i.e. the distance between tetrads is twice that between adjacent feet) which results in tetrads being associated with alternate feet. There is little evidence that the disposition of tetrads in rabbit muscle varies in different areas of the same muscle and/or the same fiber. Verifying this finding of a variable ratio of tetrads to feet would greatly weaken the direct mechanical coupling hypothesis. In addition, assuming a direct interaction, it is unclear why the four subunits of the RyR, acting as a single functional unit $^{20,64}$, should need four DHPRs. ${ }^{50}$

On the other hand, there are also findings which support the mechanical coupling hypothesis. In skeletal muscle, all arrays of feet are located at junctional sites, which is consistent with their possible role in direct transduction of the DHPR-generated signal. In muscles that depend on extracellular $\mathrm{Ca}^{2+}$ for $\mathrm{E}-\mathrm{C}$ coupling (cardiac muscle and muscles of invertebrates), feet may also be found in corbular or extended junctional SR membranes, which do not face surface membrane/T-tubules. ${ }^{104}$ RyR identity of feet on corbular SR has 
been confirmed by immunolabeling. If these free feet participate in E-C coupling, they must be activated by some indirect mechanism. Conversely, the obligatory position of vertebrate feet in the junctional gap would indicate that skeletal muscle E-C coupling, which is independent of extracellular $\mathrm{Ca}^{2+}$, requires close proximity of feet to DHPRbearing T-tubule membrane.

In the search for components of the junction that may be responsible either for holding feet and DHPRs together, or for allowing them to interact with each other, triadin has been identified. ${ }^{22}$ Triadin is a $95 \mathrm{kD}$ glycoprotein and abundant component of E-C units (approximately 1:1 stoichiometry with the foot protein) that forms multimeric assemblies; it is joined covalently by disulfide bonds. Its location in the terminal cisternae of the SR has been confirmed by immunocytochemistry. ${ }^{19}$

There are a few observations which are relevant to the question of a possible intermediate component between DHPRs and RyRs. First, dysgenic myofibers in vivo have some respectable looking triads, complete with ordered, apparently normal rows of feet, despite the lack of DHPRs. This can be interpreted as either the association between feet and T-tubule membrane is mediated by a protein other than DHPRs, or a different calcium channel, such as the one detected by Adams and Beam ${ }^{3}$, substitutes for DHPRs in the formation of these triads, although such a channel does not participate in E-C coupling.

In other experiments Chinese Hamster Ovary $(\mathrm{CHO})$ cells were co-transfected with both the cDNAs from a skeletal-cardiac chimeria of the DHPR and from the RyR. ${ }^{106}$ Calcium currents indicate appropriate insertion of DHPRs in the surface membrane; 
Electron micrographs show correct feet insertion in ER membranes; and caffeine shows function of at least a fraction of the feet. However no tetrads are seen, and no junction is formed between the DHPR-bearing surface membrane and the feet-bearing ER, which suggests the lack of a structural component necessary for junction formation.

At present, the mechanical coupling model is supported by a number of investigations in this field.

\subsubsection{Chemical Coupling}

Several chemical compounds are capable of opening and closing the CRC. Not all of them are physiologically present, but they have been used to study the behavior of the calcium channel. $\mathrm{Ca}^{2+}$ is believed to trigger the calcium channel in the heart. This mechanism is called $\mathrm{Ca}^{2+}$-induced $\mathrm{Ca}^{2+}$ release. However, in skeletal muscle this mechanism is not applicable, because experiments with skinned fibers show that contraction takes place even in the absence of extracellular calcium in the T-tubule and in the presence of $\mathrm{Cd}^{2+}$ which blocks calcium flux through the calcium channels in the $\mathrm{T}$ tubules. ${ }^{54}$ In addition, the kinetics of the DHP-sensitive $\mathrm{Ca}^{2+}$ channels don't fit with the time scale of contraction. Calcium currents through skeletal muscle DHP sensitive $\mathrm{Ca}^{2+}$ channels are slower and longer lasting than is activation of contraction. ${ }^{5}$ 


\subsubsection{Phosphorylation by inositol 1,4,5-triphosphat $\left(\mathrm{IP}_{3}\right)$}

In other tissues, $\mathrm{IP}_{3}$ causes calcium release from the endoplasmic reticulum. Thus, these calcium channels are called $\mathrm{IP}_{3}$ receptors. $\mathrm{IP}_{3}$ also causes calcium release from purified SR fractions from skeletal muscle and in skinned fibers it causes a force production. ${ }^{117}$ Yet, $\mathrm{IP}_{3}$ doesn't cause $\mathrm{Ca}^{2+}$ release from SR vesicles and it doesn't modify ryanodine binding. Vergara et al. ${ }^{115}$ showed that electrical stimulation of the muscle causes a production of $\mathrm{IP}_{3}$. A model was proposed in which depolarization of the T-tubule membrane stimulates phospholipase $\mathrm{C}$ activity that hydrolyzes phosphatidylinositol $(4,5)$ diphosphate $\left(\mathrm{PIP}_{2}\right)$ to $\mathrm{IP}_{3}$. The $\mathrm{IP}_{3}$ then diffuses to the calcium channel and opens it. The main argument against this model is that an adequate amount of $\mathrm{IP}_{3}$ is not produced and can't diffuse in such a short time to the calcium channel. In addition, the slow response of skinned skeletal muscle fibers to $\mathrm{IP}_{3}$, generated by the photolysis of caged ${ }^{119} \mathrm{IP}_{3}$, and the inability of microinjected heparin to block SR $\mathrm{Ca}^{2+}$ release in skeletal muscle fibers ${ }^{77}$ have argued against $\mathrm{IP}_{3}$ as a primary regulatory ligand in E-C coupling. Also $\mathrm{IP}_{3}$ and its non-hydrolyzable analogue IPS ${ }_{3}$ have been shown to activate the t-tubule DHP-sensitive $\mathrm{Ca}^{2+}$ channel. ${ }^{116}$ 


\subsubsection{Sulfhydryl Oxidation}

Abramson and Salama ${ }^{2}$ proposed that the calcium channel is gated by oxidationreduction reactions of sulfhydryl groups $(\mathrm{SH})$. The model suggests that an oxidation of two sulfhydryl groups to a disulfide linkage opens the channel and a reduction of this disulfide linkage closes the channel. Heavy metals, which bind to SH groups trigger calcium release. The stimulation of $\mathrm{Ca}^{2+}$ release by heavy metals correlates strongly with the affinity of those metal ions for $\mathrm{SH}$ containing agents. ${ }^{1} \mathrm{Ag}^{+}$also releases calcium most effectively under physiological conditions (i.e., at pH 7.0 and $1 \mathrm{mM}$ free ${ }^{94} \mathrm{Mg}^{2+}$ ).

The fluorogenic sulfhydryl probe 7-diethylamino-3-(4'-maleimidedylphenyl)-4methylcoumarin (CPM) has been used to characterize the functional role and location of highly reactive thiol groups on the ryanodine-sensitive calcium release channel complex of skeletal and cardiac junctional SR. ${ }^{52}$ The kinetics of the formation of fluorescent CPM adducts was highly dependent on the presence of physiological and pharmacological modulators of the ryanodine receptor calcium release channel. Pretreatment of the ryanodine receptor with the agonist $\mathrm{Ca}^{2+}$ (micromolar) and ryanodine (nanomolar) leads to a slow SR thiol-CPM reaction. On the other hand, in the presence of $\mathrm{Ca}^{2+}$ channel antagonists (millimolar $\mathrm{Ca}^{2+}$, millimolar $\mathrm{Mg}^{2+}$, or micromolar ryanodine), CPM rapidly forms adducts with a single class of highly reactive (hyperreactive) SR thiols.

Nonreducing sodium dodecyl sulfate-polyacrylamide gel electrophoresis of CPMlabeled SR proteins, and Western plot analyses with antiryanodine or antitriadin antibodies 
reveal that the hyperreactive thiols labeled by CPM under conditions favoring channel closure are localized principally on the RyR protomer and triadin.

These results show that the RyR and triadin contain a small number of highly reactive cysteine residues that selectively conjugate with CPM only when channel closure is favored. Two possible interpretations exist. Either the redox state of the critical sulfhydryl group controls the channel or the accessibility of this thiol is determined by the conformational state of the channel.

There are a other experiments which speak for the first interpretation. Covalent modification of hyperreactive thiols with nanomolar CPM inhibits both $\mathrm{Ca}^{2+}$-induced $\mathrm{Ca}^{2+}$ release and the gating activity of single channels reconstituted in bilayers. Also 1,4naphthoquinone, which selectively oxidizes hyperreactive thiols on the RyR and triadin, releases $\mathrm{Ca}^{2+}$ from $\mathrm{SR}$ vesicles, without inhibiting $\mathrm{Ca}^{2+}-\mathrm{Mg}^{2+}$-ATPase activity. In other works oxidizing reagents cause $\mathrm{Ca}^{2+}$ release from SR vesicles and activates single channel activity in the lipid bilayer. ${ }^{52}$

In summary, these experiments support a proposed model of redox control of channel gating. It has been shown that the $\mathrm{Ca}^{2+}$ release rates from SR vesicles induced by the thiol reagent ${ }^{94} \mathrm{Ag}^{+}$, and induced by the reactive disulfide compound 2,2'dithiodipyridine (2,2'-DTDP) are maximal ${ }^{121}$ at $\mathrm{pH}$ 7.0. Moreover, oxidation of thiols in an environment without protein, is maximal at around $\mathrm{pH}$ 8.0. The amino acid lysine, with its free $\varepsilon$ amine, can lower the $\mathrm{pK}_{\mathrm{a}}$ of nearby thiols. ${ }^{14}$

Thus, lysine may influence the reactivity of thiols at $\mathrm{pH} 7.0$, that are important for $\mathrm{Ca}^{2+}$ release channel gating. 


\subsubsection{Other Proteins interacting with the RyR}

In addition to triadin, calsequestrin may also play an important role in E-C coupling. Calsequestrin is a major mammalian skeletal muscle $\mathrm{SR} \mathrm{Ca}^{2+}$-binding protein that is concentrated in the terminal cisternae of SR. Observations of calsequestrin protein conformational changes preceding those of the RyR suggest that calsequestrin, in addition to increasing the $\mathrm{Ca}^{2+}$ storage capacity of $\mathrm{SR}$, may have an active role in regulating SR $\mathrm{Ca}^{2+}$ release. $^{37}$

\subsection{PHARMACOLOGY OF SR CALCIUM RELEASE}

There are several chemical compounds which are able to modulate $\mathrm{Ca}^{2+}$ release from $\mathrm{SR}$ vesicles. These modulators either inhibit or stimulate $\mathrm{Ca}^{2+}$ release and play an important role in examining the calcium release channel. 


\subsubsection{Inhibitors of $\mathrm{Ca}^{2+}$ release}

Ruthenium red inhibits $\mathrm{Ca}^{2+}$ release from isolated SR vesicles ${ }^{62,94,113}$ and inhibits the single channel activity in the lipid bilayer. ${ }^{99}$ This inhibitor is effective at concentrations less than $5 \mu \mathrm{M}$.

$\mathrm{Mg}^{2+}$ inhibits muscle fiber contraction ${ }^{28,30}, \mathrm{Ca}^{2+}$ release from isolated SR vesicles ${ }^{62}$ and single channel activity in lipid bilayer. ${ }^{100}$ It is less effective than ruthenium red, but it is more physiologically relevant because the $\mathrm{Mg}^{2+}$ concentration in muscle cells is between 0.6 and $1.0 \mathrm{mM}$. Inhibition of $\mathrm{Ca}^{2+}$ release from SR vesicles occurs above $1-2 \mathrm{mM} \mathrm{Mg}^{2+}$.

In single channel measurements, calmodulin inhibited the release channel by reducing the channel open time without having an apparent effect on single channel conductance. ${ }^{102}$ Channel inhibition with calmodulin is $\mathrm{Ca}^{2+}$-dependent, reversible, and only partial (two to threefold), rather than complete. Inhibition is observed under assay conditions that varied ${ }^{45} \mathrm{Ca}^{2+}$ release rates from heavy SR vesicles by $>1000$-fold. ${ }^{63}$

\subsubsection{Stimulators of $\mathrm{Ca}^{2+}$ release:}

The interaction between $\mathrm{Ca}^{2+}$ and the $\mathrm{Ca}^{2+}$ release channel is biphasic. Low concentrations $(>1 \mu \mathrm{M})$ stimulate the release of $\mathrm{Ca}^{2+}$ from SR vesicles and high concentrations $(>1 \mathrm{mM})$ inhibit the release. It is believed that there are two $\mathrm{Ca}^{2+}$ binding 
sites on the release channel. The high affinity binding site is responsible for channel opening, and the low affinity binding site for channel closure. $\mathrm{Mg}^{2+}$ inhibition of the $\mathrm{Ca}^{2+}$ channel opening is probably due to competition with $\mathrm{Ca}^{2+}$ for the same binding site. In addition, $\mathrm{Mg}^{2+}$, sterically blocks the channel as it binds to a site near the conducting pathway. This biphasic behavior has also been shown for single channels in lipid bilayers.

$\mathrm{Ca}^{2+}$-induced $\mathrm{Ca}^{2+}$ release can be greatly potentiated by millimolar concentrations of ATP. ${ }^{66,69,72}$ Optimal channel activation was found in the presence of $\mu \mathrm{M} \mathrm{Ca}^{2+}$ and $\mathrm{mM}$ ATP (AMP-PCP) in SR vesicles ${ }^{62,72}$ and single channel measurements. ${ }^{100}$ Various other adenine nucleotides (AMP-PCP, ADP, AMP, cAMP, adenosine, adenine) potentiate $\mathrm{Ca}^{2+}$ release, which suggests that activation occurs because of binding to an effector site rather than covalent modification of the channel protein via a phosphorylation reaction, because AMP-PCP is a non-hydrolyzable ATP analogue. It is likely that MgATP, rather than free ATP, is a major physiological regulator of the RyR ion channel because most of the nucleotide in cells is complexed with $\mathrm{Mg}^{2+}$. The addition of $\mathrm{Mg}^{2+}$ and adenine nucleotide at concentrations approximating those in muscle $\left(5 \mathrm{mM}\right.$ each, $0.7 \mathrm{mM}$ free $\left.\mathrm{Mg}^{2+}\right)$ was strongly stimulatory at $\mu \mathrm{M} \mathrm{Ca}^{2+}$ and indicated the existence of a regulatory site that, upon binding of MgATP, rendered the channel more sensitive to activation in a narrower $\mathrm{Ca}^{2+}$ concentration range. ${ }^{62}$ In the presence of $\mu \mathrm{M} \mathrm{Ca}^{2+}$ and $5 \mathrm{mM}$ AMP-PCP, a change in free $\mathrm{Mg}^{2+}$ concentration from 0.1 to $4 \mathrm{mM}$ had a profound inhibitory effect on $\mathrm{Ca}^{2+}$ efflux, which suggests that free $\mathrm{Mg}^{2+}$ may be an important effector of in vivo $\mathrm{SR} \mathrm{Ca}^{2+}$ release. 
Ryanodine is also known to show a biphasic behavior. At low concentrations (nM) it stimulates, and a higher concentrations $(\mu \mathrm{M})$ it closes the $\mathrm{Ca}^{2+}$ release channel. This was seen with SR vesicles and on the single channel level. ${ }^{16 a}$

Caffeine is known to activate muscle fiber contraction ${ }^{34}$ and stimulates $\mathrm{Ca}^{2+}$ release from SR vesicles. Actually caffeine doesn't stimulate $\mathrm{Ca}^{2+}$ release by itself, but sensitizes the channel to $\mathrm{Ca}^{2+}$ (i.e., a lower $\mathrm{Ca}^{2+}$ concentration is needed to activate the channel. ${ }^{80}$ )

\subsection{RYANODINE BINDING}

Ryanodine is a neutral alkaloid isolated from the stems of the plant Ryania speciosa Vahl. This plant uses the ryanodine to protect itself against insects. If the insect eats the bark of the plant, ryanodine causes an irreversible contraction of the insect's muscles by locking the release channel in an open state. As a result the intracellular $\mathrm{Ca}^{2+}$ concentration rises and the muscle goes into rigor. It was also shown that it has an effect in vertebrates. In skeletal muscle, ryanodine causes an irreversible muscle contraction and in cardiac muscle it lowers the contractile force.

Tritium labeled ryanodine $\left(\left[{ }^{3} \mathrm{H}\right]\right.$ ryanodine $)$ is used in ligand binding assays. Pessah et al. ${ }^{79}$ demonstrated that under appropriate conditions ryanodine remained tightly bound with a nanomolar affinity to a single class of receptor sites on the SR. The high affinity ryanodine binding occurred only in the junctional $\mathrm{SR}^{80}$, and it shows all the ligand binding pharmacology of the $\mathrm{Ca}^{2+}$ release channel. ${ }^{79,80}$ Thus, ryanodine binding is stimulated in the 
presence of adenine nucleotides, caffeine, and $\mathrm{Ca}^{2+}$, and is inhibited by $\mathrm{Mg}^{2+}$ and ruthenium red. This strongly indicates that ryanodine interacts directly with the $\mathrm{Ca}^{2+}$ release channel, and ryanodine binding is only possible if the channel is in the open state. In addition, ryanodine binding shows biphasic behavior at different $\mathrm{Ca}^{2+}$ concentrations. Binding is stimulated for $>1 \mu \mathrm{M} \mathrm{Ca}^{2+}$ and inhibited for $>1 \mathrm{mM} \mathrm{Ca}^{2+}$. This correlation between ryanodine binding and $\mathrm{Ca}^{2+}$-induced $\mathrm{Ca}^{2+}$ release enables us to monitor the state of the channel by examining the binding of $\left[{ }^{3} \mathrm{H}\right]$ ryanodine. It is believed that every chemical compound which changes the characteristics of ryanodine binding interacts with $\mathrm{Ca}^{2+}$ release channel.

There are four ryanodine binding sites on the ryanodine receptor. They have different binding affinities and are described below in the order of decreasing binding affinity. The first, highest affinity binding site is the one which is examined in ryanodine binding assays and correlates with the open or closed state of the channel $\left(\mathrm{K}_{\mathrm{d}} \approx 5 \mathrm{nM}\right)$. The second binding site is responsible for the opening of the channel, and locking the channel into a half conductance state. The third state correlates with a quarter conductance state, and the lowest affinity binding site is responsible for closing down the release channel. ${ }^{16 a}$ 


\subsection{THEORY AND EXPERIMENTAL TECHNIQUES OF LIGAND- BINDING STUDIES ${ }^{76}$}

\subsubsection{Introduction}

In organisms of higher complexity, processing information from cell to cell or from one subcellular unit to another is part of an informational network that the organism uses to maintain its integrity. The basis of this process is the recognition of chemically coded information by the receptor proteins that the cell expresses. The central mechanism of this recognition is the binding of an extracellular signaling molecule (ligand) by a receptor protein. The highly specific binding of the natural ligand leads to a conformational change within the receptor protein. This activates the receptor and leads to the subsequent activation of a more or less complex effector system. By integrating all intracellular processes, triggered by different signaling molecules, the cell responds in a way that normally fulfills the demand of the organism. By binding the ligand to the binding site, the receptor protein is activated. The triggered biological effect can be detected in vivo using pharmacological assays.

Besides the pharmacological characterization of a ligand, which includes binding to the receptor's binding site as well as the subsequently initiated effect, the characterization of the binding step is a useful task. Furthermore, the examination of a receptor's binding properties in vitro is more easily achieved than its complete pharmacological 
characterization. Assays for the receptor's activity or the biological effect are generally much more difficult. But the differentiation between specific and nonspecific binding in some cases is impossible without testing the biological effect coupled to it.

The aim of binding studies is the characterization of a ligand's binding to its accompanying receptor. For a defined ligand/receptor pair the ligand's affinity, the rate constants for the ligand's binding or dissociation, the stoichiometry of binding and the interference of multiple binding sites on a receptor molecule, which influence one another during ligand binding, (i.e., the cooperativity of the binding) are characteristic parameters, which can be determined experimentally.

Essential for a binding assay is the availability of a ligand that has been labeled in order to measure its distribution between the bound and free state. In general ligands labeled by radioisotopes like ${ }^{3} \mathrm{H}$ or ${ }^{125} \mathrm{I}$ are used. However fluorescent labels can also be used. Both types of labeled ligands have to maintain the same binding characteristics as its nonlabeled counterpart. The main criteria for the ligand is that it has a sufficient affinity for the binding site and that binding times are short enough such that equilibrium occurs within the time scale of the assay. 


\subsubsection{Experimental strategies}

As a result of a binding experiment the radioligand is distributed between a bound and a free state. The incubation time of a binding assay depends on the experimental approach. Except for kinetic experiments, the incubation proceeds until equilibrium is established. For displacement experiments a second unlabeled ligand is added, which either competes with the labeled ligand for the binding sites or binds at a related site on the receptor. The concentration of binding sites is maintained at a constant value, while the ligand concentration is varied during the experiment.

\subsubsection{Saturation experiments}

A constant concentration of binding sites (or protein) is incubated with increasing concentrations of the radioligand. The incubation is continued until the equilibrium has been established. Then the concentrations of the free and bound radioligand are determined. To draw conclusions from this kind of experiment one has to assume that the receptor preparation contains a homogenous population of receptor protein and that the receptor complexes contains one or more binding sites, which bind the ligand independently of each other (i.e., no cooperativity occurs). Furthermore, the nonspecific 
binding is negligible and neither receptor or ligand degradation nor isomerization of the receptor-ligand complex occurs during the incubation period.

Equilibrium reaction:

$$
R+L \longleftrightarrow(R L)
$$

where $\mathrm{L}$ stands for the free ligand, $\mathrm{R}$ for an unoccupied binding site, and (RL) for an occupied binding site in a receptor-ligand complex mass action law:

$$
K_{d}=\frac{[L][R]}{[(R L)]}
$$

where $\mathrm{K}_{\mathrm{d}}$ is the dissociation constant

It is also known that

$$
[R]_{T}=[R]+[(R L)]
$$

where $[R]_{\mathrm{T}}$ is the total concentration of binding sites.

The measured parameters, free ligand concentration $F=[L]$ and bound ligand $B=(R L)$ are used in the following discussion. Therefore

$$
[R]=[R]_{T}-B
$$

The total concentration of binding sites $[R]_{T}$ can also be expressed by the maximal concentration of ligand which is able to bind the finite number of binding sites in the assay volume. If the total ligand increases, the bound ligand's concentration reaches a maximal concentration $B_{\max }$, which equals the total concentration of binding sites $[R]_{T}$.

$$
[R]=B_{\max }-B
$$

(5) into (2) leads to 


$$
K_{d}=\frac{F\left(B_{\max }-B\right)}{B}
$$

From

$$
B=\frac{B_{\max } F}{K_{d}+F}
$$

one can see that the value of $\mathrm{K}_{d}$ equals the concentration of $\mathrm{F}$ at a point where $\mathrm{B}$ equals half the value of $B_{\max }$.

A saturation experiment enables us to determine $\mathrm{K}_{\mathrm{d}}$ and $\mathrm{B}_{\max }$. Historically, this was done by the linearization of the data according to Scatchard, which allows linear regression analysis. Transformation of equation 7 leads to

$$
\frac{B}{F}=\frac{-B}{K_{d}}+\frac{B_{\max }}{K_{d}}
$$

If the ratio $B / F$ is plotted versus $B$ then the slope is $-1 / K_{d}$ and the $x$-axis intercept is $B_{\max }$.

If the Scatchard analysis is used for the determination of $\mathrm{K}_{\mathrm{d}}$ and $\mathrm{B}_{\max }$ one has to have a minimum of 7-10 ligand concentrations. These concentrations should ideally cover a range of $\mathrm{B}$, which is between 10 and $90 \%$ of $\mathrm{B}_{\max }$. The occupation of binding sites should reach at least $80 \%$. It is recommended to fit the line by using the data points between about 20 and $80 \%$ saturation of the binding sites. Furthermore, the determination of $\mathrm{B}_{\max }$ by using this extrapolation is based on the assumption that the simple model of equal and noninteracting binding sites is valid over the whole range of the ligand's concentration. In addition $\mathrm{Hulme}^{35}$ recommended that the optimal concentration of binding sites for a saturation experiment is in the range of 0.1 to 0.5 times the $\mathrm{K}_{\mathrm{d}}$. 
So far only the simplest case of equal and noninteracting binding sites was considered. The resulting Scatchard plot gives excellent straight lines. On the other hand, a more complex type of binding results in a nonlinear Scatchard plot. The most obvious explanation for a nonlinear Scatchard plot is a cooperative interaction between binding sites. Binding of a ligand may cause a conformational change within the receptor protein, which either facilitates (positive cooperativity) or weakens (negative cooperativity) binding of the next ligand. Unfortunately nonlinearity can also occur because of more artificial causes like underestimating of the nonspecific binding, heterogeneity of binding sites, ligand-ligand interaction, isomerization of the receptor-ligand complex, or incomplete equilibration. The strength of cooperativity is described by the Hill coefficient $\mathrm{n}_{\mathrm{H}}$. This constant is obtained as the slope of the linear segment of the curve resulting from the Hill transformation

$$
\log \left(\frac{B}{B_{\max }-B}\right)=n_{H} \log F-n_{H} \log K_{0.5}
$$

Prerequisite for this plot is the independent determination of $B_{\max }$ by a saturation experiment. Positive cooperativity is characterized by a Hill coefficient higher than 1 , whereas a value lower than 1 indicates negative cooperativity. The more extreme this value is, the stronger the cooperative interference of the binding sites. $\mathrm{K}_{0.5}$ is an integrative constant composed of the apparent dissociation constants of the distinct binding steps. It equals the free ligand's concentration at $50 \%$ saturation. If no cooperativity is seen $\left(\mathrm{n}_{\mathrm{H}}=1\right)$, this constant is identical to $\mathrm{K}_{\mathrm{d}}$. 


\subsubsection{Kinetic experiments}

Alternatively, the dissociation constant can be determined by measuring the rate constants $\mathrm{k}_{+1}$ for the ligand's association and $\mathrm{k}_{-1}$ for the ligand's dissociation from the receptor-ligand complex. In addition one can get even more information than the $\mathrm{K}_{d}$ from this type of experiment if the ligand binding shows an unexpected behavior as a function of time.

The change in the concentration of the receptor-ligand complex over time can be expressed as:

$$
\frac{d[(R L)]}{d t}=k_{+1}[R][L]-k_{-1}[(R L)]
$$

In the dynamic equilibrium the association and dissociation reaction occur with the same rate, i.e. $d[(R L)] / d t=0$. From equation 10 follows

$$
\frac{k_{-1}}{k_{+1}}=\frac{[R][L]}{[(R L)]}=K_{d}
$$

By the kinetic approach only the equilibrium constant can be determined and not the $\mathrm{B}_{\max }$, which has to be determined by an independent saturation experiment. 


\subsubsection{Association rate}

For the determination of $\mathrm{k}_{+1}$, the ligand and the receptor are mixed at time $\mathrm{t}=0$. The concentration of bound ligand $\mathrm{B}(\mathrm{t})$ is then monitored as a function of time until no further change occurs. The concentration of $\mathrm{B}(\mathrm{t})$ at equilibrium equals $\mathrm{B}$.

One can now determine $\mathrm{k}_{+1}$ if one assumes a pseudo-first order reaction and that the concentration of the free ligand $\mathrm{F}$ is nearly unchanged over the whole period of measurement and equals approximately $[\mathrm{L}]_{\mathrm{T}}$. Therefore $\mathrm{B}$ should always remain below $10 \%$ of the ligand's total concentration. With these assumptions equation 10 becomes

$$
\frac{d B(t)}{d t}=k_{+1}\left(B_{\max }-B(t)\right)[L]_{T}-k_{-1} B(t)
$$

The equation which describes the equilibrium is

$$
0=k_{+1}\left(B_{\max }-B\right)[L]_{T}-k_{-1} B
$$

Subtraction, separation of variables, and integration leads to

$$
\ln \frac{B}{B-B(t)}=\left(k_{+1}[L]_{T}-k_{-1}\right) t=k^{\prime} t
$$

From equation (14) you can extract the apparent velocity constant $k^{\prime}$ from the slope if you plot the logarithmic expression against time t.

$$
k^{\prime}=k_{+1}[L]_{T}-k_{-1}
$$

suggests 2 possibilities to extract $\mathrm{k}_{+1}$. One method is to measure $k^{\prime}$ and determine $\mathrm{k}_{-1}$ by an independent experiment. The other is to measure $k^{\prime}$ for different total concentrations of the ligand. But the assumption that the concentration of $\mathrm{F}$ has to be nearly unchanged, 
should be considered. Using this method, $\mathrm{k}_{+1}$ can be extracted from the slope and $\mathrm{k}_{-1}$ from the intercept on the y-axis. All these considerations hold only if the binding sites are homogenous and do not interact which each other.

\subsubsection{Dissociation rate}

In dissociation one has only to consider the dissociation process. The receptor and the ligand are mixed and incubated until equilibrium is established. The bound ligand concentration equals the equilibrium concentration B. After equilibration, the association process is blocked either by dilution with the incubation buffer to a volume exceeding 100 times the initial assay volume, or by strongly reducing the radioligand's specific activity by the addition of an excess of the unlabelled ligand. The dissociation of the radioligand is measured as the loss of bound radioactivity $\mathrm{B}(\mathrm{t})$ over time. The dissociation process can be described by

$$
\frac{d B(t)}{d t}=-k_{-1} B(t)
$$

Integration of this equation results in

$$
\ln \frac{B(t)}{B}=-k_{-1} t
$$

The dissociation constant $\mathrm{k}_{-1}$ can be extracted by the slope of the plot of the logarithm of $\mathrm{B}(\mathrm{t}) / \mathrm{B}$ versus time. The determination of $\mathrm{k}_{-1}$ by dilution as well as by competition with an excess of the nonradioactive ligand should give the same result. If not, a cooperative 
reaction is probably involved. If the dissociation measured by dilution is faster, this might be caused by positive cooperativity, while a slower dissociation by dilution indicates negative cooperative interaction.

\section{8 o-PHTHALALDEHYDE (OPA)}

In 1971, Roth $^{88}$ developed a sensitive technique for detecting of amino acids on the basis of their reaction with o-Phthalaldehyde. In alkaline medium in the presence of a thiol agent, such as 2-mercaptoethanol, a strong fluorescent signal is observed. This permits fluorimetric assay of amino acids down to the nanomolar range. No heating is necessary, and the fluorescence may easily be measured 5 min after mixing of the reagents. After ion exchange fractionation, amino acids can be determined automatically. A fluorescence was obtained with all common amino acids except cysteine, proline and hydroxyproline. A sharp decrease in fluorescence was observed if the buffered amino acid was first mixed with OPA and mercaptoethanol was added last. This indicates that in the absence of a reducing agent, OPA is capable of reacting otherwise with amino acids with the formation of nonfluorescent products.

Simons and Johnson ${ }^{97}$ showed based on data collected from proton NMR, IR and mass spectral analysis of several crystallized OPA-amine-thiol derivatives that the reaction of OPA and 2-mercaptoethanol with primary amino acids gives a 1-alkylthio-2alkylisoindole product. 


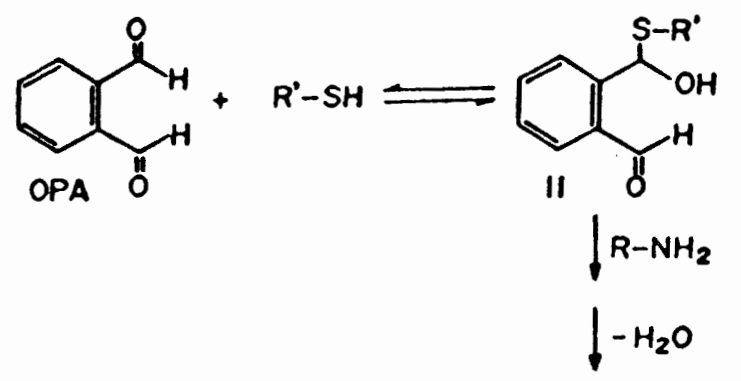<smiles>[R]N=Cc1ccccc1[C@H](O)S[R7]</smiles><smiles>[CH][AlH]</smiles><smiles>[R7]S[C@@]1([R])c2ccccc2C[N+]1[R]</smiles>

$\checkmark$
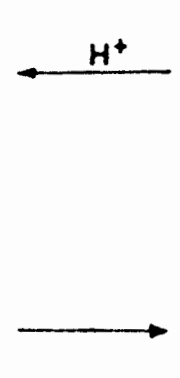<smiles>[R]N=Cc1ccccc1C(O)S[R]</smiles>

III

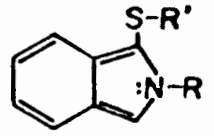

1

Figure 3 Mechanism for isoindole formation proposed by Simons and Johnson ${ }^{97}$

Analyses of the chemical shifts of the isoindole alkyl substituents in the NMR spectra support the previous conclusions that these heterocycles have relatively low levels of aromatic character. The amount of isoindole formed is severely reduced by adding an amine to OPA before adding the thiol. The formation of this isoindole proceeds rapidly under mild, stoichiometric conditions and in very high yield, so there is little need for purification before studying the physical properties or performing further chemistry. Later it was found that OPA is capable of detecting picomolar quantities of amines ${ }^{88}$, amino acids, and proteins. ${ }^{120}$ Of the various spectrophotometric methods currently available for these purposes, the OPA reaction appears to be the most sensitive 
for amino acids. ${ }^{66}$ OPA is less efficient than other methods in detecting peptides and proteins ${ }^{66}$ unless the protein sulfhydryl groups are first aminoethylated.

Simons and Johnson ${ }^{98}$ observed that when a concentration of around $100 \mathrm{mM}$ OPA in $95 \%$ ethanol was used, the reaction is unaffected by excess thiol and in all cases proceeds rapidly and in $\geq 90 \%$ yield, even at $0^{\circ} \mathrm{C}$. In each reaction apparent maximal fluorescence was observed essentially immediately after adding amine. Thin layer chromatography analyses of the final concentrated reaction solutions revealed very little, if any, of the unreacted starting materials. Thiol structure has very little effect on the $\lambda_{\text {excitation }}$ but the $\lambda_{\text {emission }}$ is more sensitive to structural changes of the thiol. Dilute solutions $\left(10^{-4}\right.$ $10^{-7} \mathrm{M}$ ) of most adducts retained $\geq 90 \%$ of their original fluorescence after 4 days at room temperature in the dark. In contrast, $0.3 \mathrm{M}$ solutions of 2-mercaptoethanol or ethanethiol adducts that were kept at room temperature in the dark for $\geq 2$ weeks and then diluted to $3 \times 10^{-7} \mathrm{M}$ exhibited $\leq 20 \%$ of the fluorescence of a $3 \times 10^{-7} \mathrm{M}$ solutions subjected to the same storage conditions. The monoisoindole adducts of thiols containing two SH groups are less stable, but even these adducts maintained $\geq 60 \%$ fluorescence after 4 days. Very high concentrations $(\approx 10 \mathrm{M})$ of the ethanethiol or 2-mercaptoethanol adduct are nonfluorescent but become fluorescent when diluted. Thus the lack of fluorescence is due to self-quenching rather than a concentration-dependent decomposition of the adduct.

It was also observed that some amino acids, such as lysine and especially cysteine, give low to nonobservable fluorescence yields in the OPA reaction. Thus for reasons which are not theoretically understood, not all thiols (e.g., methyl mercaptoacetate) or amines necessarily give isoindoles which are intensely fluorescent. The effect of three 
different solvents water, $95 \%$ ethanol, and isooctane on the spectra of the ethanethiol adduct was examined and it was shown that decreasing solvent polarity causes a progressive blue shift in the $\lambda_{\max }$ which is most evident in the emission spectra. So $\lambda_{\max }$ for the emission spectra shifts from $450 \mathrm{~nm}$ for water to $430 \mathrm{~nm}$ for $95 \%$ ethanol to $400 \mathrm{~nm}$ for isooctane. It was also seen that the presence of bulky andlor polar substituents on the isoindole ring appears to moderate the solvent effect on fluorescence intensity.

The fluorescence intensity of the adducts is in general the highest for $95 \%$ ethanol as the solvent, while for the two other solvents the fluorescence intensity is lower. It is the lowest for isooctane. The stability of the isoindole is the least stable in aqueous solution and the most stable in $95 \%$ ethanol. The shape and $\lambda_{\max }$ of the ethanethiol and 2mercaptoethanol adduct fluorescence spectra were unaffected by $\mathrm{pH}$.

In contrast, $\mathrm{pH}$ affects the stability of these adducts, as each adduct becomes less stable as the $\mathrm{pH}$ is lowered. DTT produces $30 \%$ less fluorescence in the OPA reaction than does mercaptoethanol. ${ }^{16}$ Proteins in general have been observed to give fluorescent products in reactions with OPA and with and without 2-mercaptoethanol. ${ }^{41,120}$ In the absence of 2-mercaptoethanol, the fluorescence yield of the reaction is increased by prior reduction of disulfide linkages to free $\mathrm{SH}$ groups ${ }^{41}$, and is reduced to zero by pretreatment of the protein(s) with $\mathrm{N}$-ethyl maleimide, which rapidly reacts with free SH groups. ${ }^{41,120}$ The lower fluorescence intensity and slightly different $\lambda_{\max }$ 's of the OPA-protein versus OPA-2-mercaptoethanol-protein adducts ${ }^{120}$ could easily be due to different isoindole ring substituents and/or variations in the polarity of the fluorophore's microenvironment 
Joys and $\mathrm{Kim}^{43}$ suggest that the major reaction between OPA-2-mercaptoethanol adduct and peptides leading to the production of fluorescent derivatives occurred at the $\varepsilon$ amino group of lysine. They showed that two peptides containing C-terminal arginine reacted very poorly with OPA-2-mercaptoethanol whereas peptides with C-terminal lysine reacted very well. Moreover, as an internal residue, lysine overcame the inactivity of a Cterminal arginine so that OPA fluorescence seemed dependent upon the presence of lysine and not upon the identity of the C-terminal amino acid. It was demonstrated that change in the N-terminal amino acid had little effect but substitution of a C-terminal arginine markedly increased the fluorescence.

Experiments were carried out in which fluorescence was determined after peptides and OPA-2-mercaptoethanol had been mixed and allowed to stand for various times at room temperature or at $50^{\circ} \mathrm{C}$. Fluorescence produced with all peptides was found to decrease with time and reached $50 \%$ of the original value after $15 \mathrm{~min}$ at room temperature. No increase in the low fluorescence produced by nonreactive peptides was obtained by increasing the time of contact with OPA-2-mercaptoethanol nor by heating the reaction mixture.

Chen et al. $^{25}$ showed that the fluorescent quantum yields of OPA derivatives of the naturally occurring amino acids ranged from 0.33 to 0.47 using 2-mercaptoethanol as the thiol compound. The fluorescent lifetimes were about 18-20 ns. Lower quantum yields were obtained when mercaptoethanol was replaced by dithiothreitol (DTT) or ethanethiol (ET). OPA is non-fluorescent until it reacts with primary amines, and any excess of reagent does not break down or react to form fluorescent by-products. It is therefore 
unnecessary to separate the fluorescent products and the unreacted OPA in analytical procedures using these reagents. The thiol compound included in the OPA reaction was originally thought to function simply as a reducing agent, but Simons and Johnson ${ }^{97 a}$ showed that the thiol actually becomes part of the final product. The absorption spectral properties of the OPA -mercaptoethanol and OPA-alanine complexes are clearly distinct from those of the fluorescent product OPA-mercaptoethanol-alanine (figure 4).
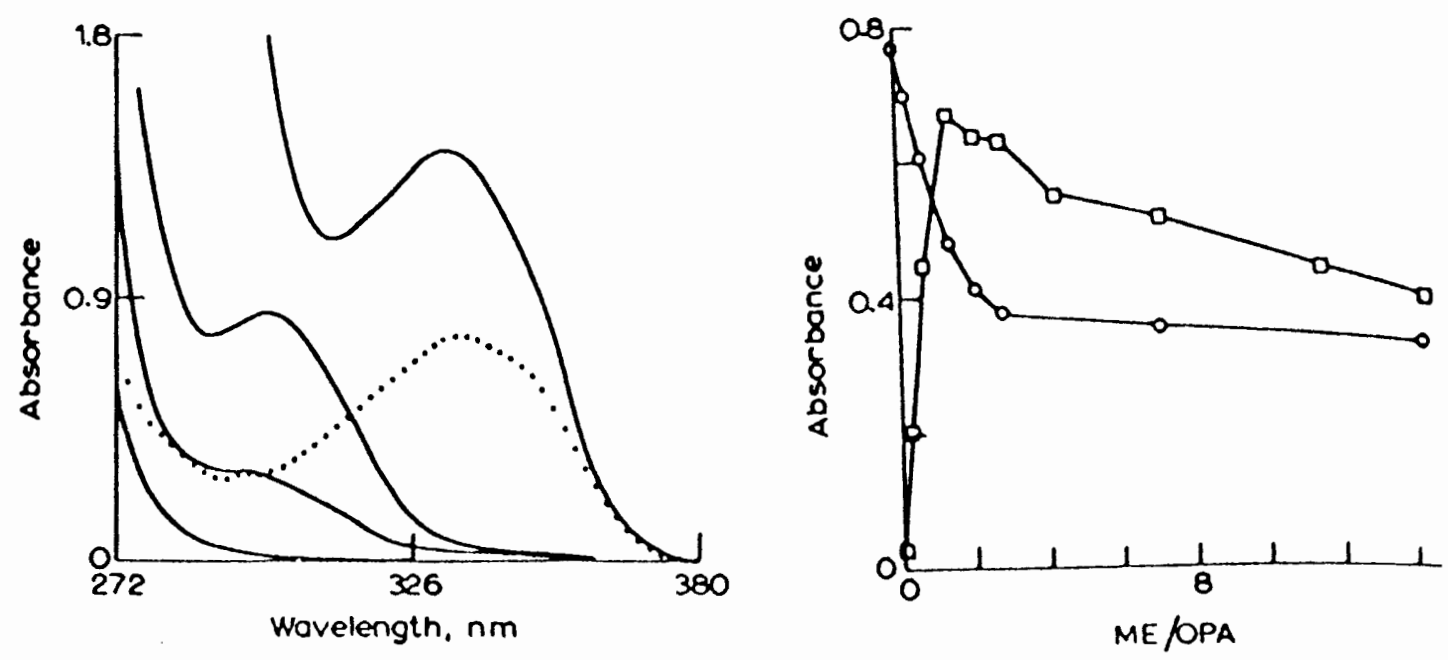

Figure 4 Absorption spectra of OPA and its derivatives. The solid curves were obtained with solutions containing $0.05 \mathrm{M}$ sodium borate buffer, $\mathrm{pH} 9.0$ and combinations of $3.310^{-3} \mathrm{M}$ OPA, 4.8 $10^{-2} \mathrm{M} \mathrm{ME}$, and $510^{-3} \mathrm{M}$ alanine. From right to left, the solid lines are spectra of solutions containing OPA + alanine, OPA alone, OPA + ME, and ME alone. The dotted curve represents a fluorescent solution of OPA(ME)-alanine formed in a solution containing $0.01 \mathrm{M}$ sodium borate, $\mathrm{pH} 9.0,1.310^{-4} \mathrm{M}$ alanine, $10^{-2} \mathrm{M} \mathrm{ME}$, and $6.710^{-4} \mathrm{M} \mathrm{OPA.}^{25}$

Figure 5 The interaction of ME with OPA. Each solution contained $0.033 \mathrm{M}$ sodium borate, pH 9.0, 3.3 $10^{-3}$ M OPA. The absorbance at $300 \mathrm{~nm}(0)$ or the absorbance at $334 \mathrm{~nm}(\square)$ in the presence of $3.310^{-3} \mathrm{M}$ alanine was followed as a function of the molar ratio of added $\mathrm{ME}^{25}$ 
Examination of the amount of mercaptoethanol required for optimum fluorescence yield showed that approximately 2 moles mercaptoethanol/mole of OPA yield the maximum amount of fluorescent product, which absorbs at $334 \mathrm{~nm}$. As a result of formation of this fluorescent product there is a corresponding reduction in the absorbance of OPA at $299 \mathrm{~nm}$.

The stability of OPA products was noted to be affected by both the thiol and the amine involved. The fact that peptides yield a small fluorescence was shown to be due to a low quantum yield rather than low reactivity. The fluorescent products obtained with OPA-ET and OPA-DTT had lower quantum yields and shorter lifetimes than those of OPA-ME. They also appear to be more stable than those using ME. The reaction of OPA-ME with alanine is blocked by adding cysteine before alanine. If cysteine is added after alanine is added to OPA-ME, there is little if any reversal of the fluorogenic reaction.

An increase in temperature decreases the fluorescence yield. It had previously been shown ${ }^{88}$ that an alkaline $\mathrm{pH}$ favors the OPA fluorogenic reaction, but a high $\mathrm{pH}$ is also needed to observe the fluorescence of the formed products. DMSO enhances the stability of the OPA product. The instability of these compounds was attributed by Simons and Johnson $^{97}$ to an intramolecular nucleophilic attack by the hydroxyl group of the ME moiety, and this is evidently prevented by $60 \%$ DMSO.

Recently ${ }^{6}, \mathrm{~N}$-acetyl-L-cysteine (NAC) has been substituted for 2-mercaptoethanol in the pre- and postcolumn OPA-derivatization of primary amines and amino acids with good results. The fluorescence of OPA-NAC derivatives is nearly identical to that of the OPA- 
2-mercaptoethanol products. This reaction is rapid, and the NAC derivatives are more stable than either 2-mercaptoethanol or ethanethiol derivatives.

Puri et al. ${ }^{83}$ used OPA to label a catalytic subunit from bovine skeletal muscle. They showed that OPA decreases the activity of the labeled enzyme. It was shown that the reaction between the catalytic subunit and OPA was not reversed by the addition of reagents containing free primary amino and sulfhydryl functions following inactivation. The reaction, however, could be arrested at any stage during its progress by the addition of an excess of cysteine or less efficiently by homocysteine or glutathione.

It is therefore reasonable to assume that the proximity of $\mathrm{SH}$ function of the cysteine residue and $\varepsilon-\mathrm{NH}_{2}$ function of the lysine residue in the $\mathrm{C}$-subunit participating in reaction with $\mathrm{OPA}$ is comparable to that of $\mathrm{SH}$ and $\mathrm{NH}_{2}$ functions in cysteine and the distance between the two CHO functions in OPA which is around $0.3 \mathrm{~nm}$. They also suggested the reaction scheme of the OPA-C-subunit reaction.

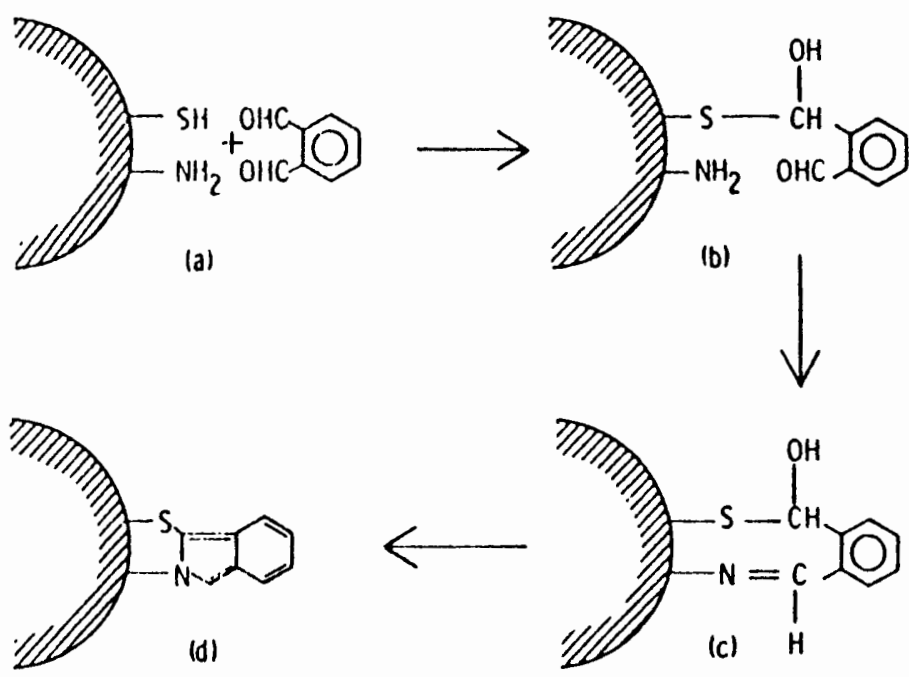

Figure 6 Schematic representation of the reaction between the $C$ subunit of an enzyme and $\mathrm{OPA}^{83}$ 
The conversion of intermediate $c$ to the isoindole derivative $d$ is thermodynamically favorable since such a process converts the benzenoid ring of OPA, a six overlapping $\pi$ electron system to an isoindole ring system, a ten overlapping $\pi$-electron system. The reaction between C-subunit and OPA is irreversible and the isoindole derivative formed is stable under the experimental conditions over a period of at least 24 hours.

Spectrofluorometric examination of the reaction mixtures containing synthetic peptides ( $\mathrm{NH}_{2}$ function donors) and $\mathrm{OPA}$ in the presence or absence of 2-mercaptoethanol (SH function donor) did not show the formation of isoindole derivative. The results of these investigations suggest that only the $\varepsilon-\mathrm{NH}_{2}$ function provided by a lysine residue (and not the secondary amino or primary amino functions of histidine or arginine, respectively) participates in an isoindole derivative formation in the reaction between the $\mathrm{C}$ subunit and OPA. $^{83}$

The aim of this thesis is to examine the interaction between OPA and the $\mathrm{Ca}^{2+}$ release channel. The motivation for using OPA comes from its ability to react with a cysteine and a lysine at the same time to form an isoindole derivative. Therefore, the possible proximity of a lysine residue on the $\mathrm{Ca}^{2+}$ release channel to a critical sulfhydryl residue was examined. 


\section{CHAPTER II}

\section{METHODS AND MATERIALS}

\subsection{SR PREPARATION}

SR vesicles were isolated according to the methods of MacLennan. ${ }^{55}$ Fast (white) muscles from the back and the hind legs of a New Zealand White rabbit were used. The fat and the connective tissues were trimmed off. The muscles are quickly ground in a meat grinder and added to buffer $\mathrm{A}(120 \mathrm{mM} \mathrm{NaCl}, 10 \mathrm{mM}$ imidazole, $100 \mu \mathrm{M}$ dithiothreitol (DTT), $\mathrm{pH}$ 7.4). The ground muscle is homogenized in a blender alternating low and high speed for 15 and 30 seconds respectively (four times). The resulting solution was then centrifuged at $1600 \times \mathrm{g}$ (3100 rotations per minute (rpm) in the large Sorvall GSA rotor) for ten minutes. The final supernatant fraction is filtered through four layers of cheesecloth and adjusted to $\mathrm{pH} 7.4$ with dry imidazole. The pelleted cell debris was discarded. Next, the filtrate is centrifuged at $10,000 \times \mathrm{g}$ ( $8000 \mathrm{rpm}$ in the GSA rotor) for 14 minutes. The supernatant was filtered through four layers of cheesecloth and the brown pellet which is composed off mitochondria primarily, was discarded. The suspension was then ultracentrifuged at $44,000 \times \mathrm{g}(19,000 \mathrm{rpm}$ in the Beckman type 19 rotor) for 70 minutes and the supernatant was discarded. The pellet was resuspended at about $10 \mathrm{mg} / \mathrm{mL}$ in 
buffer A, and homogenized with a glass homogenizer. This solution was then centrifuged at $7500 \times \mathrm{g}(11,000 \mathrm{rpm}$ in the Beckman Ti60 rotor) for $10 \mathrm{~min}$., to pellet myosin. The myosin pellet was discarded and the supernatant was centrifuged at $78,000 \times \mathrm{g}$ ( 35,000 rpm, still in Ti60 rotor) for 30 minutes. The supernatant was discarded while the SR pellet was suspended into a buffer B ( $100 \mathrm{mM} \mathrm{KCl}, 20 \mathrm{mM}$ Hepes, pH 7.0) at a final concentration at about $25 \mathrm{mg} / \mathrm{mL}$.

The SR suspension was stored in small aliquots in liquid nitrogen. The final protein concentration was determined by spectroscopy ${ }^{45 .)}$ as described below.

\subsection{CHEMICALS}

OPA with purity $\approx 99 \%$ was purchased from Sigma. The molecular weight of the OPA is $134.1 \mathrm{~g} / \mathrm{mol}$. OPA solutions were always prepared freshly in DMSO. Although OPA can be dissolved in ethanol, in control experiments it was shown that ethanol by itself caused $\mathrm{Ca}^{2+}$ release from SR vesicles and this release was inhibited by ruthenium red. Therefore, in all experiments, OPA was dissolved in DMSO. SR vesicles were less sensitive to DMSO. At the concentrations used no adverse effects of DMSO were observed. Since OPA is known to be light sensitive, OPA was shielded from ambient light.

Mg-ATP was stored in liquid $\mathrm{N}_{2}, \mathrm{~A} 23187$ and ryanodine were stored in the refrigerator, and $\mathrm{CaCl}_{2}$ and EGTA were stored at room temperature. All these reagents were purchased from Sigma. 


\subsection{DETERMINATION OF THE PROTEIN CONCENTRATION}

Protein concentration was measured by absorption spectroscopy. A cuvette with $900 \mathrm{~mL} \mathrm{H}_{2} \mathrm{O}$ and $100 \mathrm{~mL}$ of $10 \%$ sodium dodecyl sulfate (SDS) was placed in a spectrophotometer and calibrated. Subsequently, $10 \mu 1$ of the unknown protein sample was added to the cuvette and the absorbance at $230 \mathrm{~nm}, 260 \mathrm{~nm}$, and $280 \mathrm{~nm}$ was measured three times in triplicate with a Beckman DU-7 spectrophotometer. The final protein concentration was determined according to the method of Kalckar. ${ }^{45}$

Most proteins show one distinct absorption maximum at $280 \mathrm{~nm}$, due primarily to the presence of tyrosine and tryptophan. The backbone of the peptide bond absorbs at 230 $\mathrm{nm}$. The method uses those absorption characteristics as a tool to determine the protein concentration, while also considering a possible contamination of nucleic acids which absorb most strongly at $260 \mathrm{~nm}$.

$$
\begin{aligned}
& \text { Protein concentration }(\mathrm{mg} / \mathrm{mL})=100\left(1.45 \mathrm{Abs}_{280}-0.74 \mathrm{Abs}_{260}\right) \\
& \text { Protein concentration }(\mathrm{mg} / \mathrm{mL})=100\left(0.183 \mathrm{Abs}_{230}-0.075 \mathrm{Abs}_{260}\right)
\end{aligned}
$$

From all three measurements and both equations the average value was determined. This procedure was repeated and the final concentration was calculated from the average of the two determined concentrations and expressed as mean protein concentration \pm standard deviation. 


\section{$2.4\left[{ }^{3}\right.$ H]RYANODINE BINDING STUDIES}

For all $\left[{ }^{3} \mathrm{H}\right]$ ryanodine binding studies, the methods described by $P$ essah ${ }^{80}$ were used. $\left[{ }^{3} \mathrm{H}\right]$ ryanodine had a specific activity of $76.2 \mathrm{Ci} / \mathrm{mmol}$ and was purchased from Du Pont. SR vesicles $(0.5 \mathrm{mg} / \mathrm{mL})$ were incubated at $37^{\circ} \mathrm{C}$ for $3 \mathrm{~h}$ in a medium containing $250 \mathrm{mM}$ $\mathrm{KCl}, 15 \mathrm{mM} \mathrm{NaCl}, 50 \mu \mathrm{M} \mathrm{CaCl}_{2}, 20 \mathrm{mM}$ Hepes, $\mathrm{pH} 7.1,14 \mathrm{nM}$ ryanodine, and $1 \mathrm{nM}$ $\left[{ }^{3} \mathrm{H}\right]$ ryanodine. Depending on the desired conditions of the assay various concentrations of OPA or other $\mathrm{Ca}^{2+}$ channel modulators were present during the incubation.

Assays were terminated by rapid filtration through Whatman GF/B glass fiber filters in a cell harvester (Brandel, Gaithersburg, MD) and by washing of the filters with a $3 \mathrm{~mL}$ solution containing $250 \mathrm{mM} \mathrm{KCl}, 15 \mathrm{mM} \mathrm{NaCl}, 20 \mathrm{mM}$ Hepes, $\mathrm{pH} 7.1$, and $50 \mu \mathrm{M}$ $\mathrm{CaCl}_{2}$. The washing process was repeated three times. Subsequently, the filters were placed into scintillation vials, incubated with $2.5 \mathrm{~mL}$ of scintillation fluid (Beckman, ReadySafe) and shaken overnight. The efficiency of the scintillation fluid was around 53\%.

Nonspecific ryanodine binding was determined by measuring binding following the addition of $2 \mathrm{mM}$ EGTA which decreased the free $\mathrm{Ca}^{2+}$ concentration to about $16 \mathrm{nM}$ or by adding a 100 fold excess of unlabeled ryanodine. 


\subsubsection{Measurements of association kinetics}

The association rate of $\left[{ }^{3} \mathrm{H}\right]$ ryanodine binding was determined over a time range of 5 to 240 minutes. The experiment was carried out at several different OPA concentrations. OPA was added to the solution of $0.5 \mathrm{mg} / \mathrm{mL}$ SR vesicles in the buffer of $250 \mathrm{mM} \mathrm{KCl}, 15$ $\mathrm{mM} \mathrm{NaCl}, 50 \mu \mathrm{M} \mathrm{CaCl}_{2}, 20 \mathrm{mM}$ Hepes, $\mathrm{pH} 7.1,14 \mathrm{nM}$ ryanodine, and $1 \mathrm{nM}$ $\left[{ }^{3} \mathrm{H}\right]$ ryanodine. At each OPA concentration samples were incubated in a $37^{\circ} \mathrm{C}$ waterbath for varying periods of time. They were then transferred to an ice bath, and filtered through GF/B filters. Nonspecific binding was determined by the addition of $2 \mathrm{mM}$ EGTA and was measured for different incubation times, varying from 15 mins to 4 hours. Almost no variation could be observed in non-specific binding as a function of time. As a control we showed that the binding after 4 hours on ice was almost exactly as high as nonspecific binding. In other words there was negligible binding to the high affinity ryanodine binding sites when the sample was incubated on ice over the time course of the experiment.

\subsubsection{Measurements of dissociation kinetics}

The purpose of this experiment was to determine the dissociation rate constant by measuring the time dependence of dissociation of the equilibrated $\left[{ }^{3} \mathrm{H}\right]$ ryanodine-protein complex in the presence of different OPA concentrations. SR vesicles $(5 \mathrm{mg} / \mathrm{mL})$ were 
incubated in a solution of $250 \mathrm{mM} \mathrm{KCl}, 15 \mathrm{mM} \mathrm{NaCl}, 50 \mu \mathrm{M} \mathrm{CaCl}_{2}, 20 \mathrm{mM}$ Hepes, $\mathrm{pH}$ 7.1, and $10 \mathrm{nM}\left[{ }^{3} \mathrm{H}\right]$ ryanodine for 3 hours in $37^{\circ} \mathrm{C}$ and then diluted by a factor of 100 into an identical buffer containing various OPA concentrations with no $\left[{ }^{3} \mathrm{H}\right]$ ryanodine present. These diluted solutions were put on ice to prevent dissociation. As a control showed, even after 3 hours on ice only a negligible amount of $\left[{ }^{3} \mathrm{H}\right]$ ryanodine had dissociated from its receptor binding site. The dissociation experiment was done for time steps between 5 and 180 minutes and was set up such that all samples were filtered at the same time. To start the dissociation experiment the already diluted solution was taken out of the beaker on ice and was incubated in $37^{\circ} \mathrm{C}$ for the appropriate time. The nonspecific binding was determined by addition of $2 \mathrm{mM}$ EGTA to the concentrated solution for 3 hours in $37^{\circ} \mathrm{C}$.

\subsection{MEASUREMENTS OF CALCIUM EFFLUX}

$\mathrm{Ca}^{2+}$ fluxes were monitored using a dual wavelength spectrophotometer by measuring the differential absorption changes of antipyrylazo III [bis(4-antipyrylazo)-4,5dihydroxy-2,7-naphthalenedisulfonic acid] at $720-790 \mathrm{~nm}$. The presence of $\mathrm{Ca}^{2+}$ causes a marked increase in absorbance of antipyrylazo III in the spectral area between 660 and $800 \mathrm{~nm}$. At the same wavelengths $\mathrm{Mg}^{2+}$ and $\mathrm{Mn}^{2+}$ are without effect and also the absorption of other divalent ions, which are often present in cell or cell fractions, is very low. Therefore, interference by other ions does not lead to artifactual readings. Antipyrylazo neither binds to cell fractions nor affects cellular properties. In a buffered 
reaction mixture at $\mathrm{pH} 7$ containing $100 \mathrm{mM} \mathrm{KCl}$, the antipyrylazo-calcium complex has a $\mathrm{K}_{\mathrm{d}}$ of $120 \mu \mathrm{M}$ and a relaxation time of $180 \mu \mathrm{sec}$. It is mostly suitable for measurements at concentrations of $\mathrm{Ca}^{2+}$ ranging from 1 to $100 \mu \mathrm{M}$, where it has adequate sensitivity without compromising calibration linearity or disturbing the free $\mathrm{Ca}^{2+}$ in the system. ${ }^{95 \mathrm{a}}$

The measuring of differential absorption changes is accomplished using a dual wavelength spectrophotometer with a time resolution of $\approx 10 \mathrm{~ms}$. Interference filters allow the transmission of light of wavelengths of $720 \mathrm{~nm}$ and $790 \mathrm{~nm}$. A continious monitor of the absorbance difference between these two wavelengths is proportional to the free $\mathrm{Ca}^{2+}$ concentration in the extravesicular space.

$\mathrm{Ca}^{2+}$ uptake into SR vesicles $(0.2 \mathrm{mg} / \mathrm{mL})$ was carried out in a buffer containing 100 $\mathrm{mM} \mathrm{KCl}, 20 \mathrm{mM}$ Hepes, $\mathrm{pH} 7.0,1 \mathrm{mM} \mathrm{MgCl}$, and $200 \mu \mathrm{M}$ antipyrylazo III. The final volume was $1.5 \mathrm{~mL}$. During the entire experiment, the extravesicular $\mathrm{Ca}^{2+}$ concentration was recorded as a function of time on a x-y printer. Following the addition of SR to the cuvette with the described buffer, $15 \mu \mathrm{M} \mathrm{CaCl}_{2}$ was added. After equilibration of the antipyrylazo-calcium complex, $0.5 \mathrm{mM} \mathrm{Mg-ATP}$ was added to stimulate the $\mathrm{Ca}^{2+}$ uptake into the vesicles. Release was initiated by adding the OPA following the completion of $\mathrm{Ca}^{2+}$ uptake. $\mathrm{Ca}^{2+}$ efflux rates were determined from the maximal slope of the extravesicular $\mathrm{Ca}^{2+}$ versus time. At the end of some experiments the $\mathrm{Ca}^{2+}$ ionophore A23187 was added to the cuvette to determine the $\mathrm{Ca}^{2+}$ remaining in the $\mathrm{SR}$ vesicles following the release with OPA. After adding the A23187, the extravesicular $\mathrm{Ca}^{2+}$ concentration should return to the same level it was before the addition of Mg-ATP. The 
OPA concentrations ranged from $20 \mu \mathrm{M}$ to $12 \mathrm{mM}$. For each concentration at least three experiments were done and the average value of the release rate was reported.

Experiments with ruthenium red were carried out to determine if OPA induced release occured via interaction with the $\mathrm{SR}^{2+}{ }^{2+}$ release channel . The experiments were performed as described in the above section with the only difference that ruthenium red was added prior to the addition of OPA. Experiments with ruthenium red in the range between 0.25 and $10 \mu \mathrm{M}$ were carried out in triplicate and in the range between 20 and 90 $\mu \mathrm{M}$ in duplicate.

All transport assays were done with the same SR preparation. $\mathrm{Ca}^{2+}$ uptake did not vary by more than $5 \%$ from one experiment to the next. 


\section{CHAPTER III}

\section{SPECTROPHOTOMETRIC ASSAY OF CALCIUM EFFLUX}

In this section, the ability of OPA in stimulating $\mathrm{Ca}^{2+}$ release from $\mathrm{SR}$ vesicles is examined. This assay was done with the spectrophotometer as described above. As a control, the possible effect of DMSO causing $\mathrm{Ca}^{2+}$ release by interacting with the $\mathrm{Ca}^{2+}$ release channel or the membrane was examined. Addition of different concentrations of DMSO showed that up to $2 \%$ DMSO of the final solution did not cause any $\mathrm{Ca}^{2+}$ release after 5 minutes. In all subsequent experiments, the final DMSO concentration did not exceed $2 \%$.

\subsection{OPA STIMULATED CALCIUM RELEASE}

In these experiments OPA concentrations ranging from $20 \mu \mathrm{M}$ to $12 \mathrm{mM}$ were used. It was observed that OPA stimulates $\mathrm{Ca}^{2+}$ release in a concentration dependent manner.

A maximal release rate of approximately $27 \mathrm{nmol} / \mathrm{mg} / \mathrm{sec}$ was obtained at $12 \mathrm{mM}$. A linear relationship between the release rate and the OPA concentration was seen at low OPA concentrations. For higher concentrations the slope of the graph decreases indicating that the release rate approaches saturation. The release rate at high concentrations of OPA 


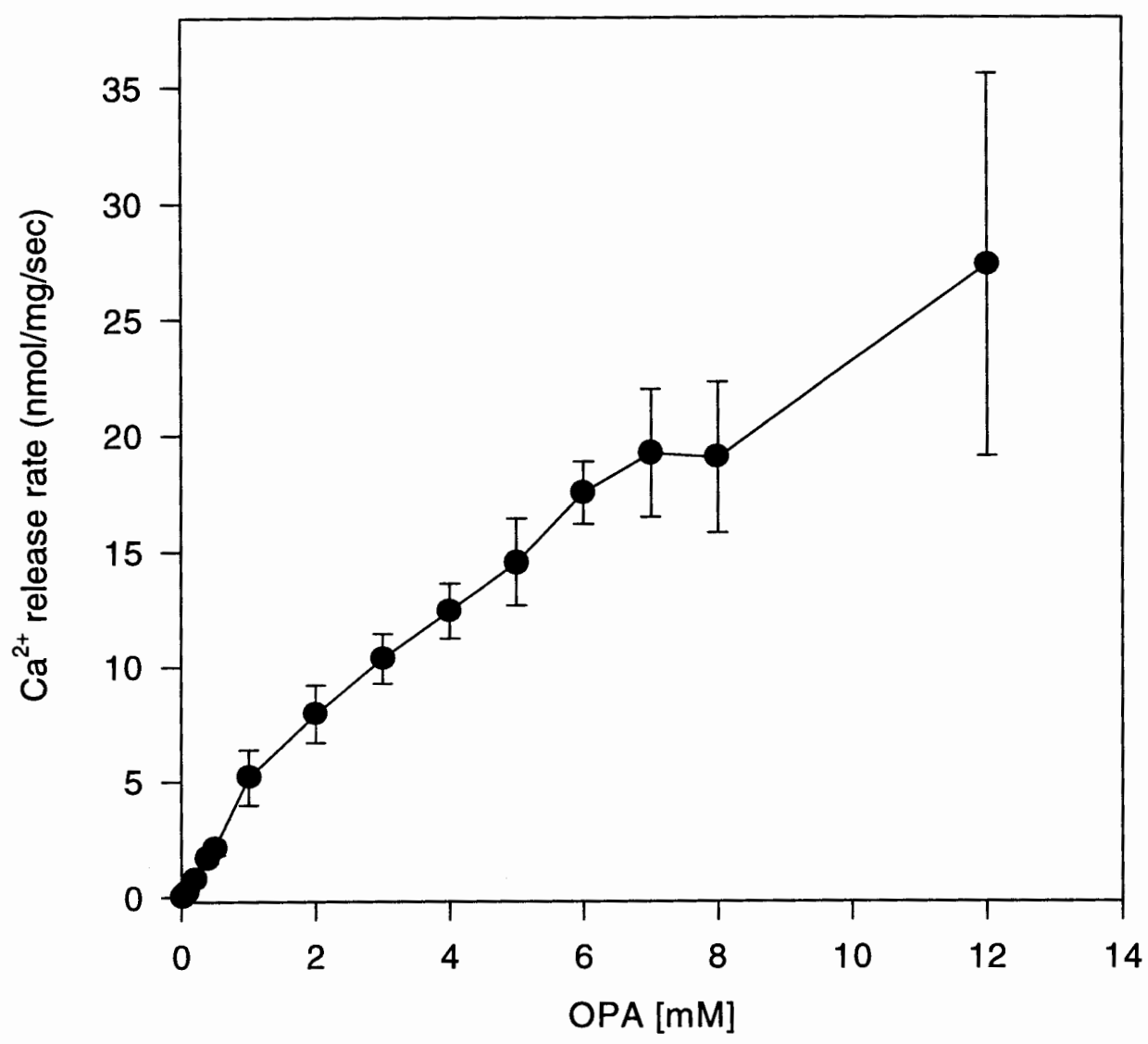

Figure 7

$\mathrm{Ca}^{2+}$ release rate from SR vesicles as a function of OPA concentration. The release rate is computed from the maximal slope of $\mathrm{Ca}^{2+}$ concentration versus time and normalized to the number of milligrams of SR. SR vesicles are suspended in $100 \mathrm{mM} \mathrm{KCL}, 1 \mathrm{mM} \mathrm{MgCl} 2,20$ $\mathrm{mM}$ HEPES, $\mathrm{pH} 7.0,200 \mu \mathrm{M}$ AP III, and $15 \mu \mathrm{M} \mathrm{CaCl}_{2}$ at a protein concentration of 0.2 $\mathrm{mg} / \mathrm{ml}$. $0.5 \mathrm{mM} \mathrm{MgATP}$ was added to stimulate the $\mathrm{Ca}^{2+}$ uptake. Extravesicular free $\mathrm{Ca}^{2+}$ concentration is recorded spectrophotometrically by measuring the differential absorbance of AP III at $720 \mathrm{~nm}$ and $790 \mathrm{~nm}$. At the end of each experiment, the ionophore A23187 was added to release intravesicular free $\mathrm{Ca}^{2+}$. Each point represents the average of at least three measurements. The error bars indicate the standard deviation. 
began to approach the limits of instrumentation. Hence, no data at OPA concentrations greater than $12 \mathrm{mM}$ were taken. It was also observed that for concentrations of OPA higher than $1 \mathrm{mM}$ all of $\mathrm{Ca}^{2+}$ was released from the vesicles. No additional $\mathrm{Ca}^{2+}$ was released from the vesicles when the $\mathrm{Ca}^{2+}$ ionophore $\mathrm{A} 23187$ was added to the cuvette.

\subsection{INHIBITION OF CALCIUM RELEASE BY RUTHENIUM RED}

In Figure 7 it was shown that OPA can stimulate $\mathrm{Ca}^{2+}$ release from SR vesicles. However, it is not clear if this release is due to a nonspecific interaction between OPA and the SR vesicles. Also OPA could interact with the $\mathrm{Ca}^{2+}-\mathrm{Mg}^{2+}-\mathrm{ATPase}$ by inhibiting its ability to pump $\mathrm{Ca}^{2+}$ into the SR vesicles. Inhibition of the $\mathrm{Ca}^{2+}$ pump could also lead to $\mathrm{Ca}^{2+}$ release, because in order to maintain the $\mathrm{Ca}^{2+}$ gradient across the $\mathrm{SR}$, an active pump is required. In the absence of a functioning pump, a slow leakage of $\mathrm{Ca}^{2+}$ across the SR would deplete internal $\mathrm{Ca}^{2+}$ stores. Alternatively, OPA might interact with the lipid bilayers and damage the integity of the lipid membrane. To determine wether OPA was interacting with the $\mathrm{Ca}^{2+}$ release channel, experiments were carried out with the channel inhibitor ruthenium red.

The ruthenium red concentration was varied from $0.25 \mu \mathrm{M}$ to $90 \mu \mathrm{M}$. Figure 8 clearly shows that ruthenium red inhibits the stimulation of $\mathrm{Ca}^{2+}$ release by $1 \mathrm{mM}$ OPA. The $K_{\mathrm{I}}$ was approx. $3.8 \mu \mathrm{M}$ (i.e., at a ruthenium red concentration of $3.8 \mu \mathrm{M}$, the release 
rate is half of the maximal release rate at $0 \mu \mathrm{M}$ ruthenium red). This result indicates that OPA interacts specifically with the $\mathrm{Ca}^{2+}$ release channel as ruthenium red is known to interact specifically with the $\mathrm{Ca}^{2+}$ release channel. However, this does not exclude an additional interaction with the $\mathrm{Ca}^{2+}-\mathrm{Mg}^{2+}-\mathrm{ATPase}$.

Since it is known that adenosine nucleotides, like $\mathrm{Mg}$-ATP, enhance $\mathrm{Ca}^{2+}$ release rates caused by other channel activators, acetylphosphate, a non-adenine nucleotide substrate, was used instead of the $\mathrm{Mg}$-ATP to load the SR vesicles with $\mathrm{Ca}^{2+}$. A release rate, which was approx. $20 \%$ smaller, was observed (data not shown), indicating that OPA stimulated $\mathrm{Ca}^{2+}$ release is enhanced when $\mathrm{Mg}$-ATP is used for the uptake. 


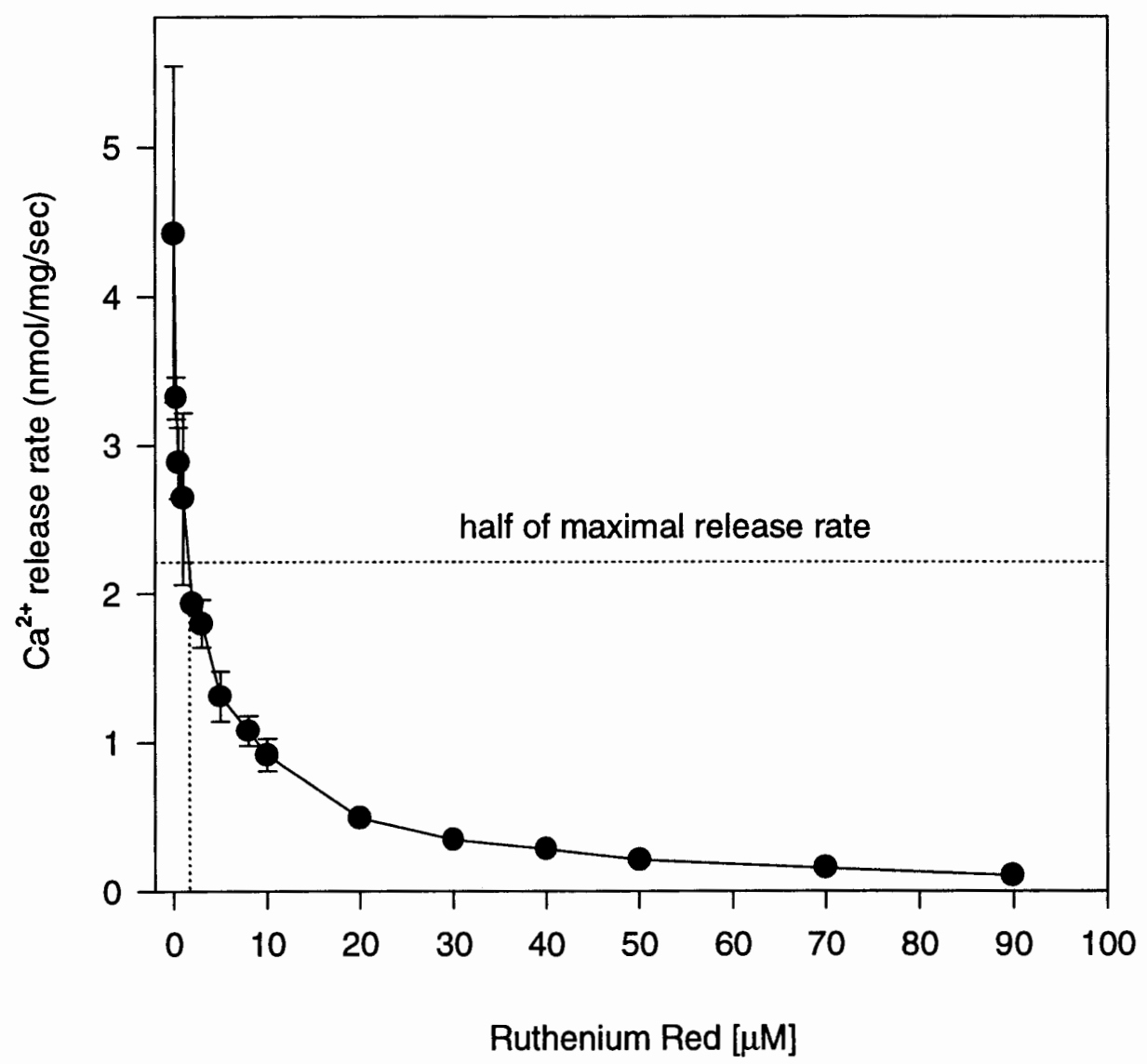

Figure 8

$\mathrm{Ca}^{2+}$ release rate as a function of ruthenium red concentration. SR vesicles are treated as described in Figure 7. The ruthenium red was added after the $\mathrm{Ca}^{2+}$ uptake was complete. Then $1 \mathrm{mM}$ OPA was added, and the $\mathrm{Ca}^{2+}$ release was recorded and the $\mathrm{Ca}^{2+}$ release rate computed as described in Figure 7. In the range between $0.25 \mu \mathrm{M}$ and $10 \mu \mathrm{M}$ ruthenium red, each point is the average of at least 3 measurements, while between $20 \mu \mathrm{M}$ and 90 $\mu \mathrm{M}$ each point is the average of 2 measurements. The error bars indicate the standard deviations. 


\section{CHAPTER IV}

\section{RYANODINE BINDING ASSAYS}

\subsection{OPA STIMULATED RYANODINE BINDING}

Ryanodine binding as a function of OPA concentrations revealed a biphasic behavior (Figure 9). Low concentrations of OPA stimulate ryanodine binding by a factor up to 2 , while higher concentrations completely inhibited the binding. The concentration dependence is relatively sharp (i.e., the stimulation and inhibition of the binding occurs over a range of about $200 \mu \mathrm{M}$ OPA). In all of these experiments and in all following ones only $1 \%$ DMSO was present in each test tube. It was shown that $1 \%$ DMSO has a negligible effect on the ryanodine binding. This biphasic behavior was observed in more than 8 different experiments with 6 different SR preparations. The only difference which was seen is that the peak was shifted a little bit and the factor of stimulation varied if a new SR preparation was used. Figure 9 shows a representative curve.

This biphasic binding behavior indicates that there are at least two different binding sites for OPA on the ryanodine receptor. Binding to the high affinity binding site stimulates ryanodine binding and binding to the low affinity binding site inhibits ryanodine binding. This is likely to correlate with opening and closing of the release channel and should be further examined in single channel reconstitution experiments. 


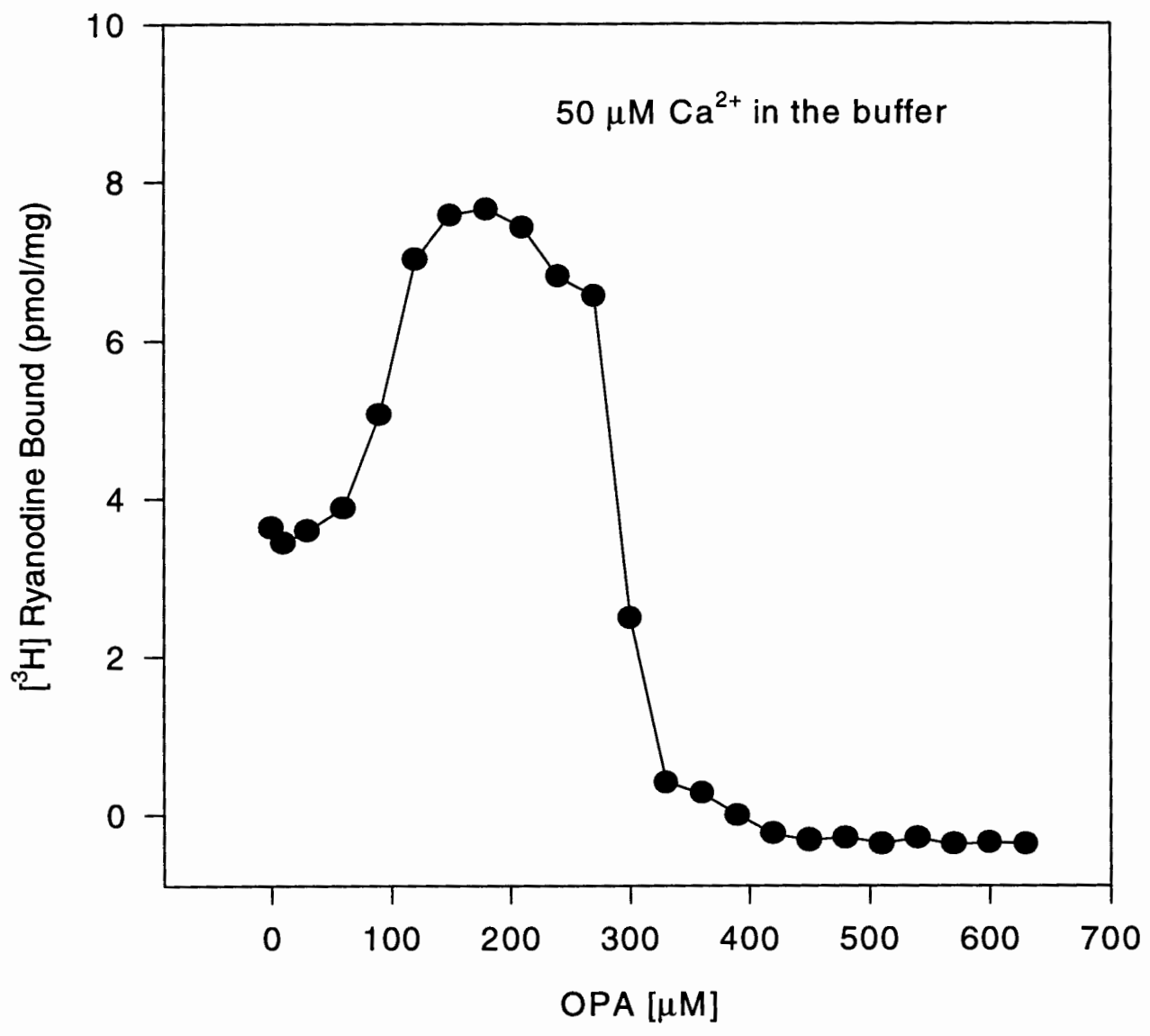

Figure 9

$\left.{ }^{3} \mathrm{H}\right]$ ryanodine binding as a function of OPA concentration. SR vesicles $(0.5 \mathrm{mg} / \mathrm{mL})$ were incubated at $37^{\circ} \mathrm{C}$ for 3 hours in a medium containing $250 \mathrm{mM} \mathrm{KCL}, 15 \mathrm{mM} \mathrm{NaCl}, 50$ $\mu \mathrm{M} \mathrm{CaCl}_{2}, 20 \mathrm{mM}$ HEPES, $\mathrm{pH} 7.1,14 \mathrm{nM}$ Ryanodine, $1 \mathrm{nM}\left[{ }^{3} \mathrm{H}\right]$ ryanodine, and the indicated OPA concentration. Assays were terminated by rapid filtration through Whatman GF/B glass fiber filters in a cell harvester and filters were then washed 3 times with a $3 \mathrm{~mL}$ solution containing $250 \mathrm{mM} \mathrm{KCL}, 15 \mathrm{mM} \mathrm{NaCl}, 20 \mathrm{mM}$ HEPES, pH 7.1, and $50 \mu \mathrm{M} \mathrm{CaCl}_{2}$. Filters sat overnight in $2.5 \mathrm{~mL}$ scintillation fluid and the bound $\left[{ }^{3} \mathrm{H}\right]$ Ryanodine was measured in a scintillation counter. Nonspecific binding was determined at $16 \mathrm{nM}$ free $\mathrm{Ca}^{2+}$ concentration. 


\subsection{ASSOCIATION EXPERIMENT}

Since the previous assay measures ryanodine binding only after 3 hours, an association experiment, where ryanodine binding was measured as a function of time, was performed and is shown in Figure 10. In Figure 10, we observe that ryanodine binding stimulated by OPA is dependent of both time and concentration. The control experiment with no OPA shows almost complete saturation after 3 hours. Low OPA concentrations show a similar time dependent behavior as does the control. On the other hand, higher OPA concentrations show a biphasic time dependent behavior. First ryanodine binding increases as a function of time, followed by decreasing to zero after a longer period of time. The debinding phase starts after approximately $30 \mathrm{~min}$ for all OPA concentrations that exhibit debinding behavior. We also observe that OPA at all concentrations enhances the initial rate at which ryanodine binds.

At 3 hours, the binding of ryanodine at higher OPA concentrations has increased and subsequently decreased, leading to the observed biphasic shape observed in Figure 9. This time dependence of ryanodine binding was observed 3 times for three different SR preparations. The only difference observed between different SR preparations was a slight change in the sensitivity to OPA. It is not yet known why the decreasing phase, which probably corresponds to the binding of OPA to a low affinity binding site on the receptor, is so slow in inactivating the receptor $(\approx 30 \mathrm{~min})$. 


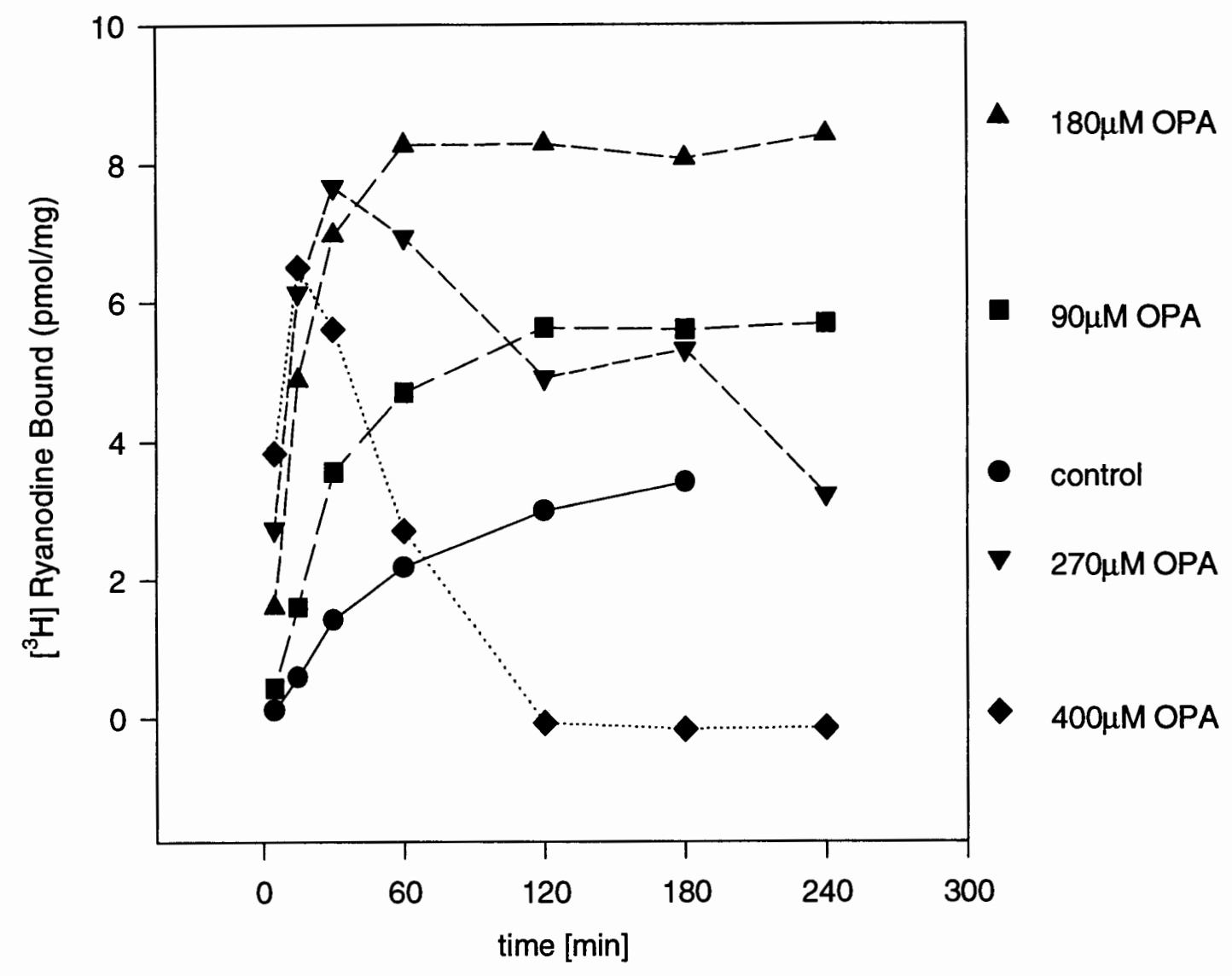

Figure 10

$\left[{ }^{3} \mathrm{H}\right]$ ryanodine binding as a function of time. This assay was performed as described in Figure 9 with the only difference that the SR was incubated for the indicated amount of time in the $37^{\circ} \mathrm{C}$ waterbath. Nonspecific binding was determined at $16 \mathrm{nM}$ free $\mathrm{Ca}^{2+}$ and was time-independent. 


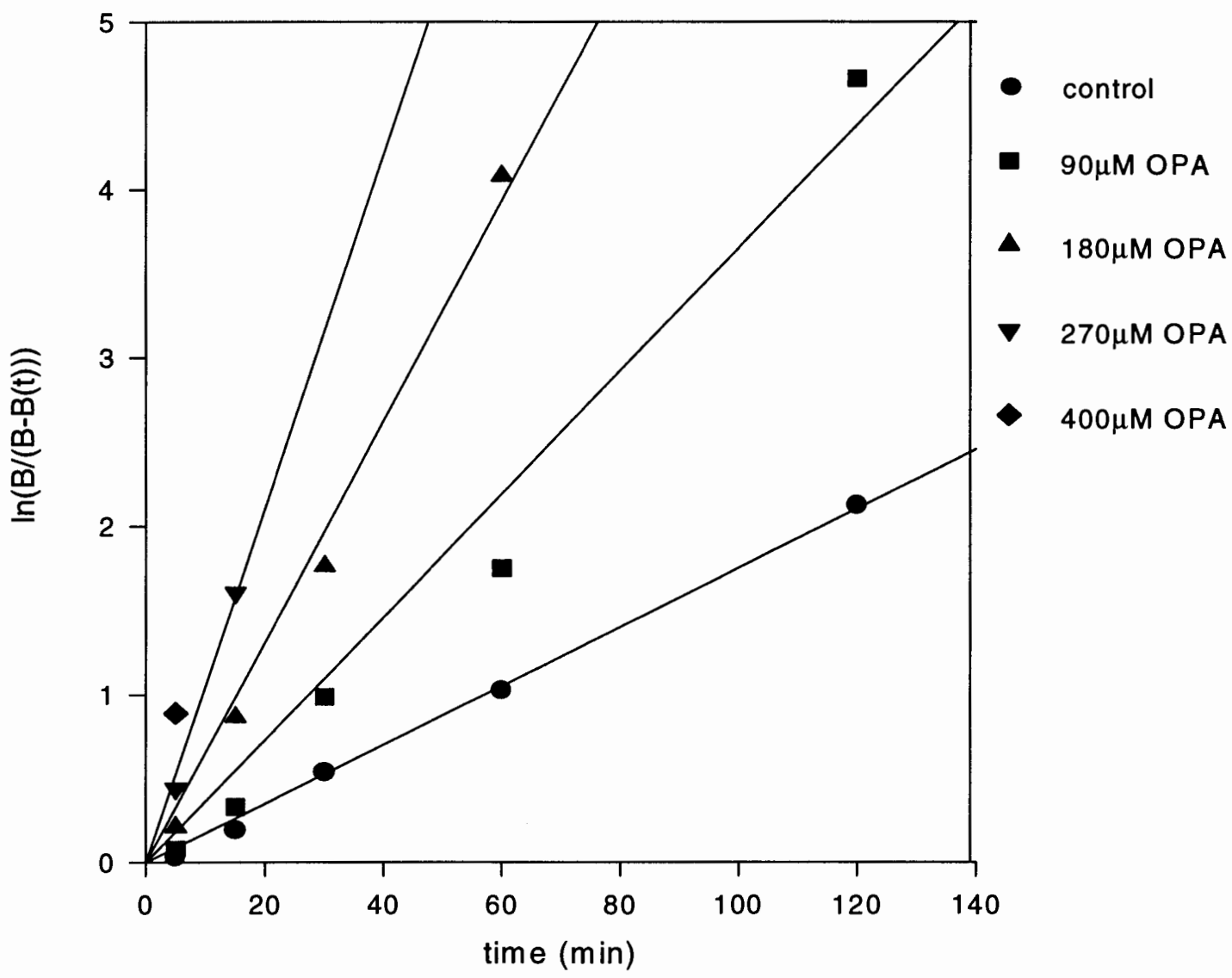

Figure 11

The logarithm of the ratio: $B_{\max } /\left(B_{\max }-B(t)\right)$ as a function of time. $B_{\max }$ is the maximal ryanodine binding from Figure 10 for each OPA concentration, respectively. $B(t)$ is the bound ryanodine at the indicate time in Figure 10. This graph is derived from data shown in Figure 10. The slope of the line shown represents the observed binding constant $\mathrm{k}$. 
From the observed binding rate, the association rate constant $\mathrm{k}_{+1}$ can be extracted as described in chapter 2.4.1, if the dissociation rate $\mathrm{k}_{1}$ is known. Therefore the dissociation rate $\mathrm{k}_{-1}$ has to be determined in an independent experiment. The observed binding rate (see Table 1) at each OPA concentration is the slope of the lines shown in Figure 11 (equation 14).

Table 1

\begin{tabular}{|c|c|}
\hline OPA $[\mu \mathrm{M}]$ & $\mathrm{k}^{\prime}\left[\frac{1}{\min }\right]$ \\
\hline 0 & 0.018 \\
\hline 90 & 0.037 \\
\hline 180 & 0.066 \\
\hline 270 & 0.11 \\
\hline 400 & 0.18 \\
\hline
\end{tabular}

\subsection{DISSOCIATION EXPERIMENTS}

This assay shows the time dependence of ryanodine dissociation in the presence of different OPA concentrations (Figure 12). If the logarithm of the ratio of bound ryanodine at time $t$ and the bound ryanodine at time $t=0$ is plotted against the time (Figure 13), the dissociation rate $k_{-1}$ can be extracted from the slope (equation 17). For all OPA 


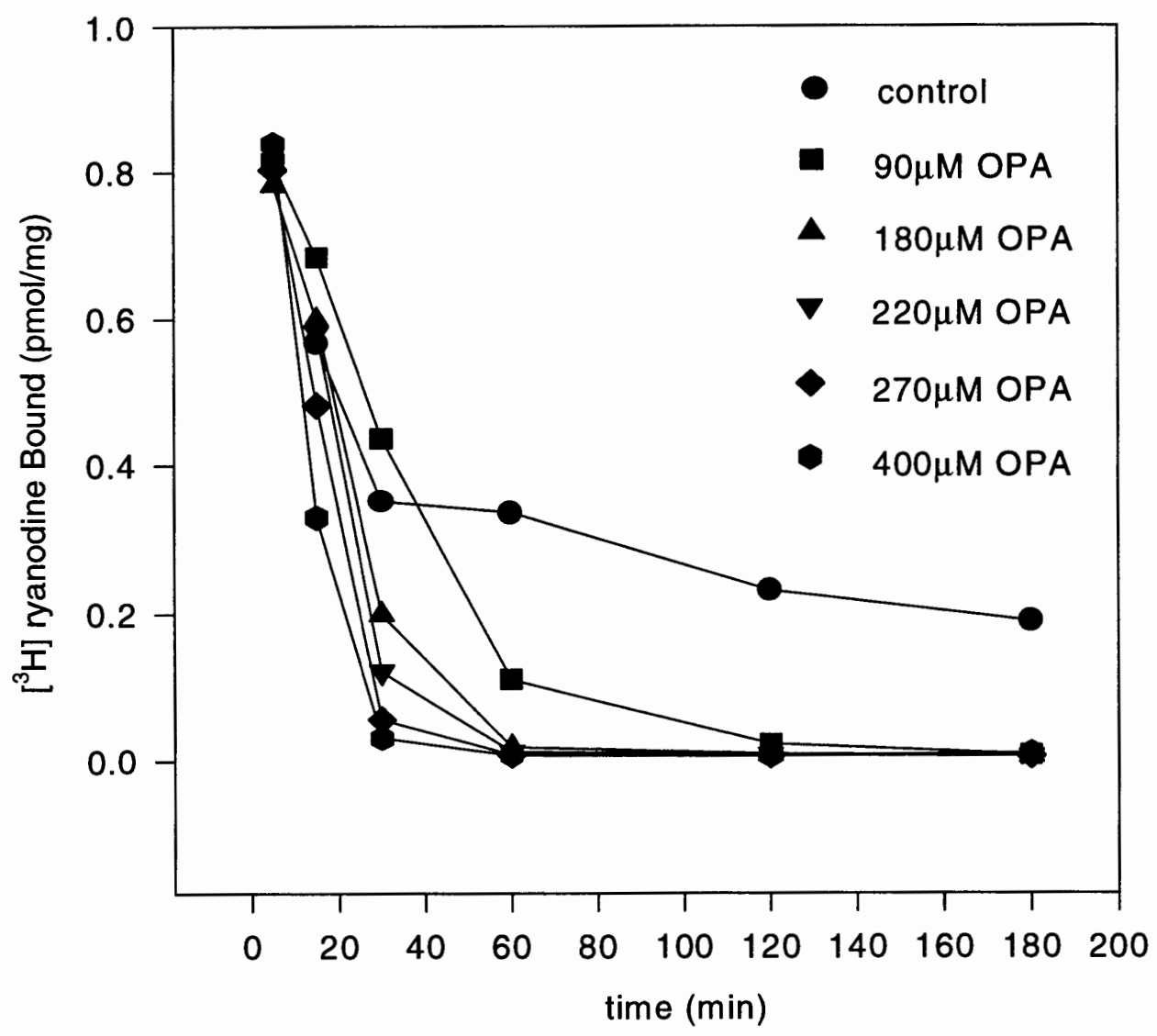

Figure 12

$\left[{ }^{3} \mathrm{H}\right]$ ryanodine dissociation as a function of time. SR vesicles $(5 \mathrm{mg} / \mathrm{mL})$ were incubated in

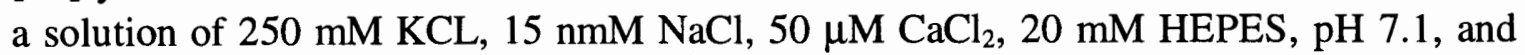
$10 \mathrm{nM}\left[{ }^{3} \mathrm{H}\right]$ ryanodine for 3 hours in $37^{\circ} \mathrm{C}$. Samples were then diluted 100 times into an identical buffer in the presence of the indcated OPA concentration with no $\left[{ }^{3} \mathrm{H}\right]$ ryanodine present. Following the indicated time in the dilution buffer, the sample was filtered, washed, and counted as described in Figure 9. Nonspecific binding was determined at 16 $\mathrm{nM}$ free $\mathrm{Ca}^{2+}$ in the concentrated solution after 3 hours in $37^{\circ} \mathrm{C}$. 


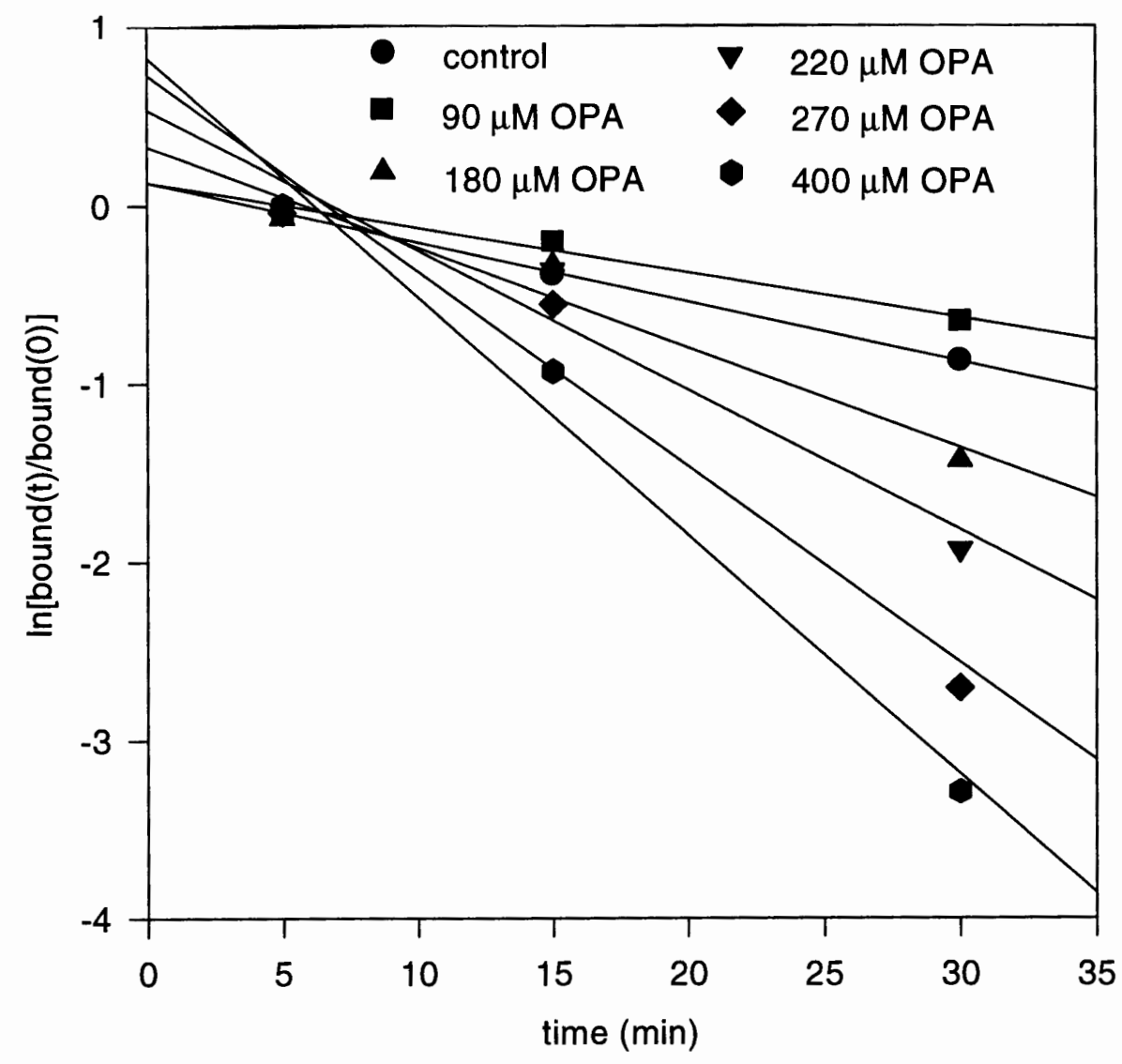

Figure 13

Logarithm of $B(t) / B(0)$ as a function of time. This graph is derived from the same data shown in Figure 12, only transformed so that the dissociation constant $\mathrm{k}_{-1}$ can be determined from the slope of the linear regression lines. 
concentrations data points at a time longer than 30 minutes weren't considered. At a concentration of $90 \mu \mathrm{M}$ OPA, the dissociation rate is slightly slower than the control ( 0 $\mu \mathrm{M}$ OPA), while for higher OPA concentrations the dissociation rate increases with increasing OPA concentrations (Table 2).

Table 2

\begin{tabular}{|c|c|}
\hline OPA $[\mu \mathrm{M}]$ & Dissociation rate $\mathrm{k}_{-1}\left[\frac{1}{\min }\right]$ \\
\hline 0 & 0.033 \\
\hline 90 & 0.025 \\
\hline 180 & 0.056 \\
\hline 220 & 0.078 \\
\hline 270 & 0.11 \\
\hline 400 & 0.13 \\
\hline
\end{tabular}

Having calculated the dissociation rate constant $\mathrm{k}_{-1}$ the association rate constant $\mathrm{k}_{+1}$ can now be calculated (equation 15). In addition, the equilibrium dissociation constant $\mathrm{K}_{d}$ can also be calculated (equation 11). 
Table 3

\begin{tabular}{|c|c|c|}
\hline OPA $[\mu \mathrm{M}]$ & $\mathrm{k}_{+1}\left[\frac{1}{\min \times \mu M}\right]$ & $\mathrm{K}_{\mathrm{d}}[\mathrm{nM}]$ \\
\hline 0 & 0.003 & 11 \\
\hline 90 & 0.004 & 6.3 \\
\hline 180 & 0.008 & 7.0 \\
\hline 270 & 0.014 & 7.9 \\
\hline 400 & 0.021 & 6.4 \\
\hline
\end{tabular}

Table 3 demonstrates that the association rate constant $k_{+1}$ for ryanodine binding increases with increasing OPA concentrations. But the dissociation constant $K_{d}$, is only slightly dependent on the OPA concentration. The affinity of the receptor for ryanodine increases slightly as the OPA concentration increases.

\subsection{SCATCHARD-ANALYSIS}

Scatchard analysis provides for an independent determination of the $K_{d}$. In addition, the maximal number of high affinity ryanodine binding sites, $\mathrm{B}_{\max }$, can be determined. SR vesicles were incubated in ryanodine concentrations from $0.5 \mathrm{nM}$ to $128 \mathrm{nM}$ for 3 hours at $37^{\circ} \mathrm{C}$. The nonspecific binding was determined by incubating SR in a 255 fold excess of 


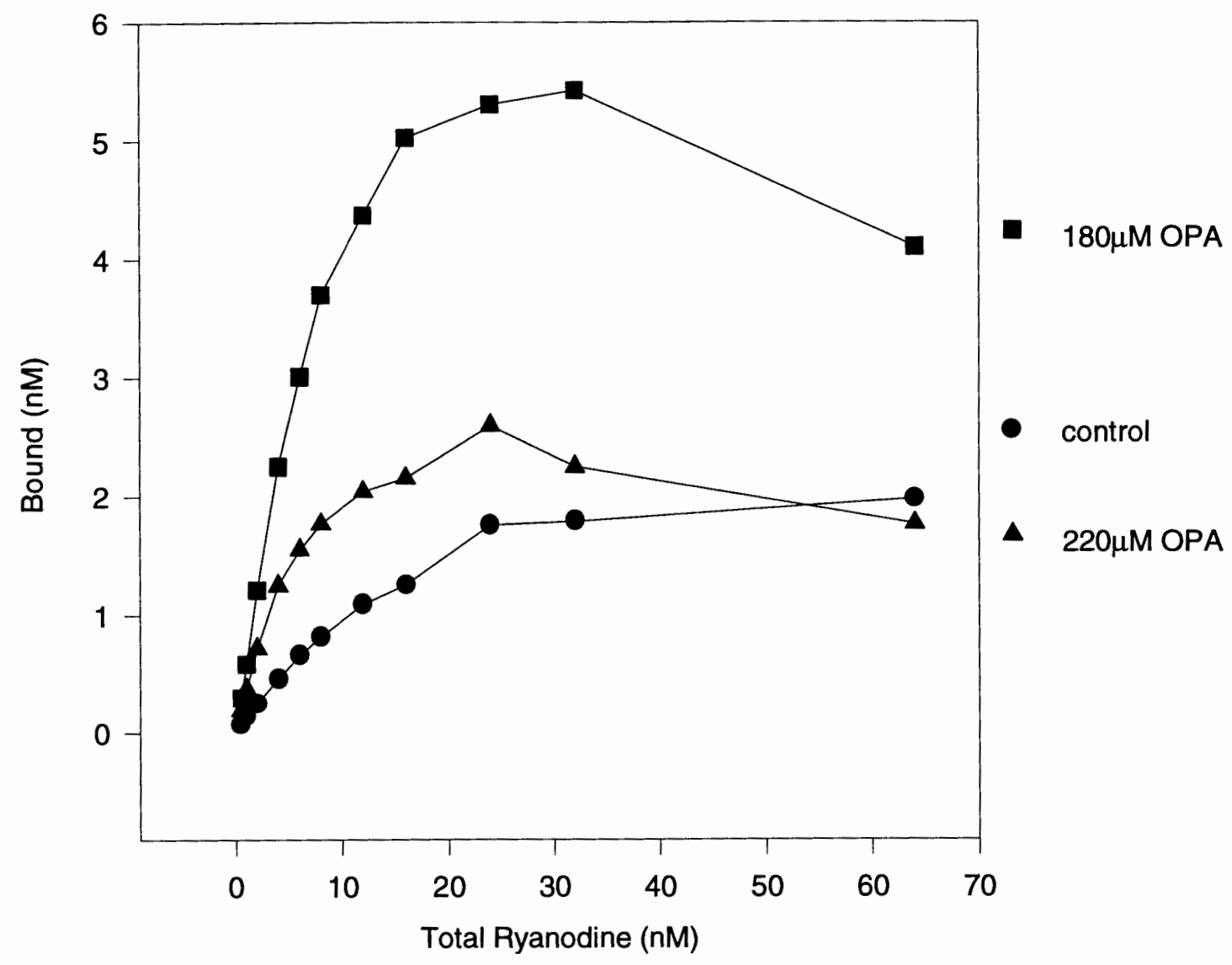

Figure 14

Saturation binding. The SR vesicles were treated as described in Figure 9 except that different concentrations of ryanodine were present. The $\left[{ }^{3} \mathrm{H}\right]$ ryanodine concentration was held constant at $0.5 \mathrm{nM}$, while the ryanodine concentration was varied from $0 \mathrm{nM}$ to 127.5 nM. Nonspecific binding was determined with a 255 -fold excess of the unlabeled ryanodine for each OPA concentration. 
unlabelled ryanodine. In Figure 14, the bound ryanodine is plotted against the added concentration of ryanodine in the assay. For the control, $180 \mu \mathrm{M}$, and $220 \mu \mathrm{M}$ the binding saturates with increasing ryanodine concentrations. One can clearly see that the initial slope is much higher in the presence of OPA and that the maximal binding for $180 \mu \mathrm{M}$ is increased by a factor of almost 3 , while for the control and $220 \mu \mathrm{M}$ the maximal binding is nearly the same.

These binding characteristics can be quantified in a more precise manner with a Scatchard plot analysis of the binding data (Figure 15) as described in chapter 1.7.3. This analysis shows that the $\mathrm{K}_{\mathrm{d}}$ for $180 \mu \mathrm{M}$ and $220 \mu \mathrm{M}$ OPA is decreased by a factor of approx. 4 , in comparison with the $K_{d}$ measured in the absence of OPA. The number of maximal binding sites $\mathrm{B}_{\max }$ for $180 \mu \mathrm{M}$ OPA is approximately 2.5 times higher than for the control and for $220 \mu \mathrm{M}$ OPA. In addition, it appears that OPA does not induce cooperativity in the ryanodine binding characteristics.

This characteristic change in the $\mathrm{K}_{\mathrm{d}}$ and in the maximal number of binding sites $\mathrm{B}_{\max }$ can help explain the biphasic shape of Figure 15. OPA increases the affinity for ryanodine binding which results in an increase of ryanodine binding for concentrations up to $180 \mu \mathrm{M}$ OPA. Also, the number of maximal binding sites is increased. At $220 \mu \mathrm{M}$, which is in the falling phase of Figure 9, the affinity for ryanodine binding is the same as for $180 \mu \mathrm{M}$, but the number of maximal binding decreases to that of the control. Since it is known that for each ryanodine receptor complex, which consists of four identical subunits, there is only one high affinity ryanodine binding site, the increase of $B_{\max }$ in the presence of $180 \mu \mathrm{M}$ 


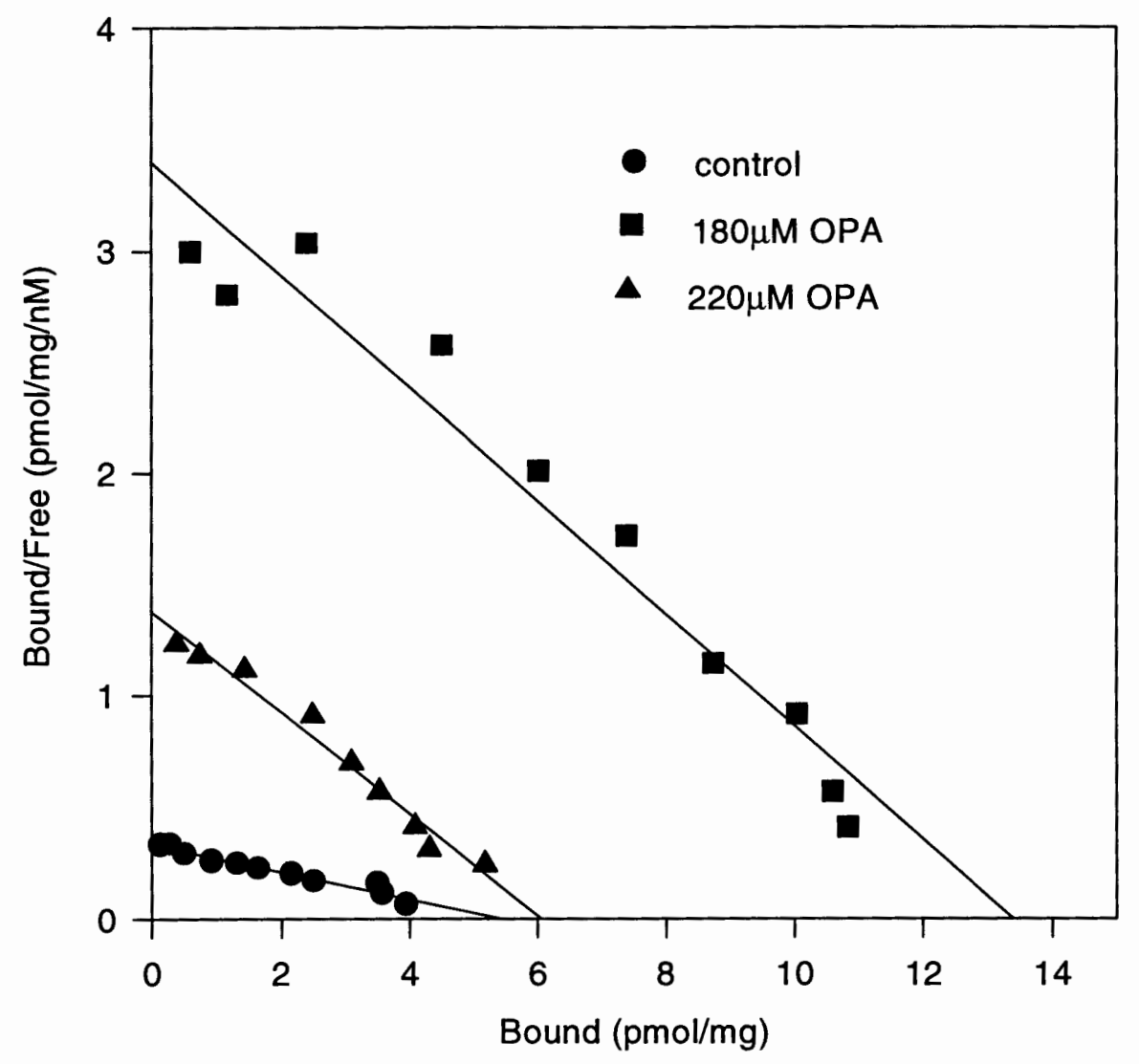

Figure 15

Scatchard analysis of the binding data from Figure 14. A linear regression was applied to the data points. The slope is the negative dissociation constant $-K_{d}$ and the $x$-intersection is the maximum number of high affinity binding sites $B_{\max }$. 
OPA must be caused by an opening of more ryanodine receptor/Ca ${ }^{2+}$ channels than are available in the open state in the presence of $50 \mu \mathrm{M} \mathrm{Ca}^{2+}$.

Table 4

\begin{tabular}{|c|c|c|}
\hline OPA $[\mu \mathrm{M}]$ & $\mathrm{K}_{\mathrm{d}}[\mathrm{nM}]$ & $\mathrm{B}_{\max }[\mathrm{pmol} / \mathrm{mg}]$ \\
\hline 0 & 16 & 5.4 \\
\hline 180 & 4.0 & 13 \\
\hline 220 & 4.4 & 6.1 \\
\hline
\end{tabular}

The values of the $K_{d}$ obtained from the Scatchard analysis (Table 4) are different than those obtained from the kinetic analysis (Table 3). One possible reason is that different SR preparations were used in the two experiments. This may explain the difference for the $\mathrm{K}_{\mathrm{d}}$ between the control and also for $180 \mu \mathrm{M}$ OPA in the two experiments. However, the effect is still the same, that the $K_{d}$ is lowered by the OPA independently of the concentration. Yet, the two different $K_{d}$ 's for ryanodine binding in the presence of 220 $\mu \mathrm{M}$ can't be compared, because in the kinetic approach, only binding of OPA to the high affinity binding site is considered. However, in the Scatchard analysis OPA binding to both the high and low affinity binding site is involved. Nevertheless, the Scatchard analysis shows that the $\mathrm{K}_{d}$ doesn't change if OPA binds additionally to the low affinity binding site. 


\subsection{CALCIUM-DEPENDENT RYANODINE BINDING}

\subsubsection{OPA Dependence}

This assay examines the effect of OPA on the calcium dependent ryanodine binding. Nonspecific binding was determined at $10 \mathrm{nM} \mathrm{Ca}^{2+}$ in the absence of OPA. Experiments with a 255 fold excess of unlabelled ryanodine in the presence of different OPA concentrations showed that the nonspecific binding is almost independent of the OPA concentration. Therefore, the same nonspecific binding was subtracted off at all OPA concentrations. Figure 16 shows the $\mathrm{Ca}^{2+}$ dependence of ryanodine binding at several different OPA concentrations. OPA does not affect the $\mathrm{Ca}^{2+}$ concentration required to stimulate or inhibit ryanodine binding. Stimulation of binding begins at approx. $0.1 \mu \mathrm{M}$ $\mathrm{Ca}^{2+}$, while inhibition of binding occurs at greater than $50-100 \mu \mathrm{M} \mathrm{Ca}^{2+}$. It appears that OPA influences ryanodine binding independent of $\mathrm{Ca}^{2+}$, which results in a biphasic binding behavior for each free $\mathrm{Ca}^{2+}$ concentration. Stimulation of ryanodine binding by OPA is $\mathrm{Ca}^{2+}$ independent. 


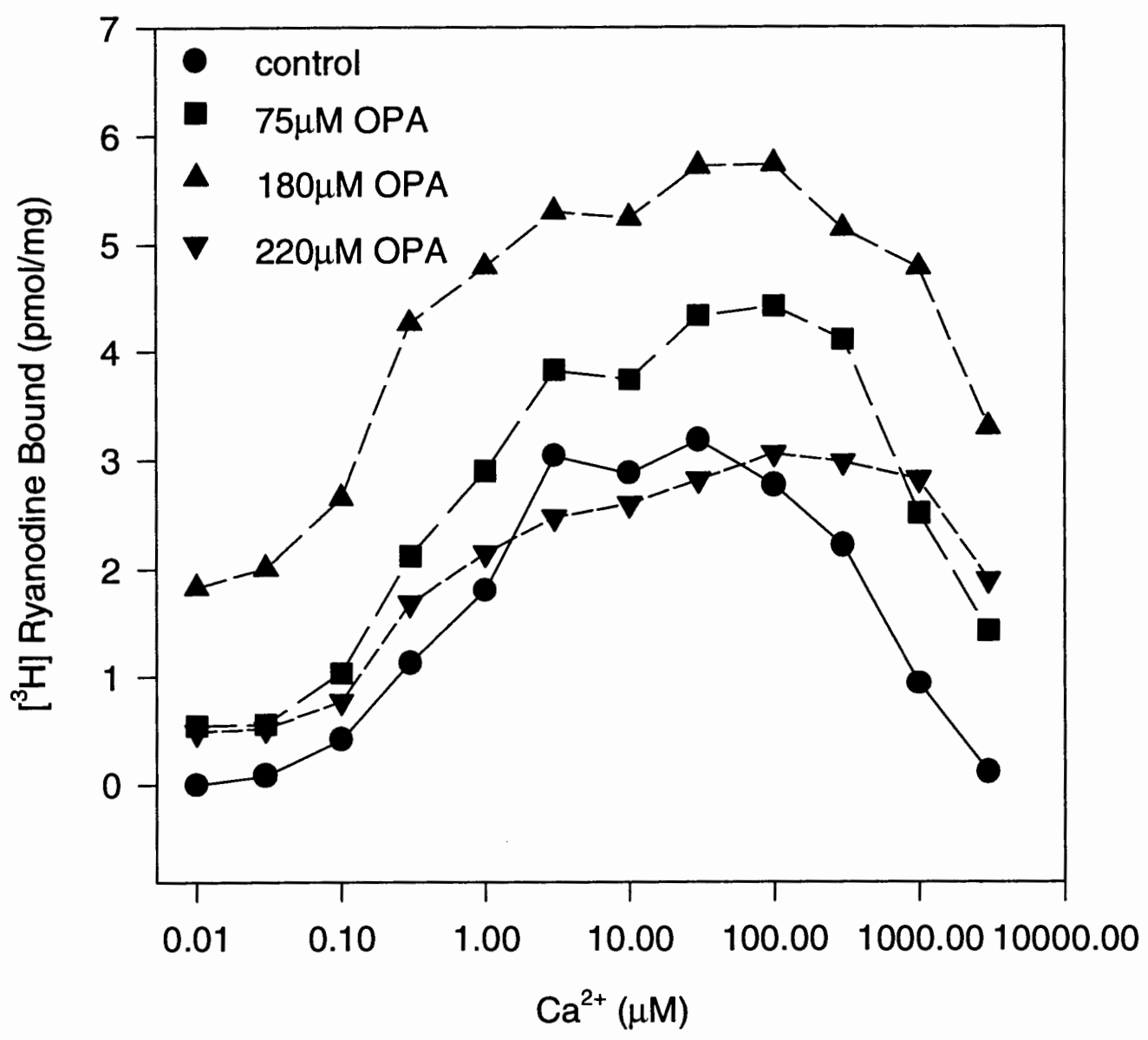

Figure 16

$\left[{ }^{3} \mathrm{H}\right]$ ryanodine binding as a function of free $\mathrm{Ca}^{2+}$ concentration in the presence of different OPA comcentrations. The SR vesicles are treated as described in Figure 9 with the exception that the free $\mathrm{Ca}^{2+}$ concentration was varied from $10 \mathrm{nM}$ to $3 \mathrm{mM}$. Nonspecific binding was determined at $10 \mathrm{nM} \mathrm{Ca}^{2+}$ without OPA. 


\subsubsection{Time Dependence}

The previous experiments suggested that the effect of OPA on ryanodine binding is both time and concentration dependent. Therefore, $\mathrm{Ca}^{2+}$-dependent ryanodine binding was measured in the presence of $220 \mu \mathrm{M}$ OPA as a function of time. In the control experiment shown, SR was incubated for 3 hours in the presence of $220 \mu \mathrm{M}$ OPA. The assay was carried out as described in Figure 9, however, the reaction was terminated at various between 10 and 100 minutes. As in Figure 16, Figure 17 shows that OPA modification of ryanodine binding is $\mathrm{Ca}^{2+}$ independent.

\subsection{DTT DEPENDENT RYANODINE BINDING}

Dithiotreitol (DTT) is a reducing agent which is cable of reducing disulfide linkages. As shown in Figure 18, DTT alone lowers ryanodine binding in the presence of $50 \mu \mathrm{M}$ $\mathrm{Ca}^{2+}$. DTT apparently reduces disulfide linkages formed by activation with $\mathrm{Ca}^{2+}$ and at least partially closes the $\mathrm{Ca}^{2+}$ release channel. As a result, ryanodine binding decreases as a function of increasing DTT concentrations. At higher concentrations $(>10 \mathrm{mM})$, DTT again stimulates ryanodine binding. Experiments with $\mathrm{H}_{2} \mathrm{O}_{2}$, which stimulates ryanodine binding by oxidizing two sulfhydryl groups to disulfides ${ }^{30 a}$, show that DTT is potent in inhibiting ryanodine binding of SR vesicles pretreated with $1 \mathrm{mM} \mathrm{H}_{2} \mathrm{O}_{2}$. In Figure $16, \mathrm{SR}$ 


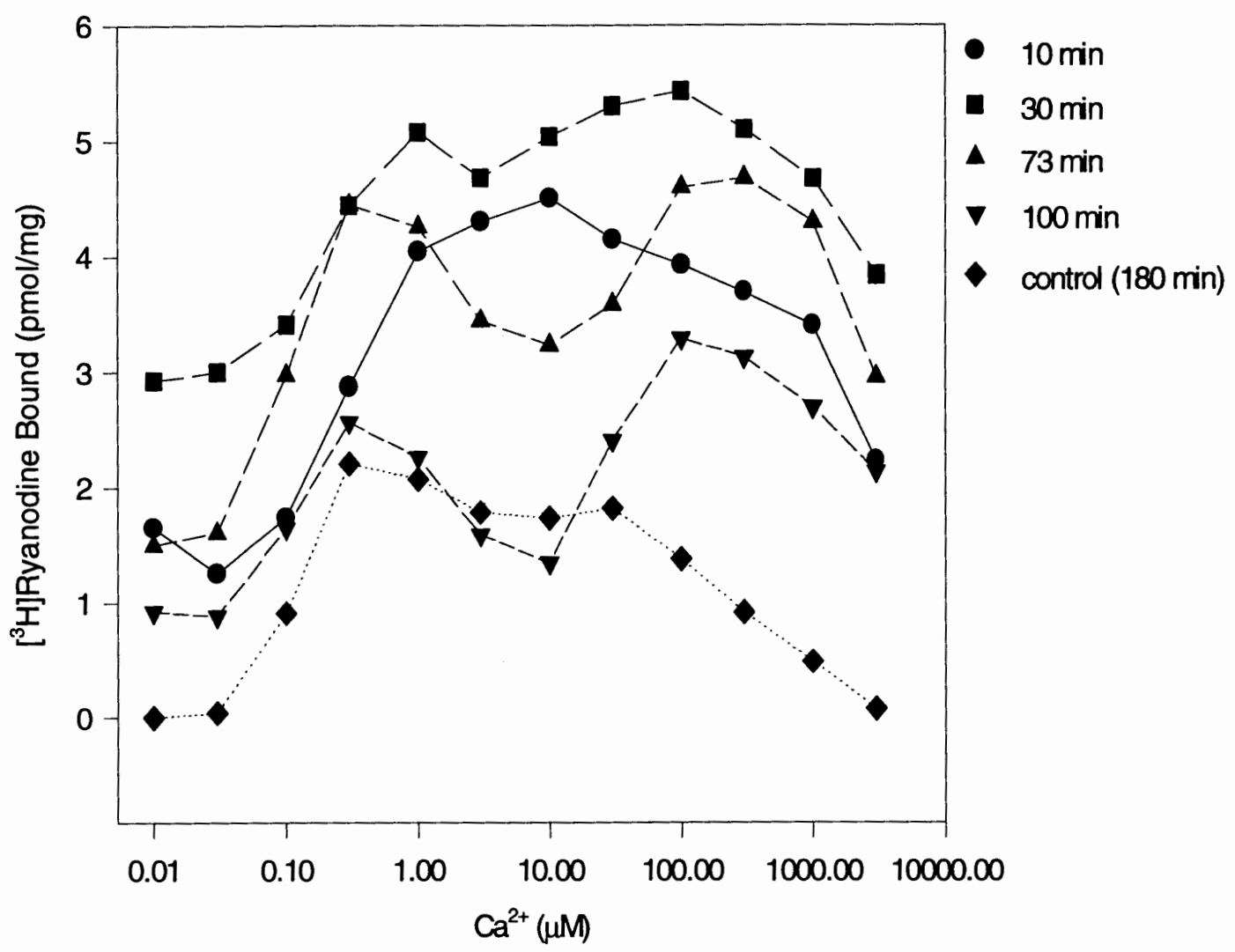

Figure 17

$\left[{ }^{3} \mathrm{H}\right]$ ryanodine binding as a function of free $\mathrm{Ca}^{2+}$ concentrations in the presence of $220 \mu \mathrm{M}$ OPA. The SR was treated as in Figure 16 except that binding was terminated at the time indicated. Nonspecific binding was determined at $10 \mathrm{nM} \mathrm{Ca}^{2+}$ without OPA. The control binding was stopped after 3 hours. 


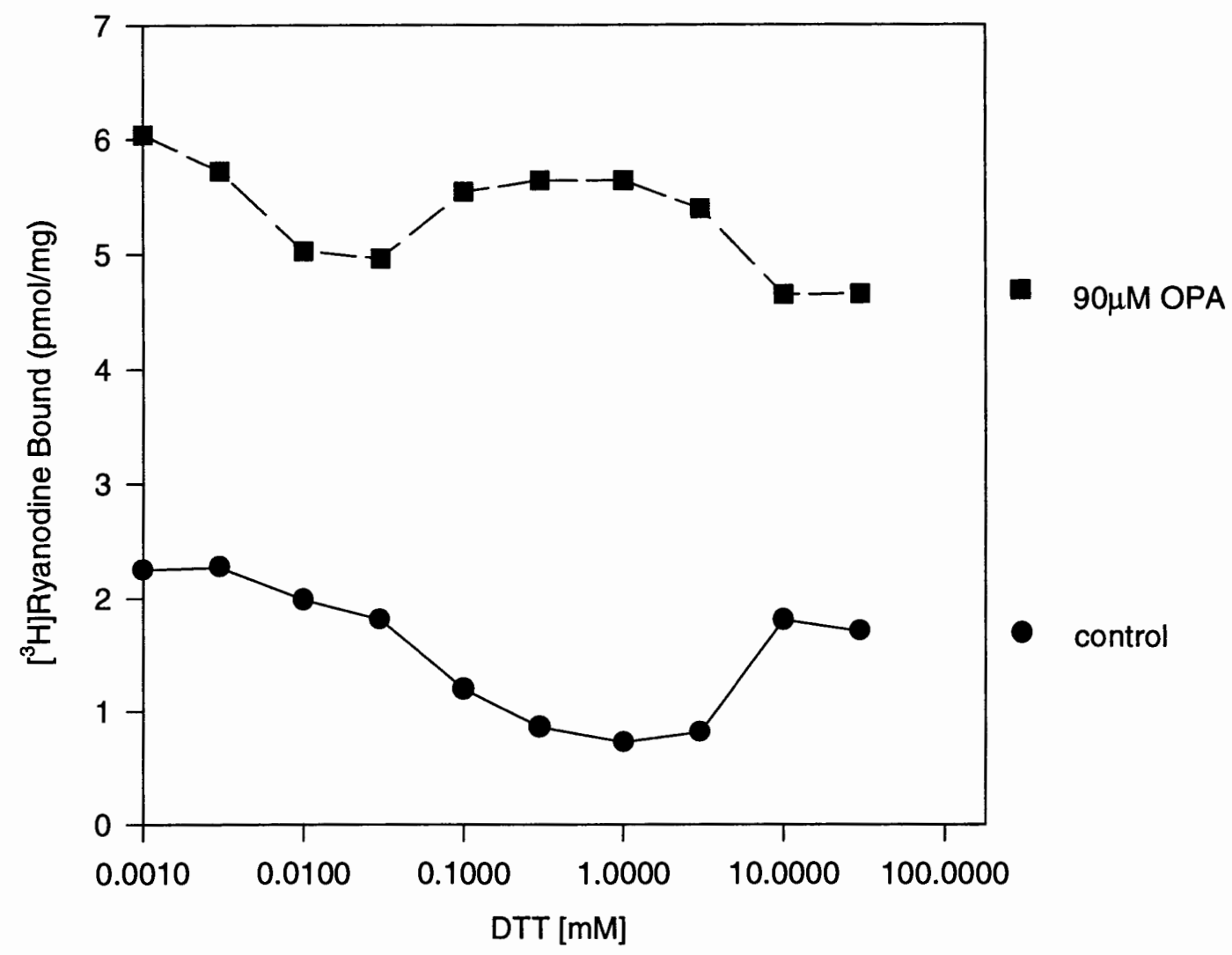

Figure 18

$\left.{ }^{3} \mathrm{H}\right]$ ryanodine binding as a function of DTT. The SR was incubated for 15 minutes with $90 \mu \mathrm{M}$ OPA before it was added to the DTT. Nonspecific binding was determined at 16 $\mathrm{nM}$ free $\mathrm{Ca}^{2+}$. 
vesicles were pretreated with $90 \mu \mathrm{M}$ OPA for 15 minutes, then DTT dependent ryanodine binding was examined.

OPA stimulated ryanodine binding is not exhibited by addition of DTT. Small variations in ryanodine binding are observed, but significant inhibition by DTT is not apparent. This suggests that OPA stimulates receptor binding by a direct interaction. There is no indirect mechanism, such as binding of OPA to one site on the receptor, resulting in activation of the channel by causing a disulfide linkage to occur. If this had been the case, DTT would reduce the disulfide and inhibit the activation induced by OPA.

\subsection{LYSINE-DEPENDENT RYANODINE BINDING}

OPA reacts with a thiol and a nearby lysine. In order to examine if both binding sites are important for channel activation, OPA was pretreated with lysine. The motivation behind this experiment is that if OPA is pretreated with an excess of lysine it should than freely react with protein thiols, and should no longer favor protein thiols that are nearby a lysine residue. In Figure 19, $90 \mu \mathrm{M}$ OPA was incubated for 10 minutes with different concentrations of lysine. This binding assay was done at $50 \mu \mathrm{M} \mathrm{Ca}^{2+}$ for 3 hours at $37^{\circ} \mathrm{C}$.

As the ratio of lysine/OPA is increased, ryanodine binding decreased to a point slightly higher than the control binding, (i.e., the same conditions but without OPA and lysine). There are several possible interpretations for this result. One possible explanation is that the OPA-lysine complex is still able to react with free thiols, but most of these 
thiols are not critical to channel function. Alternatively the OPA-lysine complex may no longer be able to react with free critical thiols. In the absence of added lysine, OPA binds to a pair of amino acids (cysteine-lysine) that are nearby each other, and critical for channel function.

\subsection{COMPETITION BETWEEN OPA AND CPM}

In this binding assay the ability of OPA to stimulate ryanodine binding to a CPM pretreated RyR was examined. The purpose of this experiment is to see if OPA and CPM have a common binding site on the RyR.

In order to pretreat the SR vesicles with $\mathrm{CPM}$, the free $\mathrm{Ca}^{2+}$ concentration was first lowered to $16 \mathrm{nM}$ to close the $\mathrm{Ca}^{2+}$ release mechanism and to expose "hyperreactive thiols". ${ }^{52} \mathrm{CPM}(0.5 \mu \mathrm{M})$ was then added to the SR for 5 minutes at $37^{\circ} \mathrm{C}$. It has previously been shown that this concentration of CPM is optimal for alkylating key hyperreactive thiols associated with channel gating. The free $\mathrm{Ca}^{2+}$ concentration was then returned to $50 \mu \mathrm{M}$ and OPA dependent $\left[{ }^{3} \mathrm{H}\right]$ ryanodine binding was measured (Figure 20). In the control experiment identical procedures were followed, but the SR was not treated with CPM. Also, at $90 \mu \mathrm{M}$ and $180 \mu \mathrm{M}$ OPA, the experiment with and without CPM was carried out at a free $\mathrm{Ca}^{2+}$ concentration of $16 \mathrm{nM}$. 


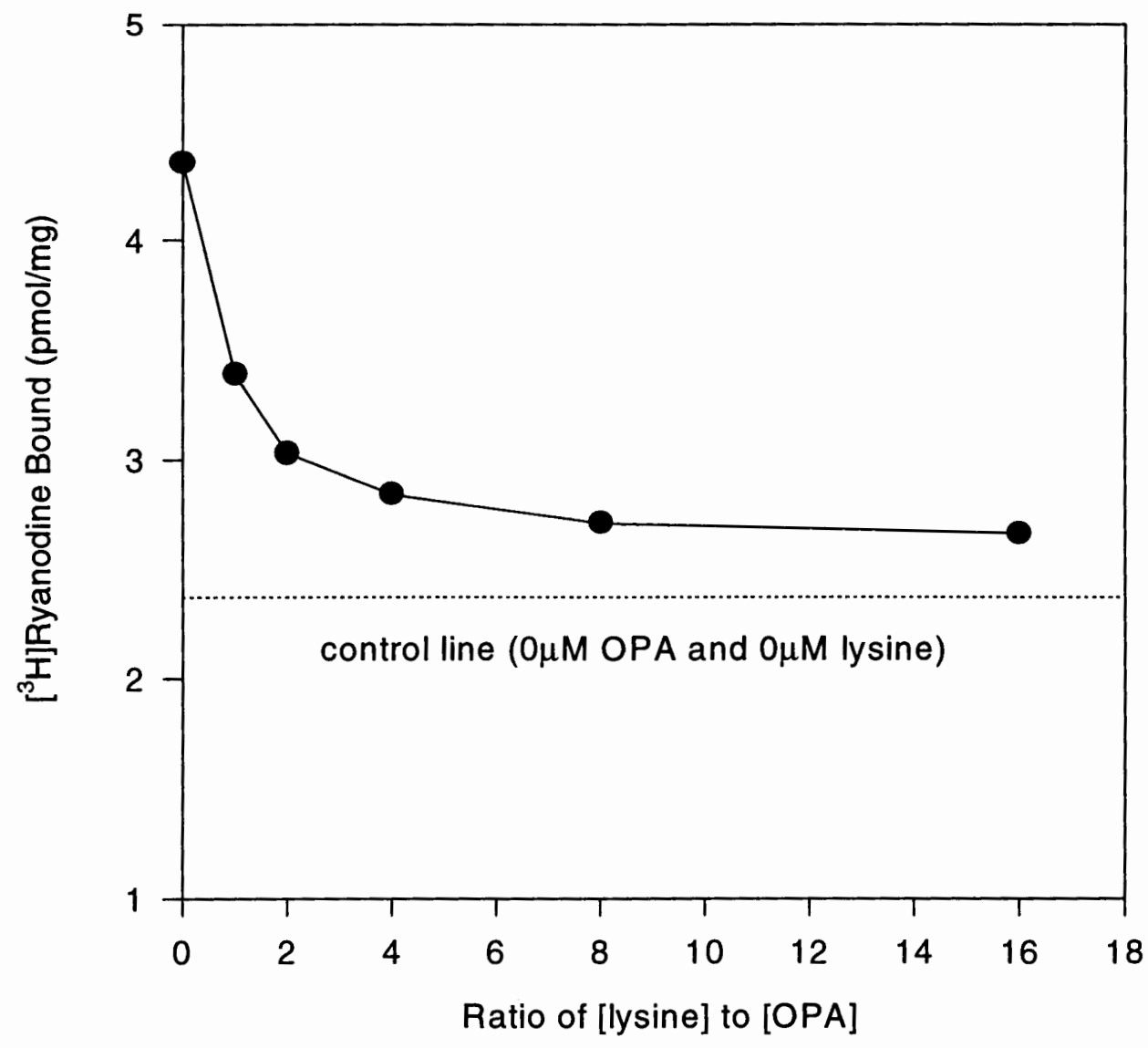

Figure 19

$\left[{ }^{3} \mathrm{H}\right]$ ryanodine binding in the presence of $90 \mu \mathrm{M}$ OPA and an excess of lysine. A mixture of $90 \mu \mathrm{M}$ OPA and a multiple of this concentration of lysine was incubated for 10 minutes before it was added to the SR. In a control experiment it was shown that the added concentration of lysine has a negligible effect on the ryanodine binding. 


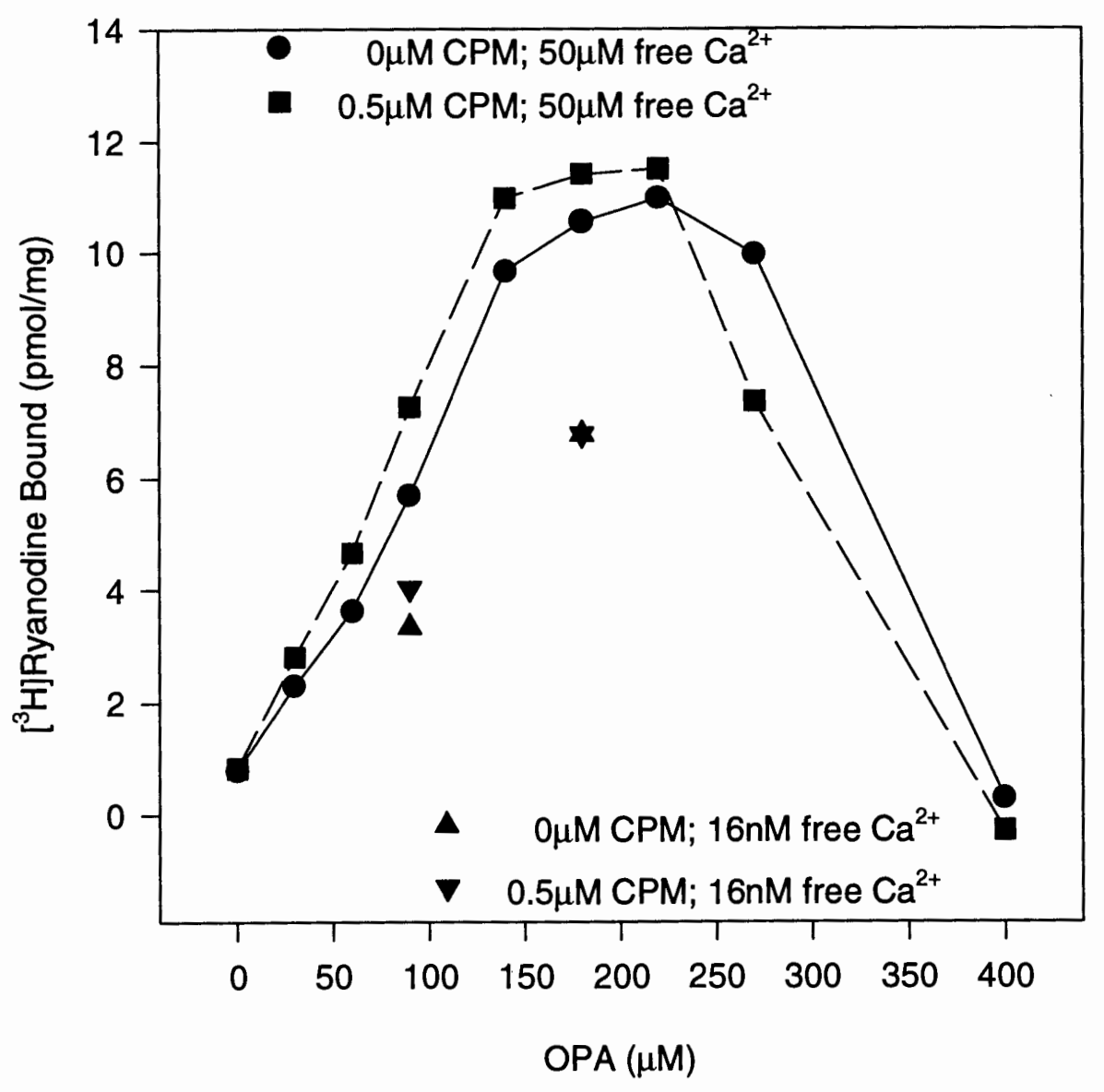

Figure 20

$\left[{ }^{3} \mathrm{H}\right]$ ryanodine binding as a function of OPA. Before the SR was pretreated with the 0.5 $\mu \mathrm{M} C P M$ for 5 minutes at $37^{\circ} \mathrm{C}$ the free $\mathrm{Ca}^{2+}$ concentration was lowered to $16 \mathrm{nM}$. The free $\mathrm{Ca}^{2+}$ concentration was then brought back to $50 \mu \mathrm{M}$. The control experiment without CPM was done exactly in the same manner but in the absence of CPM. At $90 \mu \mathrm{M}$ and 180 $\mu \mathrm{M}$ OPA these two experiments were also carried out at a free $\mathrm{Ca}^{2+}$ concentration of 16 nM. 
The "hyperreactive" thiols labelled by CPM are apparently different from those labelled by OPA. This is very consistent if one remembers that CPM inhibits $\mathrm{Ca}^{2+}$-induced $\mathrm{Ca}^{2+}$ release ${ }^{52}$ and OPA stimulates $\mathrm{Ca}^{2+}$ release. 


\section{CHAPTER V}

\section{SPECTROPHOTOMETRIC ASSAY OF THE REACTIVITY OF OPA}

The reagent 5,5'-dithiobis(2-nitrobenzoic acid)(DTNB) was extensively used in the estimation of free thiol groups in native and denatured proteins. ${ }^{28 a}$ This procedure is based on the reaction of free thiols with DTNB. The thiol reduces the disulfide of the DTNB molecule and forms a disulfide with one half of the DTNB. The other half of the DTNB, 2-nitro-5-thiobenzoic acid (TNB), has a characteristic absorbance at $412 \mathrm{~nm}$. There exists a linear relationship between free thiol concentration and the absorbance at $412 \mathrm{~nm}$ of this dianionic 2-nitro-5-thiobenzoic acid.

From the experiments described in Figure 19, it is important to figure out if the OPA-lysine complex is still able to react with a free thiol. Therefore to this complex a thiol reagent 2-mercaptoethanol (ME) was added. To see if a reaction of ME with this complex occurred, this mixture was added to a solution containing DTNB and the absorbance was measured.

This assay was done in the same buffer as the ryanodine binding assays. A solution of $1 \mathrm{mM} \mathrm{DTNB}, 250 \mathrm{mM} \mathrm{KCl}, 15 \mathrm{mM} \mathrm{NaCl}, 50 \mu \mathrm{M} \mathrm{CaCl}_{2}$, and $20 \mathrm{mM}$ HEPES at pH 7.1 was added to a cuvette of an optical pathlength of $1 \mathrm{~cm}$. The spectrophotometer was then zeroed. The absorbance of the added solutions was then recorded at $412 \mathrm{~nm}$. In order 
to determine the free thiol concentrations, the extinction coefficient $\varepsilon$ was determined first by adding known concentrations of $\mathrm{ME}$, varying from $10 \mu \mathrm{M}$ to $100 \mu \mathrm{M}$, and recording the absorbance (Figure 21). As expected, a linear relationship was observed. The extinction coefficient $\varepsilon$ was calculated as $12,200 \mathrm{M}^{-1} \mathrm{~cm}^{-1}$.

Control measurements with $90 \mu \mathrm{M}$ OPA, $1440 \mu \mathrm{M}$ lysine, and a mixture of $90 \mu \mathrm{M}$ OPA and $1440 \mu \mathrm{M}$ lysine showed a negligible absorbance at $412 \mathrm{~nm}$. A mixture of $90 \mu \mathrm{M}$ OPA and $1440 \mu \mathrm{M}$ lysine were allowed to react for varying amounts of time. Then an additional $90 \mu \mathrm{M} \mathrm{ME}$ was added reacting for another 10 minutes with this mixture, before it was added to the DTNB. The recorded absorbance is listed below in Table 5.

Table 5

\begin{tabular}{|c|c|c|}
\hline $\begin{array}{c}\text { Incubation time [min] } \\
\text { of OPA +lysine }\end{array}$ & Absorbance A & Free thiol concentration $[\mu \mathrm{M}]$ \\
\hline 10 & 1.058 & 86.7 \\
\hline 30 & 1.013 & 83.0 \\
\hline 60 & 1.086 & 89.0 \\
\hline 90 & 0.962 & 78.9 \\
\hline
\end{tabular}

These results indicate that there is a limited ability of the OPA-lysine complex to react with a thiol. Secondly, a longer incubation time of the OPA with the lysine doesn't seem to affect its reactivity with the thiol. An incubation time of 80 minutes of the OPA- 
lysine complex with $90 \mu \mathrm{M} \mathrm{ME}$ showed a small decrease in the free thiol concentration as compared with only 10 minutes incubation time. For both conditions $90 \mu \mathrm{M}$ OPA and $1440 \mu \mathrm{M}$ lysine had 10 minutes time to react (Table 6).

Table 6

\begin{tabular}{|c|c|c|}
\hline $\begin{array}{l}\text { Incubation time [min] } \\
\text { with ME }\end{array}$ & Absorbance A & Free thiol concentration $[\mu \mathrm{M}]$ \\
\hline 10 & 1.058 & 86.7 \\
\hline 80 & 0.912 & 74.7 \\
\hline
\end{tabular}

The free thiol concentration of the OPA-lysine-ME complex was also measured by letting $90 \mu \mathrm{M}$ OPA react first 10 minutes with $90 \mu \mathrm{M} \mathrm{ME}$ and then for either 10 or 40 minutes with $1440 \mu \mathrm{M}$ lysine. The observed absorbance is again listed below in Table 7 .

Table 7

\begin{tabular}{|c|c|c|}
\hline $\begin{array}{l}\text { Incubation time }[\mathrm{min}] \\
\text { with lysine }\end{array}$ & Absorbance A & Free thiol concentration $[\mu \mathrm{M}]$ \\
\hline 10 & 0.435 & 35.7 \\
\hline 40 & 0.278 & 22.8 \\
\hline
\end{tabular}


One can see that a longer reaction time of the OPA-ME complex with lysine decreases the free $\mathrm{ME}$ concentration. In addition, these results indicate that $\mathrm{ME}$ is much more potent in reacting with the OPA if the lysine is added last. These observations are consistent with others who have shown that isoindole formation of the OPA is much greater if the ME is added first to OPA and then to lysine. ${ }^{88}$ Their conclusions are based on fluorescence of the isoindole ring. Here, it could be shown that this statement is not only valid for the isoindole creation but also for the reactivity itself.

The reactivity of OPA with ME alone was also examined. A mixture of $90 \mu \mathrm{M}$ OPA and $90 \mu \mathrm{M}$ ME were allowed 15 minutes to react before the addition of DTNB. An absorbance of 1.167 was measured which corresponds to a free ME concentration of 95.6 $\mu \mathrm{M}$. This indicates that there is no covalent bond between OPA and ME, and the ME reacts preferentially with the DTNB. The fact that the apparent ME concentration has increased following treatment with OPA is not understood, since OPA alone lowers the absorbance at $412 \mathrm{~nm}$.

These experiments suggest that the inability of the OPA-lysine complex to stimulate ryanodine binding is due to its principal inability to react with a free thiol (i.e., it can't react with the cysteine residues on the release protein). The fact that ryanodine binding is a little higher than the control (in Figure 19) can be explained in terms of the small ability of the OPA-lysine complex to react with free thiols. 


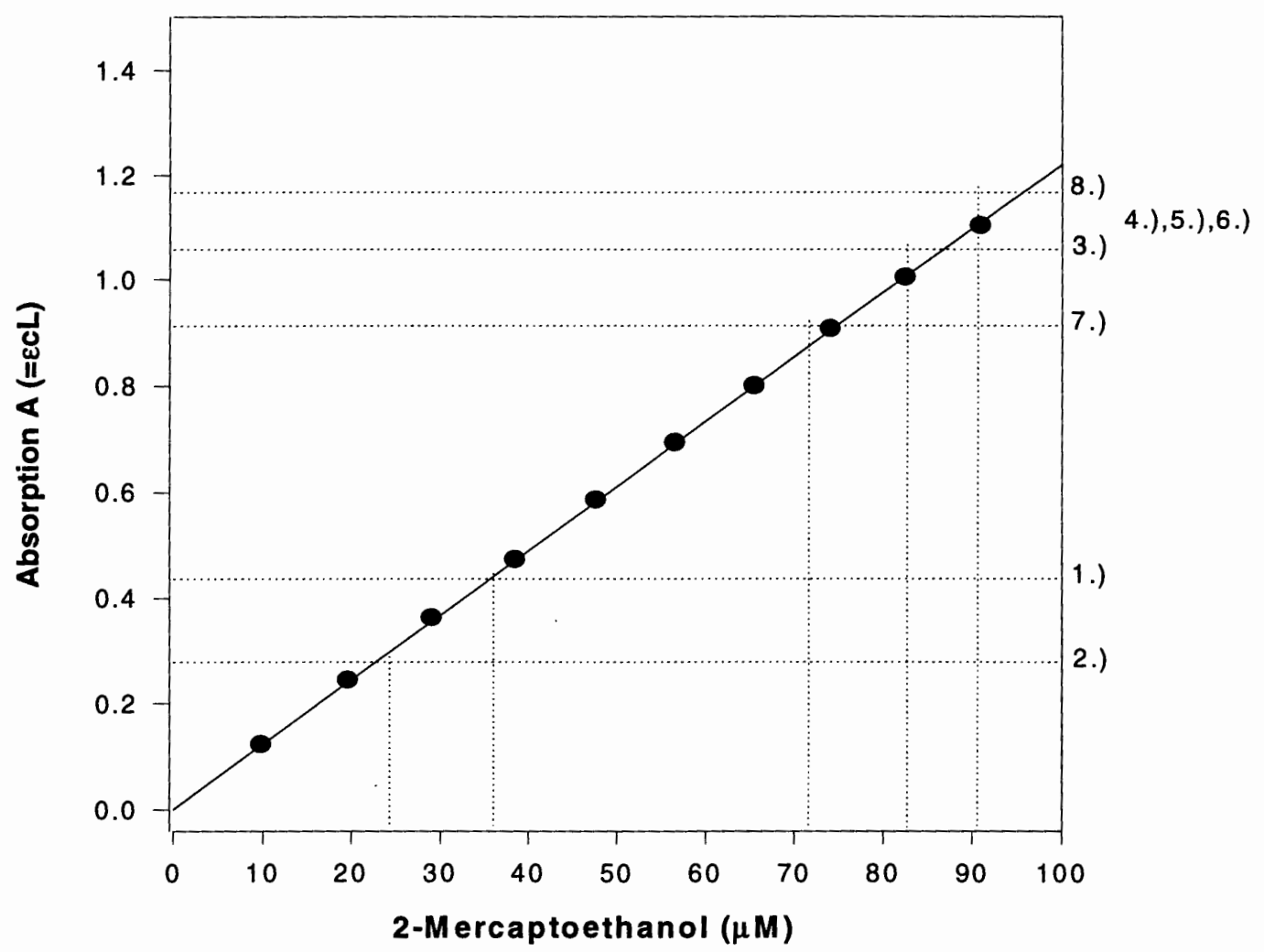

Figure 21

Absorbance at $412 \mathrm{~nm}$ of reduced DTNB as a function of 2-mercaptoethanol. 2-Mercaptoethanol was added to a 1 $\mathrm{mM}$ solution of DTNB and the absorption at $412 \mathrm{~nm}$ was measured versus 2-mercaptoethanol concentration.

Different mixtures of $90 \mu \mathrm{M}$ OPA with $1440 \mu \mathrm{M}$ lysine andlor $90 \mu \mathrm{M} 2$-mercaptoethanol was added to the $1 \mathrm{mM}$ DTNB solution after the given reaction time.

1.) $90 \mu \mathrm{M}$ OPA and $90 \mu \mathrm{M}$ ME (10 min. incubation time); then $1440 \mu \mathrm{M}$ lysine (10 min. incubation time). 2.$) 90 \mu \mathrm{M}$ OPA and $90 \mu \mathrm{M} \mathrm{ME} \mathrm{(10} \mathrm{min.} \mathrm{incubation} \mathrm{time);} \mathrm{then} 1440 \mu \mathrm{M}$ lysine ( $40 \mathrm{~min}$. incubation time).

$90 \mu \mathrm{M}$ OPA and $1440 \mu \mathrm{M}$ lysine ( $\mathrm{x}$ min. incubation time); then $90 \mu \mathrm{M} \mathrm{ME}$ (10 min. incubation time) 3.$) \mathrm{x}=10 \mathrm{~min}$ 4.) $x=30 \min 5$.) $x=60 \min 6$.) $x=90 \min$

7.) $90 \mu \mathrm{M}$ OPA and $1440 \mu \mathrm{M}$ lysine (10 min incubation time); then $90 \mu \mathrm{M} \mathrm{ME}(80$ min incubation time) 8 .) $90 \mu \mathrm{M}$ OPA and $90 \mu \mathrm{M}$ ME (15 min. incubation time). 


\section{CHAPTER VI}

\section{CONCLUSIONS}

At present it is still unknown how the T-tubule communicates with the SR to release $\mathrm{Ca}^{2+}$. It is unknown what the physiological reagent is which causes the $\mathrm{Ca}^{2+}$ release channel to open, and rapidly to close within a few milliseconds. As described in Chapter 1.5 there are a several chemical reagents which induce $\mathrm{Ca}^{2+}$ release from the SR by stimulating the $\mathrm{SR} \mathrm{Ca}^{2+}$ release channel. In order to explain the mechanism of E-C coupling, it is not only necessary to explain how the channel is opened, but also how it closes.

In this thesis the effect of o-Phthalaldehyde on skeletal muscle SR was examined. oPhthalaldehyde has the characteristics that it can form a covalent bond with a sulfhydryl group and an amino group. The $\mathrm{SR} \mathrm{Ca}{ }^{2+}$ release protein is a protein composed of approximately 5000 amino acids. It has previously been shown that OPA is only able to form an isoindole complex at a protein with the amino acids cysteine and lysine. From the structure of the OPA molecule one can conclude that the two amino acids cysteine and lysine must reside or be able to move to within $3 \AA$ in order to react with OPA.

We have shown that OPA interacts with the RyRlCa ${ }^{2+}$ release channel from skeletal muscle SR. Experiments with $\mathrm{Ca}^{2+}$ loaded SR vesicles showed that OPA is potent in 
releasing $\mathrm{Ca}^{2+}$ via the $\mathrm{SR} \mathrm{Ca}^{2+}$ release channel. OPA-induced $\mathrm{Ca}^{2+}$ release was inhibited by nanomolar concentrations of ruthenium red, a potent inhibitor of the $\mathrm{Ca}^{2+}$ release channel.

$\left[{ }^{3} \mathrm{H}\right]$ ryanodine binding experiments provided a more accurate description of the interaction of OPA with the RyRICa ${ }^{2+}$ release channel. Biphasic ryanodine binding behavior was observed. Association experiments revealed the nature of this biphasic behavior. It clearly showed that OPA interacts with two different binding sites at the $\mathrm{RyRICa}^{2+}$ release channel, a low and a high affinity binding site. Binding to the high affinity binding site increases ryanodine binding, while binding to the low affinity binding site decreases ryanodine binding. Association experiments showed that even at high OPA concentrations, ryanodine binding is first stimulated and then inhibited as a function of time. OPA appears to first bind to the activating high affinity sites and then subsequently to lower affinity sites.

Carrying out association and dissociation experiments, we have been able to calculate the dissociation constant $\mathrm{K}_{\mathrm{d}}$. It was shown that OPA lowers the $\mathrm{K}_{\mathrm{d}}$ for ryanodine binding by a factor of about 1.5 at several OPA concentrations. In order to verify this result, and to examine the influence of OPA on the maximal number of binding sites, a saturation binding assay with a Scatchard analysis was performed. The concentration independent decrease of $\mathrm{K}_{\mathrm{d}}$ by OPA could be confirmed qualitatively, if not quantitatively. The discrepancy may be explained in the different way these two experiments were performed and the fact that different SR preparations were compared. For an OPA concentration in which ryanodine binding is stimulated maximally, $\mathrm{B}_{\max }$ is increased by a factor of about 2.5, while for a concentration at which OPA is already bound to the low 
affinity binding site, $\mathbf{B}_{\max }$ decreases. With these experiments it is now understood what effect OPA has on the RyR. Binding to the high affinity binding site decreases the $K_{d}$ (i.e., it increases the affinity for ryanodine binding) and increases the number of maximal binding sites. Since the RyR has only one high affinity ryanodine binding site, the increase of maximal binding sites corresponds to an opening of more $\mathrm{RyRlCa}^{2+}$ release channels. Binding to the low affinity binding site doesn't influence the $K_{d}$ for ryanodine binding, but only decreases the number of ryanodine receptors.

This biphasic behavior of opening and closing the channel may be physiologically relevant. Binding or oxidation of the high affinity binding site may open the channel, and binding or oxidation of the low affinity binding site may close the channel. The significance of the low affinity binding site is not clear yet. It might be that binding of OPA to this site causes an irreversible damage of the $\mathrm{RyRICa}^{2+}$ release channel following the dissociation of ryanodine, or it may be that this site is really relevant for closing down the channel. The ryanodine binding assays can't reveal this uncertainty, since it is not an assay to reveal reaction kinetics.

High affinity ryanodine binding was observed to be biphasic with increasing OPA concentration, $\mathrm{Ca}^{2+}$ concentration and time. Interestingly, OPA-activated ryanodine binding was independent of the $\mathrm{Ca}^{2+}$ concentration, indicating that there are possibly two classes of RyRICa ${ }^{2+}$ release channels present in the SR, one $\mathrm{Ca}^{2+}$ dependent and the other class independent.

The inability of the reducing agent DTT to decrease OPA stimulated ryanodine binding clearly showed that the interaction of OPA with a sulfhydryl group on the $\mathrm{Ca}^{2+}$ 
release protein doesn't result in a disulfide linkage of the receptor complex, but is directly with the critical sulfhydryl groups.

The $\left[{ }^{3} \mathrm{H}\right]$ ryanodine binding experiment as a function of OPA concentration with and without CPM pretreated SR indicates that there are at least two different sulfhydryl groups which are involved in channel activation. $\mathrm{CPM}$ is able to inhibit $\mathrm{Ca}^{2+}$-induced $\mathrm{Ca}^{2+}$ release and does not bind to the $\mathrm{RyR} / \mathrm{Ca}^{2+}$ release channel if the channel is in an open state. This is most likely due to the fact that one of the SH groups to which CPM binds is disulfide linked during channel activation. The experiments performed with OPA showed that pretreatment of the SR with CPM doesn't effect OPA-stimulated ryanodine binding. This observation suggests that OPA stimulates the channel by binding to a SH group different than the one which CPM binds to. OPA binds to a sulfhydryl group which is responsible for channel activation, while CPM binds to a different sulfhydryl group which is required for normal for channel activation under physiological conditions. Both the activation and inhibition of $\left[{ }^{3} \mathrm{H}\right]$ Ryanodine binding by OPA are CPM independent.

It is still unclear if OPA reacts only with a sulfhydryl group or also with the amino group and forms an isoindole ring. If it reacts only with the sulfhydryl group, then the experiments with DTNB showed that this reaction is reversible and no covalent bond is formed. If it reacts with the cysteine and the lysine then this reaction is irreversible and a covalent bond is formed. Fluorescence experiments with the OPA treated SR should reveal if this isoindole is formed or not, because this complex has characteristic fluorescence properties. These experiments will be performed in the near future to reveal if the amino acid lysine is nearby the reactive cysteine. If a lysine is adjacent to the reactive 
thiol, it is likely responsible for decreasing the $\mathrm{pK}_{\mathrm{a}}$ of the critical thiol from around $\mathrm{pH} 8$ to $\mathrm{pH}$ 7. The strongest evidence for the formation of the isoindole ring was found in a bilayer experiment (unpublished data) in which the channel was activated by $200 \mu \mathrm{M}$ OPA. Upon changing the solution to remove unbound OPA and adding back $200 \mu \mathrm{M}$ cysteine to the cis chamber, channel activity as measured by the open probability remained unchanged. This strongly suggests that OPA is bound covalently to the $\mathrm{RyRlCa}{ }^{2+}$ release channel. When OPA binds to a cysteine on the receptor, it also binds to a lysine residue to form a covalent isoindole derivative.

It has been shown that there exist critical sulfhydryl groups on the $\mathrm{RyR} / \mathrm{Ca}^{2+}$ which exhibit channel gating properties similar to those observed in the native biological membranes. It is somewhat surprising that there are many other nonthiol reagents known which also open the channel. These reagents appear to induce conformational changes in the protein's structure such that a disulfide linked high molecular weight complex is formed. Yet, it is unclear why so many chemical compounds are able to interact and stimulate the $\mathrm{RyR} / \mathrm{Ca}^{2+}$ release channel. One possible explanation could be that this behavior is a relic of evolution. The channel gating mechanism changed over time, but these critical binding sites are still present on the protein. If this theory is correct, the possibility exists that these critical sulfhydryl groups are not physiologically relevant anymore. Further research is needed to resolve this uncertainty. 


\section{REFERENCES}

1 Abramson, J.J., Trimm, J.L., Weden, L., Salama, G. (1983)

Proc.Nat. Acad. Science 80, 1526-1530

2 Abramson, J.J., and Salama G. (1989) J. Bioenerg. Biomem. 21, 283-294

3 Adams, B.A., Beam, K.G. (1989) J. Gen. Physiol. 94, 429-444

4 Agnew, W.S. (1987) Nature 328, 297

5 Agnew, W.S. (1988) Nature 334, 299-300

6 Alvarez-Coque, M.C., Medina Hernandez, M.J., Villanueva Camanas, R.M, Mongay Fernandez., C. (1989) Anal. Biochem. 178, 1-7

7 Anderson, K., Lai, F.A., Liu, Q.Y., Rousseau, E., Erickson, H.P., Meissner,G. (1989) J. Biol. Chem. 264, 1329-1335

8 Ashley, C.C., Mulligan, I.P., Lea, T.J. (1991) Q. Rev. Biophys. 24, 1-73

9 Beam, K.G., Knudson, C.M., Powell, J.A. (1986) Nature 320, 168-170

10 Beam, K.G., and Knudson, C.M. (1988) J. Gen. Phys. 91, 781-798

11 Bean, B.P. (1989) Ann. Rev. Phys. 51, 367-384

12 Berridge, M.J. (1993) Nature 361, 315-325

13 Block, B.A., Imagawa, T., Leung, A., Campbell, K.P., Franzini-Armstrong, C. (1988) J. Cell Biol. 107, 2587-2600

14 Brocklehurst (1979) Int. J. Biochem. 10, 259-274 
15 Brunschwig, J.P., Brandt, N., Caswell, A.H., Lukeman, D.S. (1980)

J. Cell Biol. 94, 533

16a Buck, E., Zimanyi, I., Abramson, J.J., Pessah, I.N. (1992)

J. Biol. Chem. 267, 23560-23567

16 Butcher, E.C., Lowry, O.H. (1976) Anal. Biochem. 79, 33-41

17 Campbell K.P., Leung, A.T., Sharp, A.H. (1988) Trends Neurosci. 11, 425-430

18 Cannell, M.B, Berlin, J.R., Lederer, W.J. (1987) Science 238, 419-423

19 Carl, S.L., Caswell, A.H., Ball, J.W., Meissner G., Brandt, N. et al. (1992)

Biophys. J. 61, A161

20 Carroll, S., Skarmeta, J.G., Yu, X., Collins, K.D., Inesi, G. (1991)

Arch. Biochem. Biophys. 290, 239-247

21 Caswell, A.H., Brandt, N.R. (1989) Trends Biochem. Sci. 14, 161-165

22 Caswell, A.H., Brandt, N.R., Brunschwig, J.P., Purkerson, S. (1991)

Biochemistry 30, 7507-7513

23 Catterall, W.A. (1991) Cell 64, 871-874

24 Chaudhari, N. (1992) J. Biol. Chem. 267, 25636-25639

25 Chen. R.F., Scott, C., Trepman, E. (1979)

Biochem. Biophys. Acta 576, 440-455

26 DeJongh, K.S., Warner, C., Catterall, W.A. (1990) J. Biol. Chem. 265, 14738-14741

27 Eisenberg, R.S. (1987) Can. J. Phys. Pharm. 65,686-690

28a Ellman, G.L. (1959) Arch. Biochem. Biophys. 82, 70-77 
28 Endo, M., Tanaka, M., and Ogawa, Y. (1970) Nature 228, 34-36

29 Endo, M. (1977) Phys. Rewievs 57, 71-108

30a Favero, T.G., Zable, A.C., Abramson, J.J. (1995) J. Biol. Chem. (in press)

30 Ford, L.E., and Podolsky, R.J (1970) Science 167, 58-59

31 Franzini-Armstrong, C., Kenney, L.J., Varriano-Maston, E. (1987)

J.Cell. Biol. 105, 49

32 Gonzales-Serratos, H., Valle-Aguilera, R., Lathrop, D.A., and Garcia, M.C. (1982)

Nature 298, 292-294

33 Hakamata, Y., Nakai, J., Takeshima, H., Imoto, K. (1992) FEBS Lett. 312, 229-235

34 Howell, J.N. (1969) J. Phys. (London) 201, 515-533

35 Hulme, E.C. (1990) Receptor-Effector Coupling- A practical approach, Apendix I, IRL Press, Oxford pp. 203-215

36 Hymel, L., Schindler H., Inui, M., fleischer, S. (1988)

37 Ikemoto, N., Antoniu, B., Kang, J.J, Meszaros, L.G., Ronjat, M. (1991)

Biochemistry 30, 5230-5237

38 Imagawa, T., Nakai, J., Takeshima, H., Nagasaki, Y., Shigekawa, M. (1992)

J. Biochem. 112, 508-513

39 Imagawa, T. Smith, J.S, Coronado, R., Campbell K.P. (1987)

J. Biol. Chem. 262, 16636-16643

40 Inui, M., Saito, A., Fleischer, S., (1987) J. Biol. Chem. 262, 15637-15642

41 Jocelyn, P.G., Kamminga, A. (1970), Anal. Biochem. 37, 417-421 
42 Jorgenson, A.O., Shen, A.C-Y, Arnold, W., McPherson, P.S., Campbell, K.P. (1993)

J. Cell Biol. 120, 969-980

43 Joys, T.M., Kim, H. (1979) Anal. Biochem. 94, 371-377

44 Junker J., Sommer, J.R., Sar, M., Meissner, G. (1994) J. Biol. Chem. In press

45 Kalckar, H.M. (1947) J. Biol. Chem. 167, 461-475

46 Kim, Y.K., Vladivia, H.H., Maryon, E.B., Anderson, P., Coronado, R. (1992)

Biophys. J. 63, 1379-1384

47 Lai, F.A., Dent, M., Wickenden, C., Xu, L., Kumari, G., et al (1992)

Biochem. J. 288, 553-564

48 Lai, F.A., Erickson, H.P., Rousseau, E., Liu, Q.Y., Meissner, G. (1988)

Nature 331, 315-319

49 Lai, F.A., Misra, M., Xu, L., Smith, H.A., Meissner, G. (1989)

J. Biol. Chem. 264, 16776-16785

50 Lamb, D.G. (1992) J. Muscle Res. Cell Motil. 13, 394-405

51 Liu, Q.Y., Lai, F.A., Rousseau, E., Jones, R.V., Meissner, G. (1989)

Biophys. J. 55, 415-424

52 Liu, G., Abramson, J.J., Zable, A.C., Pessah, I.N. (1994) Mol. Pharm. 45, 189-200

53 Lowry, L.H., Rosebrough, N.J., Farr, A.L., and Randall, R.J. (1953)

J. Biol. Chem. 193, 265-275

54 Luttgau, H.C., Gottschalk, G., and Berwe, D. (1987)

Can. J. Phys. Pharm. 65, 717-723

55 MacLennan, D.H. (1970) J. Biol. Chem. 245, 4508-4518 
56 Martonosi, A.N. (1984) Physiol. Rev. 64, 1240-1320

57 McCleskey, E.W., Fox, A.P., Reldman, D., and Tsien, R.W. (1986)

J. Exp. Biol. 124,177-190

58 McPherson, P.S., Kim, Y.K., Valdivia, H., Knudson, C.M., Takekura, H., et al. (1991) Neuron 7, 17-25

59 Meissner, G. (1975) Biochem. Biophys. Acta 389, 51-68

60 Meissner, G. (1984) J. Biol. Chem. 159, 1365-1374

61 Meissner, G. (1984) J. Biol. Chem. 259, 2365-2374

62 Meissner, G., Darling, E., and Eveleth, J. (1986) Biochem. 25, 236-244

63 Meissner, G. (1986) Biochemistry 25, 244-251

64 Meissner, G. (1992) Adv. Exp. Med. Biol. 311, 277-287

65 Meissner, G. (1994) Ann. Rev. Physiol. 56, 485-508

66 Mendez, E., Gavilanes, J.G. (1976), Anal. Biochem. 72, 473-479

67 Mikami, A., Imoto, K., Tanabe, T., Niidome, T., Mori, Y., et al. (1989) Nature 340, 230-236

68 Mitchell, R.D., Saito, A., Palade P., Fleischer, S. (1983) J.Cell Biol. 96, 1017-1029

69 Morii, H., Tonomura, Y. (1983) J. Biochem. 93, 1271-1285

70 Morton, M..E., Caffrey, J.M., Brown, A.M., Froehner, S.C. (1988)

J. Biol. Chem. 263, 613-616

71 Nabauer, M., Callewaert, G., Cleemann, L., Morad, M. (1989) Science 244, 800-803

72 Nagasaki, K., Kasai, M. (1983) J. Biochem. 94, 1101-1109 
73 Nakai, J., Imagawa, T., Hakamata, Y., Shigekawa, M., Takeshima, H., Numa, S. (1990) FEBS Lett. 271, 169-177

74 Nakayama, H., Taki, M., Striessnig, J., Glossmann, H., Catterall, W.A., Kanaoka, Y. (1991) Proc. Natl. Acad. Sci. USA 88, 9203-9207

75 Otsu, K., Willard, H.F., Khanna, V.K., Zorzato, F. Green, N.M., MacLennan, D.H. (1990) J. Biol. Chem. 265, 13472-134-83

76 Otto, $\mathrm{H}$.

77 Pape, P.C. Konishi, M., baylor, S.M., Somlyo, A.P. (1988) FEBS Lett. 235, 57-62

78 Perez-Reyes, E., Castellano, A., Kim, H.S., Bertrand, P., Baggstrom, E., et al. (1992) J. Biol. Chem. 267, 1792-1797

79 Pessah, I.N., Waterhouse, A.L., Casida, J.E. (1985)

Biochem. Biophys. Res. Commun 128, 449-456

80 Pessah, I.N., Stambuck, R.A., Casida, J.E. (1986) J. Mol. Pharm. 31, 232-238

81 Pincon-Raymond, M., Rieger, F., Fosset, M., Lazdunski, M. (1985)

Dev. Biol. 112, 458-466

82 Powell, J.A. (1990) FASEB J. 4, 2798-2808

83 Puri, R.N., Bhatnagar, D., Roskoski Jr., R. (1985) Biochemistry 24, 6499-6508

84 Radermacher, M., Wagenknecht, T., Grassucci, R., Frank, J., Inui, M., et al. (1992) Biophys.. J. 61, 936-940

85 Rieger, F., Pincon-Raymond, M., Tassin, A.M., Garcia, L., Romey G., et al. (1987) Biochimie 69, 411-417

86 Rios, E., and Brum, G. (1987) Nature 325,717-720 
87 Rios, E., Ma, J., Gonzales, A. (1991) J. Muscle Res. cell Motil. 12, 127-135

88a Roth et al. (1973) J. Chrom. 83, 353-356

88 Roth, M. (1971) Anal. Chem. 43, 880-882

89 Ruth, P., Rohkasten, A., Biel, M., Bosse, E., Regula, S., et al. (1989)

Science 245, 1115-1118

90 Sabbadini, R.A., and Dahms, A.S. (1989) J. Bioenrg. Biomem. 21, 163-213

91 Saito, A., Seiler, S., Chu, A., Fleischer, S. (1984) J.Cell Biol. 99, 875

92 Saito, A., Inui, M., Radermacher, M., Frank, J., Fleischer, S. (1988)

J. Cell. Biol. 107, 211-219

93 Saito, A., Inui, M., Walls, J.S., Fleischer, S., Biophys. J. 55, $206 a$

94 Salama, G., and Abramson, J.J. (1984) J. Biol. Chem. 259, 13363-13366

95a Scarpa, A. Meth. Enzy. 56, 317-332

95 Schwartz, L.M., McCleskey, E.W., and Almers, W. (1985) Nature 314, 747-751

96 Seok, J.H., Xu, L., Kramarcy, N.R., Sealock, R., Meissner, G. (1992)

J. Biol. Chem. 267, 15893-15901

97a Simons, S.S., Johnson, D.F. (1976) J. Am. Chem. Soc. 98, 7098-7099

97 Simons, S.S., Johnson, D.F. (1978) J. Org. Chem. 43, 2886-2891

98 Simons, S.S., Johnson, D.F. (1978) Anal. Biochem. 90, 705-725

99 Smith, J.S., Coronado, R., and Meissner G. (1985) Nature 316, 446-449

100 Smith, J.S., Coronado, R., and Meissner G. (1986) J. Gen. Phys. 88, 573-588

101 Smith, J.S., Imagawa, T., Ma, J., Fill, M., Campbell, K.P., Coronado, R. (1988)

J. Gen. Physiol. 92, 1-26 
102 Smith, J.S., Rousseau, E., Meissner, G. (1989) Circ. Res. 64, 352-359

103 Sommer, J.R., Johnson, E.A. (1979)

Handbook of Physiology, ed. R.M. Berne ,Sec. 2, pp. 113-186

104 Sommer, J.R., Bossen, E., Dalen, H., Dolber, P., High, T., et al. (1991)

Acta Physiol. Scand. S599, 5-21

105 Takekura, H., Bennett, L., Tanabe, T., Beam, K., Franzini-Armstrong, C. (1993)

Biophys. J. 64, 241a

106 Takekura, H., Takeshima, H., Nishimura, S., Takahashi, M., Tanabe, T., et al. (1993)

Biophys. J. 64, 153a

107 Takeshima, H., Nishimura, S., Matsumoto, T., Ishida, H., Kangawa, K.

Minamino, N., Matsuo, J, Ueda, M., Hanaoka, M., Hirose, T., Numa, S. (1989)

Nature 339, 439-445

108 Tanabe, T., Takeshima, H., Midami, A., Flockerzi,V., Takahashi,M,

Kangawa, K., Kojima, M., Matsuo, H., Hirose, T., and Numa, S. (1987)

Nature 328, 313-318

109 Tanabe, T., Beam, K.G., Powel, J.A., Numa, S. (1988) Nature 336, 134-139

110 Tanabe, T., Mikami, A., Numa, S., Beam, K.G. (1990) Nature 344, 451-453

111 Tanabe, T., Beam, K.G., Adams, B.A., Nicodome, T., Numa, S. (1990)

Nature 346, 567-569

112 Thorley-Lawson, D.A. (1977) J. Biochem. 167, 739-748

113 Trimm J.L., Salama, G., and Abramson, J.J. (1986) J. Biol. Chem. 261, 16092-16098

114 Venosa, R.A., and Horowicz, P. (1981) J. Mem. Biol. 58, 225-232 
115 Vergara, J., Tsien, R.Y., and Delay, M. (1985)

Proc.Nat. Acad. Science 82, 6352-6356

116 Vilven, J., Coronado, R. (1988) Nature 336, 587-589

117 Volpe, P., Salviati, G., Di Virgilia, F., and Pozzan, T. (1985) Nature 316, 347-349

118 Wagenknecht, T., Grassucci, R., Frank, J., Saito, A., Inui, M., Fleischer, S. (1989)

Nature 338, 167-170

119 Walker, J.W., Somlyo, A.V., Goldman, Y.E., Somlyo, A.P., Trentham D.R. (1987)

Nature 327, 249-252

120 Weidekamm, E., Wallach, D.F.H., Flueckinger, R. (1973)

Anal. Biochem. 54, 102-114

121 Zaidi, N.F., Lagenaur, C.F., Abramson, J.J., Pessah, I., and Salama, G. (1988)

J. Biol. Chem. 264, 21725-21736

122 Zorzato, F., Fujii, J., Otsu, K., Phillips, M., Green, N.M., et al. (1990)

J. Biol. Chem. 265, 2244-2256 